\title{
Teil II: Biographien
}

\section{Wie die Biographien zustande kamen}

Der biographische Teil setzt sich aus Biographien unterschiedlicher Herkunft und Länge zusammen. Er enthält die - meist ausführlicheren - Lebensläufe der 71 Personen, deren Briefe in der vorliegenden Edition veröffentlicht werden; des weiteren Biographien und biographische Angaben zu Personen, die in den Briefen erwähnt werden, seien es überregional bekannte ehemalige Funktionäre und Mitglieder der SPD, KPD, KPO, SAP, des ISK, der Gruppe „Neu Beginnen“, Emigranten oder solche Sozialisten, die im lokalen Rahmen der Briefschreiber Widerstand gegen das NS-Regime leisteten. Die unterschiedliche Länge der Biographien ergibt sich zum einen aus dem Stellenwert, der den Personen in den Briefen zukommt, zum anderen aus der Quellenlage. Die Lebensläufe der 71 Briefschreiber sind zum allergroßten Teil von mir recherchiert; soweit sie in der Literatur Erwähnung finden, ist diese benutzt und verzeichnet. Bei allen anderen Biographien wurde Literatur nur dann genannt, wenn sie in größerem Umfang weiterführt; bei den prominenteren Vertretern der linkssozialistischen Parteien und Gruppen, sofern sie in der Emigration waren, wird nur das ${ }_{n}$ Biographische Handbuch der deutschsprachigen Emigration nach $1933^{{ }^{{ }_{1}}}$ angeführt, das neben meist ausführlicheren Biographien vollständige Literaturhinweise enthält.

Ausgangspunkt der Recherchen über die Briefschreiber waren im Januar 1979 die in den Briefköpfen vermerkten Anschriften aus den Jahren 1946 bis 1949. Das Gros der heutigen Adressen der Briefschreiber bzw. ihrer Angehörigen ließ sich über Einwohnermelde- und Statistische Ämter ermitteln. Darüber hinaus bot die wissenschaftliche Literatur zu den sozialistischen Kleinparteien ISK, SAP, KPO, zur Lokal- und Regionalgeschichte der Arbeiterbewegung sowie zum Widerstand im „Dritten Reich ${ }^{\alpha}$ Hinweise, die es mir ermöglichten, mich mit gezielten Fragen an einschlägig bekannte Personen zu wenden (vgl. Verzeichnis b). In einigen Fällen war es erforderlich, an Ort und Stelle, d. h. bei Stadtarchiven, Erbschaftsgerichten und anhand von Todesanzeigen und Telefon- und Adreßbüchern zu recherchieren. Trotz der zeitlichen Distanz konnten so mit einer Ausnahme alle Gesuchten ausfindig gemacht werden. Von den $7 \mathrm{r}$ Sozialisten, deren Briefe in die Edition aufgenommen wurden und die der Veröffentlichung zustimmten - sechs Personen lehnten eine Veröffentlichung ihrer Briefe bzw. der Briefe ihrer Eltern ab - lebten 1979 nur noch dreißig. In zehn Fällen lebten die Ehefrauen, in 22 konnten Kinder, in einigen weiteren Fällen entferntere Verwandte aufgefunden werden. Sieben Briefschreiber waren kinderlos und ohne sonstige Angehörige verstorben. Nach Ermittlung der Adressen besuchte ich die genannten Personen, bat sie um die Erlaubnis, die Briefe zu publizieren und befragte sie zu ihrem Leben bzw. zum Leben der Briefschreiber. Bei den Interviews nahm ich so weit wie möglich in schriftliche Unterlagen Einblick, die die Erinnerungen und Erzählungen in vielen Fällen außerordentlich präzisierten und ergänzten: Rentenbescheide, Haftbefehle, Briefe aus dem $\mathrm{KZ}$ und aus der Nachkriegszeit, selbstverfaßte Lebensläufe von Verstorbenen und andere diverse Dokumente. Auf der Grundlage der so gewonnenen Daten und in Verbindung mit Informationen aus der Literatur verfaßte ich Lebensläufe, die dann den Briefschreibern bzw.

\footnotetext{
' Biographisches Handbuch der deutschsprachigen Emigration nach 1933. Hrsg. v. Institut für Zeitgeschichte München und v. d. Research Foundation for Jewish Immigration. Unter der Gesamtleitung v. Werner Röder u. Herbert A. Strauss. München/New York usw. Bd. ı: Politik, Wirschaft, öffentliches Leben. Leitung u. Bearbeitung Werner Röder, Herbert A.Strauss. Unter Mitwirkung v. Dieter Marc Schneider, Louise Forsyth. 1980.
} 
ihren Angehörigen zur Begutachtung vorgelegt wurden. Später wurde bei einem zweiten Durchgang versucht, die Biographien in den jeweiligen lokalen bzw. gruppenspezifischen Zusammenhang zu stellen. Ergänzende Hinweise verdanke ich einer Reihe von Organisationen und Institutionen (vgl. Verzeichnis b). Besonders hervorzuheben ist das NordrheinWestfälische Hauptstaatsarchiv in Düsseldorf, durch dessen Gestapo-Akten die Biographien der bereits in den fünfziger und sechziger Jahren verstorbenen Arbeiter und Arbeiterfunktionäre aus dem Ruhrgebiet zum Teil substantiell erweitert werden konnten. Bei den ohne Angehörigen verstorbenen Briefschreibern war es durch mündliche und schriftliche Befragungen ebenfalls möglich, einige Angaben zur Erstellung von Kurzbiographien in $\mathrm{Er}$ fahrung zu bringen. Ein Briefschreiber und ein Angehöriger legten Wert darauf, die Namen durch Pseudonyme zu ersetzen.

Bernd Klemm

a) Verzeichnis der befragten Briefschreiber bzw. ibrer Angebörigen

Werner Aßmus, Wesel

Willy Blind, Stuttgart

Sofie J.Bowman, Dowal, Quebec, Kanada

(Frieda Rudolph)

Martha Brenner t, Frankfurt

Emil Brune, Dortmund

Ilse Bühring, Hamburg (Dora Hoffmann)

Gertrud Deutsch, Nürnberg

Eberhard Dörfler, Bielefeld

Edith Doil, Schwelm (Bernhard Molz)

Günter Eckstein, Köln

Ella Ehlers, Bremen

Paul Elflein, Salzgitter

Irmgard Enderle, Köln

Frida Euchner, Stuttgart

Wilhelm Fingerle, Bad Rothenfelde

Heinrich Galm, Offenbach

Hermann Grzeski, Köln

Flora Halbach, Trier

Kurt Heise, Frankfurt

Walter Heist, Mainz

Gerritt Hensel, Anholt

Hans Ils, Freiburg

Ottilie Issel, Duisburg (Oskar Triebel)

Emma Jahnke, Hamburg

Ursula Kappius, Bremen

Irmgard Keun †, Köln

O. Klostermann, Solingen (Otto Hensel)

Sophie König, Nürnberg (Karl und Emma Grönsfelder)

Margarete Kunz, Berlin

Friedel Linder, Solingen

Walter Märten, Berlin
Angelika Mager, Bamberg

Franz Marx, München

Irmgard Müller, Berlin (Karl Müller)

Helene Nagel, Bamberg

Günter Nelke, Bonn

Karin Neumann, Kaltenkirchen

(Karl Grunert)

Kurt Oppler, Baden-Baden

Margarete Ostermann †, Berlin-DDR

Elisabeth Pauli, Köln

Louis Pilz, Stuttgart

Hugo Röhrig, Solingen

Gustav Roos, Mannheim

Frieda Ruhnau, Hamburg

Hans-Joachim Sabo, Köln (Ludwig

A. Jacobsen)

Margarete Samoray, Gelsenkirchen

Gerhard Sauter, Stuttgart

Richard Schmid, Stuttgart

Walter Schmitz, Bocholt

Maximilian Schöneseiffen jun., Köln

Thomas Schöttle, Stuttgart

Lisbeth Schultz, Gelsenkirchen

(Albert Kornett)

Erich Schumacher, Stuttgart

Adolf Stephan, Hannover

Maria Stockhaus, Dortmund

Fried Theissen, Essen

Fritz Treu, Monroe, New York, USA

Hertha Tüsfeld-Heine, Dortmund

Martha Tulatz, Oberursel

Maria Walter, Leutkirch (Stefie Restle)

\section{b) Auskunftsperson und-institutionen}

Lisa Abendroth, Prof. Dr. Wolfgang Abendroth, Frankfurt; Ernst Behm, Sollentuna, Schweden; Prof. Dr. Theodor Bergmann, Stuttgart; Martin Bier, Unterhaching; Elisabeth Bier, Schwendt/Kössen, Österreich; Dr. Jörg Bremer, Frankfurt; Dr. Holger Christier, 
Hamburg; Clara Döhring, Stuttgart; Dr. Hanno Drechsler, Marburg; Prof. Fritz Eberhard, Berlin; Eugen Eberle, Stuttgart; George G.Eckstein, Great Neck, New York, USA; Ruth Fabian, Paris; Prof. Dr. Walter Fabian, Köln; Erwin Gräff, Linköping, Schweden; Herrmann Grzeski, Köln; Ilse Hacks, Wiesbaden; Dr. Beatrix Herlemann, Mannheim; Rudolf Holz, Berlin; Henry Jacoby, Genf; Gerhard Kaulich, Wiesbaden; Louise Köhler, Berlin; Dr. Hartmut Kokott, Frankfurt; Otto Kraus, Nürnberg; Marianne Kühn, Köln; Dr. Barbara Mausbach-Bromberger, Frankfurt; Dr. Susanne Miller, Bonn; Hans Picard, Stuttgart; Hilde Ruge, Hamburg; Albert Schmidt, Stuttgart; Hans Schoemann, Brüssel; Günter Spruch, Berlin; Charles Sternberg, Forest Hills, New York, USA; Georg Stierle, Butzbach; Hanspeter Stockhaus, Dortmund; Herta Thielcke, Hamburg; Hans Tittel, Nürnberg; Helmut Tulatz, Lippstadt; Prof. Dr. Hermann Weber, Mannheim; Fritz Wiest, Stuttgart.

Archiv der sozialen Demokratie, Bonn-Bad Godesberg (Dr. Ilse Fischer); Institut für Zeitgeschichte München (Dr. Norbert Frei, Dr. D.M.Schneider); Institut für Politikwissenschaft der Universität Marburg (Prof. Dr. Georg Fülberth); Internationales Institut für Sozialgeschichte Amsterdam (Gơzz Langkau), Nordrheinwestfälisches Hauptstaatsarchiv (Dr. Ziegahn); Stadtarchiv Frankfurt; Deutscher Bundestag, Parlamentsarchiv; Landtag von Nordrhein-Westfalen (Herr Eyckers); Stadt Duisburg, Dezernat für Bildung und Kultur; Stadt Schwelm; Die Quelle. Funktionärszeitschrift des DGB Köln; SPD Schwelm (Ulrich Härtel); SPD Wesel (Dieter Heisig); SPD-Landesverband Berlin; DGB-Berlin; IG Druck und Papier Nümberg; Aubeiterwohlfahrt Nürnberg; VVN-Bund der Antifaschisten Niedersachsen e.V., Hannover.

\section{Biographien in alphabetischer Reibenfolge}

Abendroth, Wolfgang, geboren am 2.5. 1906 in Elberfeld, nach Besuch des Realgymnasiums in Frankfurt a.M. Jura-Studium, 1920 Mitglied des KJV, 1929 der KPO, 1932 Gruppe „Neu Beginnen“, bis zur Entlassung 1933 Gerichtsreferendar, Anfang 1935 in Basel Promotion zum Dr. jur., 1936 Angestellter bei einer Bank in Berlin; seit 1933 konspirativ tätig, in Kontakt mit der KPO-Reichsleitung, im Februar 1937 Verhaftung und Verurteilung zu vier Jahren Zuchthaus, nach deren Verbußung Soldat im Strafbataillon 999 in Griechenland, 1945/46 Kriegsgefangenschaft in England; im November 1946 Rückkehr nach Deutschland (Ost), 1947 Oberjustizrat der Deutschen Justizverwaltung für die Sowjetische Besatzungszone in Berlin, im selben Jahr Mitglied der SPD, 1948 o. Prof. an der Universität Jena, 1948 Ubersiedlung in den Westen, seit 195 I Professor für die Wissenschaft von der Politik in Marburg, als dezidierter Marxist Engagement auf dem linken Flügel der SPD, Mitglied in der Programm-Kommission der SPD, 1959 Verfasser eines „Alternativ-Entwurfs “ zum Godesberger Programm der SPD, wegen seiner Mitgliedschaft in der Förderergesellschaft des SDS I96I Ausschluß aus der SPD. Seit den sechziger Jahren steht A., der neben bedeutenden staatsrechtlichen Arbeiten umfangreiche Forschungen zur Geschichte der deutschen Arbeiterbewegung betrieben und angeregt hat, politisch der DKP nahe. A. lebte I98 I in Frankfurt.

Wolfgang Abendroth: Ein Leben in der Arbeiterbewegung. Gespräche, aufgezeichnet und hrsg. von B. Dietrich und J. Perels. Frankfurt a.M. 1976.

Angermeier, Heinrich (1884-1945), Bauer in der Gemeinde Groß-Zimmern, seit 1924 KPDAbgeordneter im Hessischen Landtag, 1929 Übertritt zur KPO. Angermeier war mit Heinrich Galm* politisch und persönlich eng befreundet. 1933-1934 im KZ Osthofen; im Juli I 944 ins KZ Dachau deportiert, dort kam er am 22.2. 1945 ums Leben.

Hermann Weber: Die Wandlung des deutschen Kommunismus. Bd. 2. Frankfurt a. M. 1969. 
ABmus, August, geboren am 30. 3. 1909 in Neheim. Der Vater war BuchdruckmaschinenMeister, die Mutter Hausfrau. Nach der Volksschule ließ sich A. zum Pflasterer ausbilden. Bei Ausübung des Pflastererberufs zog er sich eine Rückgratverkrümmung zu, die ihn zwang, diesen Beruf aufzugeben. Er absolvierte deshalb eine Schneiderlehre und war bis etwa 1930 bei verschiedenen Meistern tätig. Seitdem erwerbslos. Eine Zeitlang betrieb er einen kleinen Straßenhandel mit Kurzwaren. Seit 1922 Mitglied der SAJ, 1931 gründete er mit einem Teil der SAJ-Gruppe, darunter auch Heini Landsiedel, den SJV und dic SAP in Wesel.

Bedingt durch seine Krankheit konnte $A$. nicht sehr aktiv sein, doch beteiligte er sich seit 1933 im Rahmen der SAP am Widerstand durch Flugblattverteilen u.ä. Im Jahre 1933 fanden bei ihm Haussuchungen statt; es ist nicht bekannt, daß er wegen politischer Aktivitäten angeklagt wurde. Nach dem Zweiten Weltkrieg erhielt er jedoch wegen gesundheitlicher Schäden eine Rente nach dem Bundesentschädigungsgesetz; seine Mutter wurde als politisch Verfolgte eingestuft. Ab 1938 war A. an den Rollstuhl gefesselt. Im September 1944 wegen der starken Luftangriffe auf Wesel nach Thüringen evakuiert.

In der Nachkriegszeit trat A. der SPD bei, wegen seiner Krankheit konnte er jedoch nicht mehr aktiv werden. Heini Landsiedel war nach 1945 SPD-Stadtverordneter. A. starb am 20. 1. 1959 .

Baier, Karh, einflußreicher KPO-Funktionär; seit Dezember 1930 einer der Wortführer der KPO-Minderheit, im Januar 1932 wegen Geheimverhandlungen mit der SAP zusammen mit sieben anderen führenden Vertretern der KPO-Minderheit (u.a. Enderle*, Frölich*; Lang*, Walcher*) Parteiausschluß; SAP, 1933 Mitglied der illegalen SJV-Reichsleitung, am 22.8. 1933 verhaftet und zu einer Zuchthausstrafe verurteilt; nach 1945 Mitglied der SED.

Baumeister, Heinz (1902-1969), Drogist; von 1924 bis $x 933$ hauptamtlicher Sekretär beim Gau Westliches Westfalen des „Reichsbanner Schwarz-Rot-Gold“. B. war einer der engsten politischen Freunde von Ernst Niekisch und gründete in Dortmund die nationalrevolutionäre "Widerstands ${ }^{*}$-Bewegung; über Franz Osterroth vom ehem. Hofgeismar-Kreis der Jungsozialisten Verbindung zur SOPADE in Prag; wiederholt in "Schutzhaft “, am 6. II. 1937 verhaftet und am 25.8. 1938 in das KZ Buchenwald eingeliefert, dort am I I.4. 1945 befreit; nach Kriegsende in der SBZ, wo er Präsident einer Handwerkskammer und 1947 Abgeordneter des Thüringischen Landtags war. Später - der genaue Zeitpunkt ist unbekannt kehrte B. wieder nach Dortmund zurück und leitete bis zu seinem Tod eine Speditionsfirma.

Widerstand und Verfolgung in Dortmund 1933-1945. Katalog der ständigen Ausstellung. Dortmund $198 \mathrm{I}$.

Bergmann, Josef, geboren am 4. 10. I913, Buchdrucker; KPO, nach illegaler Arbeit Anfang 1939 Emigration nach Schweden, Mitglied der "Landesgruppe deutscher Gewerkschafter" in Schweden; Anfang 1946 Rückkehr nach Hamburg, dort führendes Mirglied der „Gruppe Arbeiterpolitik“.

Birkelbach, Willi, geboren am 12.1. 1913 in Höchst bei Frankfurt a.M. Gymnasium und kaufmännische Ausbildung, Fremdsprachenkorrespondent, nach 1933 illegale Tätigkeit im Rahmen der SAP, Verbindungsmann zur SAP- „Zentrale“ in Mannheim, 1938 zusammen mit anderen Mitgliedern der Gruppe verhaftet, 1939-194 I im Zuchthaus, ab 1942 Soldat im Strafbataillon 999, 1944-1946 Kriegsgefangenschaft; nach der Rückkehr Eintritt in die SPD, 1947-1950 Leiter der Gewerkschaftsschule Hessen, 1949-1964 MdB, 1958-1963 Vorsitzender der sozialistischen Fraktion im Europäischen Parlament, 1954-1963 Vorsitzender der SPD Hessen-Süd, I 954-1957 Mitglied des PV der SPD, I 964-1969 Staatssekretär, Chef der Hessischen Staatskanzlei und Direktor des Landespersonalamtes Wiesbaden. 
Blachstein, Peter, geboren am 30.4. 191 I in Dresden; Gymnasium, Studium der Nationalökonomie, Literatur und Geschichte, kaufmännische Ausbildung im Buchhandel, Tätigkeit als Journalist; 1928 SPD, 1931 Mitbegründer der SAP in Sachsen, Agitpropleiter. Von März 1933 bis August 1934 im Gefängnis und im KZ Hohnstein; Ende 1934 Emigration, in Oslo zusammen mit Willy Brandt Mitarbeiter im „Internationalen revolutionären sozialistischen Jugendbüro"; seit 1936 Freiwilliger im Spanischen Bürgerkrieg, im Mai 1937 in Barcelona von Mitgliedern der spanischen KP verhaftet und bis Januar 1938 in Haft; über Frankreich Rückkehr nach Norwegen, 1940 Schweden, dort in der „Landesgruppe deutscher Gewerkschafter“; 1945 Betreuer der Juden, die im Rahmen der "Bernadotte-Aktion“ nach Schweden kamen; im April 1947 Rückkehr nach Deutschland, Mitglied der SPD in Hamburg, 1949-1968 MdB, seit Mitte der fünfziger Jahre einer der Exponenten der SPD-Linken. Mitglied des Landesvorstands der SPD Hamburg; 1968/69 Botschafter in Jugoslawien; B. starb am 4. 10. 1977.

Biographisches Handbuch der deutschsprachigen Emigration nach 1933. Bd. I. München 1980.

Blencke, Ema, geboren 1896, Pädagogin; 1928-1933 Studienrätin in Frankfurt a.M. und Hannover, 1933 entlassen, daraufhin Gründung eines Brotgroßhandels, der gleichzeitig der Tamung illegaler ISK-Arbeit galt; im Februar 1938 nach Frankreich, bei Kriegsausbruch interniert, $194^{\circ}$ im Lager Gurs in Sudfrankreich, August 1940 Flucht aus dem Lager; Emigration in die USA, politische Täigkeit u. a. im deutschsprachigen Zweig des Workmen's Circle in New York; 1951 Rückkehr nach Deutschland, bis 1954 Leiterin der Heimvolkshochschule Springe am Deister; in den sechziger Jahren Vorstandsmitglied der SPD-Frankfurt a. M.; Tätigkeit in der Erwachsenenbildung.

Biographisches Handbuch der deutschsprachigen Emigration nach 1933. Bd. I. München 1980.

Blind, Wilhelm (Willy), geboren am 23.9. 1913 in Stuttgart. Der Vater war von Beruf Magazinarbeiter im Konsum, er gehörte der Gewerkschaft und der SPD an; die Mutter war Hausfrau. Nach Beendigung der Volksschule 1928 absolvierte B. eine vierjährige Modellschreinerlehre. 1932/1933 arbeitslos, fand er Anfang 1934 Arbeit bei der Fa. Daimier-Benz. 1929 schloß sich B. dem Holzarbeiterverband an, er war Delegierter des Verbands im Kartell der Gewerkschaftsjugend des ADGB. 1930 SAJ, im Januar 1932 SJV.

1933-1934 war B. in der illegalen SAP in Stuttgart aktiv. 1934 verhaftet und im September 1934 wegen Vorbereitung zum Hochverrat zu acht Monaten Gefängnis verurteilt. Nachdem er 1937 wegen politischer Unzuverlässigkeit seinen Arbeitsplatz bei Daimler-Benz verloren hatte, arbeitete er in einer Bäckereimaschinen-Fabrik. Im August 1939 wurde er als Soldat eingezogen, im April $194^{\circ}$ verunglückte er und wurde daraufhin im Herbst entlassen. Durch Selbstumschulung Zeichner und Maschinentechniker bei den Technischen Werken der Stadt Stuttgart.

1946 wurde B. Mitglied der ÖTV und der SPD, in beiden Organisationen war er von 1946 bis Anfang bzw. Mitte der sechziger Jahre Kreis-Delegierter. 1947 Beitritt zum „Touristenverein Die Naturfreunde", dort ist B. seit mehreren Jahren Senioren-Obmann.

Bobzien, Franz, Lehrer; seit 1931 Vorsitzender des Hamburger SJV, Mitglied der SJVReichsleitung, 1933 zuständig für die Unstellung der Hamburger und Schleswig-Holsteiner SAP auf die Illegalität; Ende des Jahres Flucht nach Dänemark. Im Februar 1934 nahm B. an der beabsichtigten Gründung einer revolutionären Jugend-Internationale in der holländischen Kleinstadt Laaren teil. Kaum war die Konferenz jedoch eröffnet, da ließ der mit den Nationalsozialisten sympathisierende Bürgermeister alle ausländischen Teilnehmer verhaften und nach Belgien „abschieben “; B. und drei weitere SJV-Funktionäre, die die deutsch-holländische Grenze illegal überschritten hatten, wurden gefesselt an die Gestapo ausgeliefert. In Hamburg schwer gefoltert; am 27.7. 1934 in einem SAP-Prozeß gegen B. 
und fünfzehn weitere Angeklagte zu drei Jahren Zuchthaus verurteilt; zunächst im Zuchthaus Bremen-Oslebshausen, dann im KZ Sachsenhausen, dort kam B. am 21.3. I94I zusammen mit anderen politischen Häftlingen bei einem Bombenräumkommando ums Leben.

Ursel Hochmuth; Gertrud Meyer: Streiflichter aus dem Hamburger Widerstand 1933-1945. Frankfurt 2.M. 1969.

Böbme, Fritz, arbeitete mit Emil Brune*, Emil Heyen* und Hans Möller* in der Dortmunder SAP zusammen. Nach 1945 beschritt er in der SBZ eine juristische Laufbahn und wurde Landgerichtspräsident und Hauptabteilungsleiter im Justizministerium der DDR. Zahlreiche dienstliche Besuche in der Bundesrepublik in Sachen Gefangenenaustausch. In den fünfziger Jahren floh Böhme aus der DDR. In Dortmund wurde er erneut in seinem früheren Beruf als Verkäufer im Bürohandel tätig und schloß sich der SPD an.

Brandel Kuno, Ende der zwanziger Jahre Mitglied der KPO, nach 1933 Emigration in Frankreich; 1949-1956 Redakteur, anschließend bis März 196 I Chefredakteur der IG Metall-Zeitung „Metall“ und ebenfalls Redakteur der Funktionärzeitschrift „Der Gewerkschafter", später in derselben Funktion bei der IG Bau-Steine-Erden.

Brandler, Heinrich, geboren am 3.7. I88I in Warnsdorf/Böhmen, Fliesenleger, 1897 Deutscher Bauarbeiterverband, I901 SPD; $1909-1914$ in Zürich; ab 1914 in Chemnitz hauptamtlicher Sekretär des Bauarbeiterverbandes; Mitbegründer der Spartakus-Gruppe und der KPD, im Februar 192 I als Nachfolger von Paul Levi Mitvorsitzender der KPD; enge politische Kooperation mit August Thalheimer*; Vertreter der Einheitsfrontpolitik gegenüber der SPD; 1922 Sekretär des Politbüros der KPD; 1923 führend bei den Umsturzvorbereitungen der KPD; nach dem Scheitern des anvisierten Bündnisses mit der linken Sozialdemokratie für den geplanten Generalstreik Abbruch der Aufstandsvorbereitungen, im Februar 1924 als "Hauptschuldiger ${ }^{*}$ an der "Oktoberniederlage“ von der Komintern seiner Ämter enthoben und nach Moskau befohlen; 1926 rehabilitiert, Ämter im sowjetischen Staats- und Parteiapparat; im Oktober 1928 illegale Rückkehr nach Deutschland, mit August Thalheimer Organisator der rechten Opposition in der KPD, im Dezember 1928 Parteiausschluß; Mitglied der KPO-Reichsleitung, ab I93 I ihr Sekretär; im März 1933 Emigration nach Frankreich, Sekretär des Auslandskomitees der KPO; im Spanischen Bürgerkrieg Solidarisierung mit der POUM; 1939 zeitweise interniert, 1940 in südfranzösischen Lagern; 194I mit Thalheimer nach Kuba; nach 1945 Herausgeber der „Briefe aus der Ferne" an ehemalige Parteifreunde; nach zweijährigem Aufenthalt in London 1949 Rückkehr nach Deutschland, bis 1956 Leitungsmitglied der „Gruppe Arbeiterpolitik“; B. starb am 26. 9. 1967 in Hamburg.

Biographisches Handbuch der deutschsprachigen Emigration nach 1933. Bd. I. München 1980. Hermann Weber (Hrsg.): Unabhängige Kommunisten. Der Briefwechsel zwischen Heinrich Brandler und Isaac Deutscher 1949 bis 1967 . Berlin 1981.

Brandt, Willy, geboren am I 8. I 2. I 193 in Lübeck als nichtehelicher Sohn einer Verkäuferin; unter Schulgeldbefreiung Besuch der Realschule, ab 1928 eines Reformgymnasiums; 1929 SAJ, 1930 SPD, im Oktober 193 I Übertritt zur SAP, Vorsitzender des Lübecker SJV; 1932 Abitur, 1932-1933 Volontär bei einer Schiffsmaklerfirma; Anfang 1933 Mitwirkung am Aufbau einer illegalen Parteiorganisation, am I 1./12.3. 1933 Delegierter auf dem in der Illegalität tagenden II. Reichsparteitag der SAP in Dresden. Nach der Verhaftung Paul Frölichs* erhielt B. den Auftrag, in Oslo ein SAP-Büro einzurichten, am 1.4. 1933 auf einem Fischkutter von Travemünde aus Flucht nach Dänemark, von dort nach Oslo, Tätigkeit für die Presse der Norwegischen Arbeiterpartei und der Gewerkschaften; Verbindung zu illegalen Gruppen in Berlin und in Nordwestdeutschland; 1934-1938 häufige Informations- 
und Kurierreisen zur SAP-Auslandszentrale nach Paris; von Juli bis Dezember 1936 als norwegischer Student getarnt in Berlin Leiter einer SAP-Untergrundorganisation, von Februar bis Juni 1937 Journalist und Verbindungsmann der SAP-Auslandsleitung zur POUM in Barcelona, im September 1938 von den Nationalsozialisten ausgebuirgert, seitdem staatenlos; nach dem deutschen Überfall auf Norwegen am 1.5. 1940 in norwegischer Uniform um seine Identität zu verbergen - in deutsche Kriegsgefangenschaft; im Juli 1940 illegaler Grenzübertritt nach Schweden; über die norwegische Exilregierung in London Erwerb der norwegischen Staatsbürgerschaft. In Schweden war B. einer der maßgeblichen Vertreter der norwegischen und der deutschen Emigration, von 1942 bis Mai 1945 Mitinitiator und ehrenamtlicher Sekretär der „Internationalen Gruppe demokratischer Sozialisten “, zusammen mit August und Irmgard Enderle* treibende Kraft bei der Annaherung der SAP an die SOPADE, im Oktober 1944 Übertritt zur Ortsgruppe Stockholm der SOPADE; seit Sommer 1945 Berichterstatter für norwegische Zeitungen bei den Nümberger KriegsverbrecherProzessen, 1947 Presseattaché an der Norwegischen Militărmission in Berlin; Ende 1947 als deutscher Staatsbürger wiedereingebürgert; seit Februar 1948 Vertreter des SPD-Parteivorstands in Berlin. 1957-1966 Regierender Bürgermeister von Berlin, seit 1964 als Nachfolger von Erich Ollenhauer Vorsitzender der SPD, 1966-1969 Vizekanzler und Außenminister, 1969-1974 Bundeskanzler.

Biographisches Handbuch der deutschsprachigen Emigration nach 1933. Bd. I. München 1980; Willy Brandt: Links und frei - Mein Weg 1930-1950. Hamburg 1982.

Bräuning, Karh geboren am s.1. 1886 in Ilversgehofen bei Erfurt, Metalldreher; 1903 DMV, 1906 SPD, Arbeiter in den Zeiss-Werken Jena, 1917 USPD, Sparakusbund, im Herbst 1920 mit dem linken USPD-Flügel zur KPD; von 1923 bis Januar 1924 inhaftier, im Juli 1925 Verurteilung zu einem Jahr Gefängnis wegen Beihilfe zum Hochverrat; anschlieBend bis 1928 Organisationsleiter der KPD in Thüringen; im März 1929 Parteiausschluß; Sekretär des KPO-Bezirks Thüringen; 1933 Emigration ins Saargebiet, 1934 Organisationsleiter des illegalen Berliner Komitees der KPO, anschließend in der CSR Tätigkeit für die Exil-KPO; 1936 Freiwilliger im Spanischen Bürgerkrieg, wegen seiner Verbindung zur POUM ubber ein Jahr lang als „Trotzkist“ inhaftiert; Ende 1938 Trennung von der KPO, Übertritt zur SOPADE; 194I Emigration in die USA, Mitarbeit im Workmen's Circle und in der von Marie Juchacz ${ }^{*}$ geleiteten „Arbeiterwohlfahr ${ }^{*}$; 1955 Rückkehr nach Deutschland, Mitglied der SPD; B. starb am 14.9. 1962 in Darmstadt.

Biographisches Handbuch der deutschsprachigen Emigration nach 1933. Bd. I. München 1980.

Brenner, Otto, geboren am 8. I1. 1907 in Hannover als Sohn eines Orthopädiemechanikers, die Mutter arbeitete seit dem Ersten Weltkrieg als Aufwartefrau, ein Bruder, zwei Schwestern; seit 1917 bis zur Schulentlassung 192 I Laufjunge bei einer Firma. Eine berufliche Ausbildung B's scheiterte an der durch den Kriegsdienst und die langjährige Kriegsgefangenschaft des Vaters entstandenen wirtschaftlichen Notlage der Familie; 1922-24 Hilfsarbeiter in verschiedenen Betrieben, im Inflationsjahr 1923 Erntearbeiter; Ende 1924 Hilfsmonteur bei der Fa. Hanomag, Ausbildung zum Betriebselektriker, 1926-32 Beschäftigung als Elektromonteur; Fortbildung auf der Berufsschule und in Abendkursen; 1921 DMV, Vertrauensmann und Mitglied der Branchenleitung der Elektriker des DMV bei Hanomag; 1920 „Arbeiter-Jugend“, später 2. Vorsitzender der SAJ Hannover, 1928 Bezirksvorsitzender der Jungsozialisten, seit 1926 Mitglied der SPD, 1925 Eintritt in den „Aubeiter-AbstinentenBund ", von 1928 an dessen Vorsitzender; aufgrund dieser Funktion und seines ausgeprägten Bildungsstrebens enger Kontakt zum ISK; 1930 wegen des Panzerkreuzerbaus Austritt aus der SPD. I93 I SAP, Leiter des Bezirks Hannover-Braunschweig. Seit 1932 verheiratet mit Martha B.

Anfang 1933 arbeitslos; illegale Fortführung der SAP; Ende August verhaftet und zusam- 
men mit anderen SAP-Mitgliedern wegen Vorbereitung zum Hochverrat zu 2 Jahren Gefängnis verurteilt. Nach der Entlassung aus der Haft Ende 1935 wurde B. unter Polizeiaufsicht gestellt; da er seinen erlernten Beruf nicht mehr ausüben durfte, arbeitete er im Tiefund Straßenbau und als Zeitungsbote; Ende 1936 wieder als Elektromonteur bei einer antinationaisozialistisch eingestellten kleinen Montagefirma tätig, dadurch illegale Verbindungen.

Nach Kriegsende Mitbegründer einer aus ehem. SAP- und ISK-Mitgliedern bestehenden ${ }_{n}$ Arbeitsgemeinschaft zur Bildung der sozialistischen Einheit" in Hannover, die am 18.8. 1945 einen Aufruf zur Vereinigung von SPD und KPD erließ. Nach Verhandlungen von B., Willi Eichler* (ISK) u. a. mit Kurt Schumacher im August und September Beitritt zur SPD, seit 1946 in der Hannoveraner SPD Aufbau eines "Marxistischen Arbeitskreises“, der zur Schulung von Funktionären beitrug; Betriebsratsvorsitzender bei der Fa. Hanomag. Im November 1946 führte B. bei der Fa. Panzer-Bode den ersten Nachkriegsstreik durch, der zu einer Vereinbarung über gewerkschaftliche Mitbestimmungsrechte führte. Seit Ende 1945 Vorsizzender der Wirtschaftsgruppe Metall, von 1946 an Landesvorsizzender von Niedersachsen; 1947 auf dem I. Gewerkschaftstag der IG-Metall für die Britische Zone gegen den Widerstand des Hauptvorstandes der IG Metall Wahl zum Bezirksleiter der IG Metall Hannover, Ende 1952 wurde B. neben Hans Brümmer gleichberechtigter Vorsitzender der IG Metall Bundesorganisation; 1951-1954 Mitglied des Niedersächsischen Landtags, Vorsitzender des Sozialausschusses; 1956-1972 Vorsitzender der IG Metall; 196 I Präsident des „Internationalen Metallarbeiterbundes“. Als Vorsitzender der bei weitem mitgliederstärksten DGB-Organisation stellte B. die Weichen für zahlreiche wichtige politische Entscheidungen. Nach dem Scheitern der Sozialisierung und nach der Niederlage der Gewerkschaften im Kampf um das Betriebsverfassungsgesetz 1952 war er einer der Initiatoren des DGBAktionsprogramms von 1956, das die Durchsetzung folgender Nahziele in der Hochkonjunktur anstrebte: Arbeitszeitverkürzung von der 45- zur 40-Stunden Woche, Lohn- und Gehaltserhöhungen, verbesserter Arbeitsschutz, Mitbestimmung. In den fünfziger und sechziger Jahren mobilisierte B. für diese Ziele die Kampfkraft der IG Metall, der in zum Teil harten Tarifkämpfen bis hin zu Streiks und gerichtlichen Auseinandersetzungen häufig eine Vorreiterrolle unter den Gewerkschaften zukam. Auch in den außerparlamentarischen politischen Kampagnen spielte B. eine bedeutsame Rolle - 1954/5s beteiligte sich die IG Metall am Kampf gegen die Wiederbewaffnung, 1958 gegen die Atomrüstung. Im Unterschied zur SPD und zu anderen Gewerkschaftsführern hielt B. an dem langfristigen Ziel der Sozialisierung von Schlüsselindustrien und dem Ausbau der paritätischen Mitbestimmung fest und versuchte den Gewerkschaften gesellschaftspolitische Ziele zu weisen, die über die Lohn- und Arbeitszeitpolitik hinausgingen. Nach der Verabschiedung des Godesberger Programms 1959 lockerten sich die Beziehungen B's zur SPD, einen vorübergehenden Tiefpunkt erreichten sie Ende der sechziger Jahre, als die IG Metall zusammen mit dem SDS entschieden gegen die von der SPD in der Großen Koalition mitgetragene Notstandsgesetzgebung auftrat. Anfang der sechziger Jahre wurde auch ein zweiter gewerkschaftspolitjscher Neubeginn von B. mitkonzipiert: die Hinwendung zur gewerkschaftlichen Basis in den Betrieben, z. B. durch das Konzept der paritätischen Mitbestimmung. B. starb am 1 5.4. 1972.

Gerda Zorn: Widerstand in Hannover. Frankfurt a. M. 1977; Franz Hartmann: Entstehung und Entwicklung der Gewerkschaftsbewegung in Niedersachsen nach dem Zweiten Weltkrieg. Hannover 1977; Theo Pirker: Die blinde Macht. Die Gewerkschaftsbewegung in der Bundesrepublik. Bd.2 (1953-1960). Berlin 1979; Johannes Hermanns: Persönlichkeiten der Gegenwart. Otto Brenner. Freu . denstadt 1967; Peter von Oerzen: Otto Brenner. In: Gewerkschaftliche Monatshefte, 23.Jg. 1972, H. 6 .

Brünen, Eberbard (1906-1981), Dreher; 1925 SAJ, SPD, 1931 Unterbezirksleiter der SAP; seit Herbst 1933 Leiter der westdeutschen SAP-Organisation (Mittelrhein, Niederrhein, 
Westfalen). Am 3. I1. 1934 wurde Brünen verhafiet und im Juli 1935 zu fünfzehn Jahren Zuchthaus verurteilt, bis Kriegsende in Haft; nach 1945 Unterbezirkssekretär der SPD Duisburg, Ratsherr, 1947-1950 und 1954-1961 MdL Nordrhein-Westfalen, 1949-1953 und $1961-1972 \mathrm{MdB}$.

Brumlop, Kurt (1909-1977), seit 1924 im ZdA organisiert, bis 1929 Angestellter bei einer Bremer Tageszeitung, danach arbeitslos; führendes Mitglied des KJVD, als solcher 1930 aus der Gewerkschaft ausgeschlossen; 1934 verhaftet, von 1935 bis 1944 war B. als Werfarbeiter beschäfuigt; seit 1947 Tätigkeit als Gewerkschaftsjoumalist bei der Zeitschrift des DGB für die britische Zone „Der Bund“, seit I 949 Redakteur der „Welt der Arbeit ; Anfang 1955 Chefredakteur der DGB-Funktionärszeitschrift „Die Quelle ${ }^{\star}$, von 1963 bis 1970 leitete B. die Gewerkschaftsorgane der IG Chemie-Papier-Keramik.

Bnune, Emil, geboren am 3r.5. 1913 in Dortmund. Der Vater war Schlosser, die Mutter Hausfrau; ein Bruder. B. besuchte die Volks- und die Mittelschule und absolvierte dann eine Lehre als Versicherungskaufmann. Auf Grund der schlechten wirtschaftlichen Lage Ende März 1932 als Versicherungskaufmann entlassen, arbeitslos; im Juni 1934 Kontorist bei einem Dortmunder Bauunternehmen; seit 1924 Mitglied des „Touristenvereins Die Naturfreunde ${ }^{\star}, 1927$ der „Freien Schwimmer ${ }^{*}$ im .Arbeiter-Turn-und Sportbund ${ }^{\star}$; 1929 im freigewerkschaftlichen Zentralverband der Angestellten. Im Januar 1933 wurde B. zum Vorsitzenden des Dortmunder SJV gewählt. Die Umstellung der zu diesem Zeitpunkt etwa 300 Mitglieder zählenden SAP auf die Illegalität, die in Dortmund bereits mehrere Wochen vor der Machtübernahme Hitlers in Angriff genommen wurde, ging in erster Linie auf ihn zurück. In den folgenden Monaten trugen die Mitglieder des SJV, dessen führende Köpfe Emil Heyen*, Hans Möller*, Walter Mertin und Emil B. waren, die Hauptlast von Aktionen gegen das NS-Regime. Hans Möller* leitete den Bezirk III Westfalen der sich im Herbst unter Leitung des Duisburger Gebietsinstrukteurs Eberhard Brünen* herausbildenden westdeutschen SAP-Organisation. Über B. existierten 1933/34 Verbindungen zu einer etwa zehn bis zwanzig Personen starken „Naturfreunde ${ }^{\alpha}$-Gruppe, die ihren politischen Diskussionen das von der SAP erhaltene Material zugrundelegte. Moller seinerseits nahm im Fruhjahr und Sommer 1933 Kontakte zu einem Kreis um den Sozialdemokraten Fritz Henßler* auf. Nachdem die Gestapo die SAP in Dortmund mit Hilfe eines Spitzels mehrere Monate lang hatte observieren lassen, schlug sie am 30. 10. $1934 \mathrm{zu}$ und verhaftete Hans Möller* und B. In den folgenden Tagen wurde die illegale Organisation im Raum Dortmund, in Düsseldorf, Duisburg und in Köln zerschlagen. Auch Eberhard Brünen * wurde am 3. 11 . 1934 in Essen festgenommen.

B. wurde im Juli 1935 vom Oberlandesgericht Hamm wegen Vorbereitung zum Hochverrat zu zwei Jahren Zuchthaus verurteilt; im November 1936 aus der Haft entlassen. Von der Arbeitsvermittlung aus politischen Gründen zunächst ausgeschlossen, fand er im Juni 1937 eine Arbeit als Angestellter im Versicherungswesen, durfte jedoch nur in untergeordneten Stellen beschäftigt werden; Ende Januar 1943 Einberufung zum Strafbataillon 999.

Seit April 1945 in Kriegsgefangenschaft; im März 1947 Rückkehr nach Deutschland. B. wurde Mitglied des Gründungskomitees der Sozialistischen Einheitspartei Deutschlands (SED) im Ruhrgebiet. 1948 trat er mit der Begründung aus, die westdeutsche SED sei nur ein verlängerter Arm der KPD; im gleichen Jahr Beitritt zur SPD; seit Mai 1947 Mitglied der DAG. In der Dortmunder SPD hatte B. in den folgenden Jahren verschiedene Ämter inne, u.a. war er Vorsitzender der Jungsozialisten und 1957-1961 stellvertretender Vorsitzender der Partei; is Jahre ehrenamtlicher Verwaltungsrichter, vier Jahre ehrenamtlicher Arbeitsrichter. Aufsichtsratsfunktionen in der Stadtsparkasse und im Hafen. 1976 Vorsitzender der "Arbeitsgemeinschaft Verfolgter Sozialdemokraten “ (AVS) im Unterbezirk. Seit 1979 Vorsitzender im Bezirk westliches Westfalen und Mitglied des Bundesausschusses der AVS. 
Widerstand und Verfolgung in Dortmund 1933-1945. Katalog der ständigen Ausstellung. Dortmund 1981 .

Buchbeister, Wemer, geboren am 5.6. I901; 1928-1931 Hilfslehrer in Wolfenbüttel und Braunschweig, 193 I-31.3. 1933 Lehrer an der Polizeischule in Hannover; 1928 Mitglied der Allgemeinen freien Lehrergewerkschaft, seit I93 I der SAP; 1933-1935 in "Schutzhaft", anschließend in die Emigration, 1937-1940 Tätigkeit als Journalist in Christiansand (Norwegen), 1940-1946 in Sundsvall (Nordschweden); 1946 Politischer Redakteur der „Braunschweiger Zeitung ${ }^{\alpha}$, 1947-1949 Redakteur der Niedersachsenausgabe der DGB-Zeitschrift für die britische Zone "Der Bund“; 1950 Leiter der DGB-Bundesschule Bad Münster am Stein (jetzt: Bad Kreuznach), 1956 Leiter der DGB-Bundesschule Niederpöcking am Starnberger See; B. starb am 16.9. 1963.

Bübrer, Karl Otto (190I-1942), Lehrer, seit 1922 Mitglied der SPD und des „Reichsbanners ${ }^{\alpha}$, besonders in der Arbeitersportbewegung tätig; seit Oktober 1931 führendes SAP. Mitglied in Pforzheim; nach 1933 herausragender Kopf des SPD-Widerstandes gegen das ${ }_{n}$ Dritte Reich“ in Baden; Bührer wurde am 9.6. 1939 vom Volksgerichtshof zu zehn Jahren Zuchthaus verurteilt und kam am 27. 12. 1942 im Zuchthaus Brandenburg/Havel ums Leben.

Jörg Schadt (Hrsg.): Verfolgung und Widerstand unter dem Nationalsozialismus in Baden. Die Lageberichte der Gestapo und des Generalstaatsanwalts Karlsruhe 1933-1940. Stuttgart 1976; Karl Schroth Und immer wieder für die Freiheit. Pforzheimer sozialdemokratische Arbeiterbewegung 1924-1939. Pforzheim 1977.

Buttinger, Joseph, geboren am 30.4. 1906 in Reichersbeuren/Bayern als Sohn eines armen österreichischen Straßenarbeiters und einer elternlosen Magd; nach dem Tod des Vaters 1917 Knecht bei einem Bauern, 1921 Hilfsarbeiter in dem Fabrikdorf Schneegattern/Österreich; sozialdemokratischer Jugendfunktionär, 1926-1930 Leiter eines Heimes der sozialistischen Kinderfreunde in St. Veit an der Glan/Kärnten; Betriebsobmann der SAJ, 1930 sechsmonatiges Studium an der Partei-Arbeiterhochschule in Wien; Leiter des Parteibezirks St. Veit; nach dem 12.2. 1934 illegale Arbeit, von Mai bis August inhaftien, dann nach Wien ausgewiesen; 1935-1938 Vorsitzender des ZK der „Revolutionären Sozialisten Österreichs “, der im Untergrund tätigen Nachfolgeorganisation der verbotenen SPÖ (vgl. dazu seine eindrucksvolle dokumentarische Studie „Am Beispiel Österreichs. Ein geschichtlicher Beitrag zur Krise der sozialistischen Bewegung “). 1934 Bekanntschaft mit seiner späteren Ehefrau Muriel Gardiner"; im März 1938 Emigration nach Paris, Obmann der Auslandsvertretung der österreichischen Sozialisten; 1939 Flucht in die USA, I940 Rückzug aus der Parteipolitik; 1943 amerikanischer Staatsbürger; seit 1940 Unterstützung und Rettungsarbeit für politische Flüchtlinge im Rahmen des IRRC, 1945-1947 europäischer Direktor des IRCC in Paris und Genf; ab 1954 intensive politische Beschäftigung mit dem VietnamProblem, Berater der US-Regierung, mehrere Buchveröffentlichungen über Vietnam; I 956 anläßlich des Ungarn-Aufstandes erneut Europa-Direktor des IRRC; Mitarbeiter an zahlreichen amerikanischen und österreichischen Zeitschriften und Zeitungen. B. lebte $1980 \mathrm{im}$ US-Staat New Jersey.

Biographisches Handbuch der deutschsprachigen Emigration nach 1933. Bd. I. München 1980.

Colditz, Anni, wohnte seit I9 I in der Familie von Ella Ehlers* zur Untermiete und wurde als Familienmitglied angesehen. Von Beruf Zigarettendreherin, vor dem Ersten Weltkrieg Mitglied der SPD, dann Spartakus-Gruppe und KPD. Seit 1920 arbeitete sie als Sekretärin von Wilhelm Pieck in der KPD-Zentrale in Berlin; Ende 1924 zur Komintern nach Moskau; 1926 Rückkehr, 1929 Mitglied der KPO, 1932 der SAP. Während des Zweiten Weltkrieges arbeitete Anni C. illegal in Berlin, $1943 \mathrm{kam}$ sie bei einem Bombenangriff ums Leben. 
Deutsch, Emil geboren am 28.9. 1889 in Silberberg/Schlesien als fünftes von acht Kindem. Der Vater war Handweber. Seit seiner Kindheit arbeitete D. zuhause mit. Nach Abschluß der Volksschule begann er eine Elektromechanikerlehre, später arbeitete er als Elektriker im Bergwerk. Seit 1908 aktives Mitglied des Verbands der Bergarbeiter Deutschlands und der SPD. Wegen seiner Beteiligung an einem Streik wurde er 1914 von seiner Grube nicht reklamiert und kam als Soldat an die Front. 1916 wurde er nach mehrfacher Verwundung als arbeitsverwendungsfähig in die Heimat entlassen. Berufliche Weiterbildung in einer Kriegsverletztenabteilung. Im Frühjahr 1918 Betriebsleiter eines Elektrizitätswerks. 1919 wurde D. Sekretär des SPD-Unterbezirks Oels/Schlesien. In dieser Funktion unternahm er große Anstrengungen, die Arbeiterbewegung organisatorisch zu stärken. Er grindetc einen Ortsausschuß der Gewerkschaften und eine soziale Beratungsstelle, das sog. Arbeitersekretariat. 1920 spielte D. eine führende Rolle im regionalen Widerstand gegen den Kapp-Putsch. Seit 1922 Redakteur der sozialdemokratischen „Volkszeitung für Oels und Umgebung ${ }^{\alpha}$, Stadtverordneter, Unterbezirksvorsitzender, Leiter der SPD-Kreistagsfraktion, Mitglied des Niederschlesischen Provinziallandtages, Mitbegrunder einer Siedlungsgenossenschaft. 1931 wurde D. auf Wunsch des Preußischen Ministerpräsidenten Otto Braun technischer Direktor der halbstaatlichen Siedlungsgesellschaft für Mittel- und Niederschlesien, die in den Jahren 1928-1932 rund 7000 Siedlerstellen schuf.

Im März 1933 wurde D. wegen seiner „staatsfeindlichen Einstellung“ entlassen, im selben Monat erfolgte ein SA-Überfall auf sein Haus, dem er nur knapp entkam. Durch die Verhafung seiner Frau und seiner beiden Töchter, die ebenfalls ihre Arbeit verloren, versuchte die Polizei, seinen Aufenthaltsort ausfindig zu machen. Bis Anfang Dezember hielt sich D. im Gebirge verborgen. Da er nicht emigrieren wollte, stellte er sich am 12. 12.1933 in seinem Geburtsort Silberberg der Polizei. Er wurde von einem SA-Trupp nach Oels gebracht, dor als "roter Hund " durch die Stadt geführt und anschließend so schwer mißhandelt, daß ihm die Haut in Fetzen am Körper hing. Danach wurde er in das KZ Papenburg gebracht. Nach seiner Entlassung im Sommer 1934 war er arbeitslos. Erst im Frühjahr 1938 fand er eine Anstellung bei einer Baufirma, 1939 wurde er durch Beziehungen zu einem ehemaligen SPDMitglied Verwalter eines Handelshofes in Breslau; im August 1944 verhaftet und zwei Monate lang im KZ Groß-Rosen inhaftiert.

Nachdem er bei der örtlichen sowjetischen Militärverwaltung gegen Gewalttaten russischer Soldaten protestiert hatte, wurde D. im Frühjahr 1945 zusammen mit seiner Frau verhaftet, zwangsweise nach Oberschlesien gebracht und dort von der polnischen Miliz ausgewiesen. Seit August 1945 lebte er in Bamberg; erneut SPD-Mitglied. Von Februar 1946 bis März 1948 war er Flüchtlingskommissar in Hof; 1950 Geschäftsführender Vorsitzender des DGB-Kreisausschusses in Bamberg; seit I955 im Ruhestand. D. kam am I 1. 8. 1970 bei einem Autounfall ums Leben.

Wilhelm Matull: Ostdeutschlands Arbeiterbewegung. Abriß ihrer Geschichte, Leistung und Opfer. Würzburg 1973 .

Dörfler, Eberhard, geboren am 6.10. 1901 in Bielefeld. Der Vater war von Beruf zunächst Schlosser, seit 1923 Gewerkschaftssekretär des DMV. Die Mutter arbeitete in einem Kolonialwaren-Großhandelsgeschäft. Nach Beendigung der Volksschule 1916 Ausbildung als Werkzeugmacher; „Arbeiter-Jugend“ (AJ), im November 1918 Mitglied des DMV, im April 1919 der SPD; Stellvertretender Bezirksvorsitzender der AJ Ostwestfalen-Lippe. 1922 wanderte D. nach Nürnberg und arbeitete dort einige Zeit. Nach seiner Rückkehr wurde er auf Vorschlag des Bezirksvorstandes der SPD zu einem Kurzstudium an die von Alfred Braunthal geleitete Heimvolksschule Schloß Tinz bei Gera delegiert; 1924 Polizeischule für Rheinland-Westfalen, im März 1925 in Bielefeld in den Polizeidienst übernommen. Im August desselben Jahres mußte D. wegen eines schweren Herzschadens aus dem Polizeidienst ausscheiden. Bis 1927 war er erneut im Werkzeugbau tätig. Danach trat er die Stelle eines Gausekretärs des „Reichsbanners Schwarz-Rot-Gold“ an; der Reichsbanner-Bundes- 
vorstand lehnte jedoch die Anstellung eines Nichtkriegsteilnehmers unter Berufung auf die Satzung ab; seit September 1927 selbständiger Handelsvertreter. In der Bielefelder SPD bildete D., der sich entschieden gegen den Panzerkreuzer-Bau wandte, auf dem linken Flügel eine ${ }_{n}$ Arbeitsgemeinschaft sozialdemokratischer Arbeitnehmer", 193 I Übertritt in die SAP.

Nach der Machtübernahme durch die Nationalsozialisten Verfasser und Verteiler illegaler Flugschriften; am 3.11. 1933 nach einer Denunziation verhaftet, im Mai 1934 in einem Prozeß gegen D. und "Genossen ${ }^{\alpha}$ wegen Vorbereitung zum Hochverrat als Rädelsführer zu 22 Mon. Gefängnis verurteilt. Die Einreichung eines Gnadengesuches lehnte er ab; im September 1935 Entlassung aus dem Abeitslager Eggeberg bei Halle/Westfalen. Ab Dezember mußte D. in einem der Stadt Bielefeld gehörenden Steinbruch arbeiten; seit August 1936 erneut als Werkzeugmacher tätig. Durch ein dreijähriges Abend-Fernstudium Qualifikation für eine Konstrukteur- und Ingenieurtätigkeit. Seit August 1940 Konstrukteur in verschiedenen Betrieben, u. a. bei den Dürrkopp-Werken; zu dieser Zeit in Verbindung mit einer Gruppe um den Sozialdemokraten Paul Brockmann und einer KPD-Gruppe bei Dürrkopp; am 3.8. 1944 verhaftet und wegen "Hochverrates" sowie "Rundfunkverbrechens" in "Schutzhaft" gebracht. D. wurde zehn Tage lang von der Gestapo verhört, in diesem Zeitraum wurden aus seinem Freundes- und Bekanntenkreis zwölf politische Gefangene in Dortmund hingerichtet. Wegen der anhaltenden Bombardierung Bielefelds stellte die Gestapo die Verhöre ein; am 26.3. 1945 aus der Haft entlassen.

Nach dem Einmarsch der Amerikaner Leiter eines „Sondereinsatzes für den Wiederaufbau“, der Mitglieder der NSDAP zu Aufräumarbeiten heranzog. Auf Vorschlag der Militärregierung im August 1945 Arbeitsamtsdirektor, 1946 Ernennung zum Oberregierungsrat. 195 I wurde D. als Direktor zum Arbeitsamt Hagen versetzt, 1962 zum Verwaltungsdirektor befördert, seit 1966 im Ruhestand. D. war seit 1945 Mitglied der SPD und der Gewerkschaft ÖTV. Er starb am 6. 1. 1981.

Dobr, Hein (1895-1976), Schwiegervater von Hubert Pauli*, Heizungsinstallateur bei der Westdeutschen Waggonfabrik Köln-Deutz; Anfang der dreißiger Jahre Mitglied der SAP; von 1933 bis 1940 Verbindungsmann einer Vierergruppe zur illegalen Kölner SAP-Leitung; nach I945 aktiver Gewerkschafter in der IG Metall.

Ebeling, Grete, geboren 1910, Kinderfreunde-Helferin, Abitur über Arbeiter-AbiturientenKurse an der Karl-Marx-Schule in Berlin 1930, bis 1932 Studium der Erziehungswissenschaften an der TH Braunschweig, Mitglied der SPD, der SAP und des "Sozialistischen Studentenbundes“, 1932 Relegation; im Juli 1933 verhaftet, im Oktober desselben Jahres Emigration ins Saarland. 1934 heiratete sie Hermann E.*, 1935 nach Frankreich, Arbeit als Putzfrau, Tätigkeit für die Exil-SAP und die FDJ in Paris, Adoption eines behinderten jüdischen Kleinkindes; I941 mit ihrem Mann in die USA, Sozialarbeit in den Slums; gegen Kriegsende in New York Tätigkeit im Central Location Index, einer Suchdienstkartei. Grete E. lebte 1981 bei Frankfurt a. M.

Ebeling, Hermann (1909-1980), 1930-1932 Studium der Erziehungswissenschaften an der THI Braunschweig, 1930 SPD, 1931 SAP; wegen antinationalsozialistischer Aktivität Stipendienentzug und Relegation von der Universität durch die NS-Landesregierung, im November 1932 Emigration nach Paris, journalistische Tätigkeit, u.a. Korrespondent der „SAZ - Sozialistische Arbeiter Zeitung“, Ende 1933 bis Januar 1935 Lehrer an einer französischen Schule im Saarland, danach wieder in Frankreich; führender Mitarbeiter in der $\mathrm{Pa}$ riser SAP-Gruppe, 1936-1940 Redakteur der "Pariser Tageszeitung“; von September 1939 bis April 1940 internier, anschließend Prestataire beim britischen Expeditionskorps; im Juni 1941 in die USA, Sozialarbeit in den Slums, 1943-1946 Militärdienst, danach u. a. bis 1949 Assistant Director des „Unitarian Service Committee“ (USC) New York für die Deutschlandhilfe, ab 1950 Mitarbeiter der "National Conference of Christians and Jews", 
1951-1955 als deren Vertreter in Deutschland; 1952 Begründer der „Woche der Brüderlichkeit $^{\text {" }}$; lange in der kommunalen Sozialarbeit im Staate New York tätig, kehrte E. in den siebziger Jahren mit seiner Frau in die Bundesrepublik zurück.

Biographisches Handbuch der deutschsprachigen Emigration nach 1933. Bd. I. München 1980.

Eckert, Erwin (1893-1972), ev. Pfarrer; 1911 Mitglied der SPD, 1926-I93 I geschäfusführender Vorsitzender des „Bundes der religiösen Sozialisten Deutschlands“; 1931 wegen „Zellenbildung " und „Sonderbündelei “ aus der SPD ausgeschlossen, Beitritt zur KPD; im Oktober $1936 \mathrm{zu}$ drei Jahren und acht Monaten Zuchthaus verurteilt; von 1946 bis 1950 I. Vorsitzender der KPD Baden, 1947-1956 MdL von Baden und Baden-Württemberg; Vorsizzender des "Westdeutschen Friedenskomitees"; in den sechziger Jahren stand Eckert der DKP nahe.

Friedrich Martin Balzer: Klassengegensätze in der Kirche. Erwin Eckert und der Bund der Religiösen Sozialisten Deutschlands. Koln 1973.

Eckstein, Emst geboren 1897 , aus ärmlichen Verhältnissen stammend. E. ließ sich nach einem Jurastudium in Breslau als Rechtsanwalt nieder, dort genoß er bald einen Ruf als „Anwalt der Armen "; langjähriger Vorsitzender der SPD Breslau, Stadtverordneter und Mitglied des SPD-Bezirksvorstandes; Mitarbeiter in der linksoppositionellen „KlassenkampfGruppe ${ }^{\alpha}$, Gegner der Koalitions- und Tolerierungspolitik; 1931 fuhrendes Gründungsmitglied der SAP, Vorsitzender der Bezirksleitung Mituelschlesien, Mitglied des SAP-Parteivorstandes; als der von den Nationalsozialisten in Breslau bestgehaßte Mann - bereits 1932 war ein Attentat auf ihn erfolgt - unmittelbar nach dem Reichstagsbrand verhaftet. Im Anschluß an schwere Mißhandlungen durch die SA erlag E. am 8.5. 1933 im KZ BreslauDürrgoy den Folgen der Folterungen. Seine Beisetzung wurde zur letzten großen Demonstration der Breslauer Arbeiterbewegung.

Eckstein, George (Güntber), geboren am I. 1 2. 1909 in München; der Vater, ein assimilierter jüdischer Rechtsanwalt, wurde im Ersten Weltkrieg wegen seines Pazifismus aus der Anwaltskammer ausgeschlossen; 1925 mittlere Reife, 1925-1927 Lehrling in einer Spielwarenfabrik, 1927-1933 in der Betriebsleitung der elterlichen Spielwarenfabriken in Nürnberg und Sonneberg/Thüringen tätig; 1925-1932 Mitglied und zeitweise Ortsvorsitzender des „Deutsch-jüdischen Wanderbunds Kameraden“ in Nürnberg. 1932-1933 Reichsvorsitzender der "Freien Deutsch-Jüdischen Jugend ${ }^{“}$, die eine Assimilation der Juden auf der Grundlage einer sozialistischen Gesellschaftsordnung anstrebte; ab 1931 SAP; von April bis Juli 1933 "Schutzhaft", im Oktober 1933 Emigration nach Paris, 1934-1937 Mitglied der SAPAuslandsgruppe; im Februar 1939 mit Frau und zweijähriger Tochter in die USA, Aufbau eines Spielwarenunternehmens, nach 1945 Beiträge für die "Stuttgarter Zeitung ", ab 1958 für die "Gewerkschaftlichen Monatshefte"; nach dem Rückzug aus dem Geschäftsleben 1966 regelmäßige Beiträge für die deutsche Presse und den Rundfunk über die soziale und politische Entwicklung in den USA. E. lebte $198 \mathrm{I}$ in Great Neck/N.Y.

Biographisches Handbuch der deutschsprachigen Emigration nach 1933. Bd. r. München 1980.

Eckstein, Günter, geboren am 26.7. 1915 in Breslau. Der Vater starb im Juni 1918 an den Folgen einer Kriegsverwundung. Die Mutter heiratete 1920 erneut; der Stiefvater, ein Metalldrücker, war SPD-Mitglied und Führer des „Reichsbanner Schwarz-Rot-Gold“; zwei Schwestern. Im Anschluß an die Volksschule begann E. 1929 eine vierjährige Installateurund Klempner-Lehre; seit 1933 als Installateur tätig. Von 1933 bis Anfang 1934 nahm E. an illegalen Fahrten der Breslauer Gewerkschaftsjugend teil, nach 1934 hielt er lose Verbindungen aufrecht. Bis 1936/1937 bekam er den "Neuen Vorwärts" aus der Tschechoslowa- 
kei; 1935 sechsmonatiger Reichsarbeitsdienst; 1937-1939 Wehrdienst, seit Kriegsbeginn im September 1939 Soldat. 1940 meldete er sich zur Feuerwerkerschule und ließ sich als Waffen- und Munitions-Prüfer ausbilden; seit 1943 als Feuerwerker an der Ostfront. Bei Kriegsende vergrub $\mathrm{E}$. in Radis/Wittenberg seine Uniform und seine Papiere und entging dadurch der sowjetischen Kriegsgefangenschaft. Im Juli r945 Mitglied, wenig später Funktionär der SPD in Radis. Im September 1946 verließ E. die SBZ und ging über Hannover nach Bayreuth. Dort verdiente er sich seinen Lebensunterhalt als Gelegenheitsarbeiter. Ende 1947 nach Stuttgart, dort bis Dezember 1949 offentlicher Kläger. 1948 führendes Mitglied der "Arbeiter-Partei“. Seit 1951 arbeitete E. in Frankfurt als Installateur. 1957 verzog er nach Köln-Mülheim. Dort trat er 1960 der SPD bei; Vorstandsmitglied der SPD KölnMülheim und Unterbezirks-Delegierter. Seit Juni 1978 ist E. Rentner.

Ehlers, Adolf (Adje), geboren am 21.2. 1898 in Bremen als zwölftes und letztes Kind. Der Vater, der in wirschaftlich guten Zeiten Fuhrmann und in schlechten Transportarbeiter war, starb 1904. Im Anschluß an die Volksschule absolvierte E. eine Handlungsgehilfenlehre, er wollte Kaufmann werden. Nach dem Tod der Mutter im August 1916 zog er zu seinem Schwager und zukünftigen politischen Mentor Wilhelm Deisen, einem Anhänger der „Bremer Linksradikalen ${ }^{\alpha}$; seit November 1916 Soldat. Im April 1918 wurde E. an der Westfront verschüttet, erlitt einen Nervenschock und verlor eine Zeitlang die Sprache. Da er im Frühjahr 1919 keine Arbeit finden konnte, ging er auf Anraten seines Schwagers als ungelernter Arbeiter zur größten Bremer Werf, der A.G. Weser, deren Belegschaft den Kern der radikalen Bremer Arbeiterbewegung bildete; Qualifizierung zum Schweißer und Brenner; Mitglied des KJVD und der Gewerkschaft; bereits 1919 in den Ortsvorstand des DMV und des ADGB gewählt. Nach der Arbeit besuchte E. Volkshochschul-Kurse in Philosophie, Soziologie und Kunstgeschichte; 1921-1923 Politischer Leiter des KJVD im Bezirk Nordwest. Nach der Entlassung des alten Betriebsrats im Anschluß an einen politischen Streik wurde E. 192 I Betriebsratsvorsitzender der A. G. Weser. In dieser Funktion trat er im Oktober 1923 anläßlich des Einmarsches der Reichswehr in Sachsen im Gewerkschaftshaus für einen politischen Generalstreik zugunsten der sächsischen SPD-KPD-Regierung Zeigner ein; daraufhin verhaftet und bis zum März 1924 in „militärischer Schutzhaft “; am I8. I I. 1923 als jüngster KPD-Abgeordneter in die Bremische Bürgerschaft gewählt; Anfang April 1924 Delegierter des in der Illegalität tagenden IX. Parteitags der KPD in Frankfurt a.M. Ende 1924 wurde E. als Anhänger des rechten Parteiflügels aus der KPD und aus der KPDFraktion in der Bürgerschaft ausgeschlossen. Anfang $1926 \mathrm{im}$ Zusammenhang mit einer Rehabilitierung der 1924 und 1925 ausgeschlossenen Rechten durch die Kontrollkommission der Komintern jedoch formlos wieder aufgenommen; hauptamtlicher Sekretär der "Roten

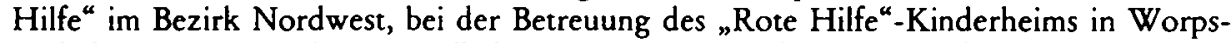
wede lernte E. 1926 seine Frau Ella kennen; 1927 Leiter der Propagandaabteilung im Zentralvorstand der ${ }_{n}$ Roten Hilfe ${ }^{\alpha}$ in Berlin; 1929 zusammen mit anderen führenden Funktio-

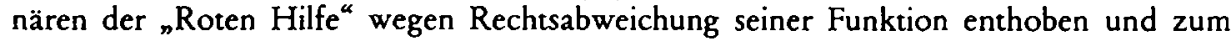
zweiten Mal aus der KPD ausgeschlossen; Rückkehr nach Bremen, seit I931 erwerbslos; die A. G. Weser, deren Belegschaft von 9500 - Mitte der zwanziger Jahre - auf 400 Arbeiter und Angestellte 193 I gesunken war, bot keine Beschäftigungsmöglichkeit; Politischer Leiter des Bezirks Nordwest der KPO; mit der ca. soköpfigen Bremer KPO-Gruppe im Februar 1932 Übertritt zur SAP, der in der Hansestadt vor allem ehemalige SAJ-Mitglieder angehörten; Organisationsleiter der SAP im Weser-Ems-Gebiet.

1933 konnten die Mitglieder der Bremer SAP, die bei der Reichstagswahl vom 6. I I. 1932 nur 63 I Stimmen erhalten hatte, ihre Organisation trotz Hausdurchsuchungen und Polizeikontrollen ohne Verluste auf die Illegalität umstellen. In den folgenden Jahren verzichteten sie auf eine riskante Öffentlichkeitsarbeit und bemühten sich in erster Linie darum, ihre Kader zusammenzuhalten, neue Anhänger zu gewinnen und zu schulen. Durch diese defensive Taktik war es der SAP in Bremen möglich, bis 1945 einen handlungsfähigen antifaschistischen Kreis zu bewahren, der unmittelbar nach Kriegsende Führungsaufgaben übernehmen 
konnte. Als Leiter der illegalen SAP-Gruppe unternahm E. mehrere Jahre lang Kurierfahrten nach Berlin. Bis 1939 unterhielt er Verbindungen zu SAP-Genossen in Skandinavien, u.a. zu Willy Brandt', die für eine regelmäßige Übermitulung von Material sorgten; noch während des Krieges schickten August und Irmgard Enderle* von Stockholm aus durch schwedische Seeleute sporadisch Nachrichten nach Bremen. Nach siebenjähriger Arbeitslosigkeit - 1934/1935 war gegen E. ein Arbeitsverbot in der Rüstungsindustrie verhängt worden - erneute Beschäftigung bei der A. G. Weser; 194I Verwalter eines Magazins, dadurch Gelegenheit zu illegalen Kontakten. Seit Ende 1943 bereirete sich E. politisch auf die Zeir nach dem Krieg vor. Auf seine Initiative hin trafen sich im Mai 1944 erstmalig ehemalige Funktionäre der SAP, SPD, KPD, des ISK und der „Deutschen Friedensgesellschaft“. Zusammen mit dem ehemaligen KPD-Mitglied Hermann Wolters Ausarbeitung eines überparteilich-antifaschistischen Akrionsprogramms für den „Tag X $\mathrm{X}^{\alpha}$. Im selben Jahr erfuhr $\mathrm{E}$. durch einen kommunistischen Kurier, daß er - ohne sein Zutun - wieder in die KPD aufgenommen worden war.

Unmittelbar nach der Besetzung Bremens durch englische Truppen Mitbegründer und Vorstandsmitglied der Bremer "Kampfgemeinschaft gegen den Faschismus" (KGF), die Mitte des Jahres in 35 Stadtteil- und Ortsgruppen ca. 6500 Mitglieder zăhlte. Ende April 1945 beantragte E. bei der Militärbehörde erfolglos die Zulassung einer Einheitsgewerkschaft; entschiedenes Eintreten für die Zusammenfassung aller sozialistischen Strömungen in einer Partei; von Juni bis August 1945 im Dreier-Ausschuß für die Neugrundung des Gewerkschaftsbundes; im Juni 1946 Leiter des Arbeitsamts, im August Senator für das Wohlfahrtsund Gesundheitswesen; Mitglied der KPD-Bezirksleitung, doch in Opposition gegen die Politik des ZK der KPD; im Mai 1946 zusammen mit Hermann Wolters Ubertritt zur SPD; 1948 Senator für Inneres; 1948/1949 Vertreter Bremens im Parlamentarischen Rat und im Bundesrat; seit 1959 zweiter Bürgermeister der Hansestadt. 1962 wurde E. auf dem Landesparteitag der SPD Bremen einstimmig zum Spizzenkandidaten für die Bürgerschaftswahl 1963 und damit zum Nachfolger Wilhelm Kaisens gewählt. Nach einem gesundheitlichen Zusammenbruch verzichtete er auf Anraten von Ärzten auf die Kandidatur, Ende 1963 schied er aus der Bremer Landesregierung aus; 1962-1964 Mitglied des Bundesvorstands der SPD, 1967-1969 des Landesvorstands der SPD Bremen. E. starb am 20. 5. 1978.

Hermann Weber: Die Wandlung des deutschen Kommunismus. Bd. 2. Frankfurt a. M. 1969. K. H.Tjaden: Struktur und Funktion der "KPD-Opposition" (KPO). Meisenheim am Glan 1964; Peter Brandt: Antifaschismus und Arbeiterbewegung. Aufbau - Ausprägung - Politik in Bremen 1945/46. Hamburg 1976; Horst Adamietz: Das erste Kapitel. Bremen 1975; ders.: Freiheit und Bindung. Adolf Ehlers. Bremen 1978.

Ehlers, Ella, geb. Schimpf, geboren im Mai 1904 in Dresden als jüngstes von drei Kindern. Der Vater war Glaser und Tischler; die Mutter, die in einer großen Zigarettenfabrik gearbeitet hatte, drehte nach der Geburt ihrer Kinder Zigaretten in Heimarbeit. E. entstammt einer politisch interessierten und engagierten Familie. 1914 traten die Eltern aus Protest gegen die Bewilligung der Kriegskredite aus der SPD aus. 1920 schlossen sie sich der KPD an. Seit 1916 verteilte E. die oppositionelle „Leipziger Volkszeitung“. Als letzte der Geschwister organisierte sie sich 1922 im KJVD; nach Abschluß der Volksschule 1918 anderthalb Jahre in der Kinderstation eines Krankenhauses; die von ihr gewünschte Ausbildung zur Krankenschwester scheiterte an der Armut der Eltern; Haushaltshilfe in einem Sanatorium. Dank einer Freistelle am „Fröbel-Institut" konnte sie seit 1922 den Beruf einer Kindergärtnerin bzw. -pflegerin erlernen; 1924 Tätigkeit in einer Kinderbewahranstalt mit Halbwaisen und Kindern kriegsversehrter Väter. Im Februar 1926 wurde sie Helferin in einem Kindererholungsheim der "Roten Hilfe ${ }^{\star}$ in Worpswede, seit November dessen Leiterin. Auf dem „Barkenhof", den der Maler Heinrich Vogeler gestiftet hatte, betreute sie Kinder, deren Eltern in den Unruhen nach der Novemberrevolution ums Leben gekommen waren oder aus politischen Gründen im Gefängnis saßen. Als im November 1926 staatliche Behörden die Entfer- 
nung der revolutionären Wandgemälde Vogelers forderen, löste dies eine Welle der Solidarität aus, an der sich ein Großteil der deutschen Intellektuellen beteiligte. Seitdem galt der Barkenhof als beliebter Treffpunkt zahlreicher Sozialisten, Schriftsteller und Maler. Seit I 927 fuhr Ella Sch. häufiger zu Adolf Ehlers nach Berlin, zusammen mit ihrem späteren Mann nahm sie intensiven Anteil am kulturellen Leben der Stadt, besuchte Theatervorstellungen und Filmvorführungen, über die "Rote Hilfe " lernte sie die Schriftsteller Theodor Plievier, Ernst Toller, Max Brod kennen; 1929-1931 Leiterin eines Kinderheims der „Roten Hilfe $^{u}$ in Elgersburg in Thüringen, verlor jedoch nach Adolf E.s KPD-Ausschluß ihre Arbeit. Nach der Rückkehr nach Bremen kümmerte sich Ella E. um die materielle Existenz der Familie. Da sie als Erzieherin keine Abeit finden konnte, besuchte sie die Handelsschule und arbeitete in den Jahren 1931-1945 als Kontoristin und Stenotypistin bei verschiedenen Firmen; bis 1938 bestritt sie den Lebensunterhalt für sich und ihren arbeitslosen Mann.

Nach 1933 beteiligte sich Ella E. an den politischen Aktivitäten der illegalen Bremer SAPGruppe, auch an Kurierfahrten. Eine engere Freundschaft verband sie und Adolf E. mit dem I935 verstorbenen Kunsthistoriker Julius Meier-Graefe, der dem Impressionismus in Deutschland zur Anerkennung verholfen hatte, und mit dem Kunst-Schriftsteller Wilhelm Hausenstein. Ein Skatclub und ein Wanderclub ermöglichten gelegentlich Treffen in einem größeren Kreis.

Im August 1945 Mitbegründerin des „Bremer Arbeiterhilfswerks ${ }^{\star}$ und dessen 2. Vorsitzende. Auf ihre Initiative hin und durch enge Kontakte zum Schwedischen und zum Schweizer Arbeiterhilfswerk sowie zu den freien Wohlfahrtsverbänden in den USA kam in der Nachkriegszeit eine internationale Hilfs- und Spendenaktion für notleidende Bremer Bürger zustande. In späteren Jahren galt ihr besonderes Engagement der Gründung eines Nachbarschaftshauses für Jung und Alt in Bremen-Gröpelingen, eines Mutter- und Kinderheimes für ledige Mütter, der Einrichtung eines Programms „Essen auf Rädern“ für Alte und Behinderte, der Hauspflege für Kranke und der Betreuung von Altentagesstätten. Seit 196 I 1. Vorsitzende des Landesverbands Bremen der ${ }_{n}$ Arbeiterwohlfahrt ${ }^{*}$. 977 wurde sie für ihre Verdienste im Bereich der sozialen Hilfe mit dem Bundesverdienstkreuz ausgezeichnet. Ella E. lebte $198 \mathrm{I}$ in Bremen.

Horst Adamietz: Freiheit und Bindung. Adolf Ehlers. Bremen 1978.

Eichler, Willi, geboren am 7.1. I896 in Berlin; Kaufmännischer Angestellter; 1919 Mitglied der SPD; 1923-1927 Privatsekretär des Göttinger Philosophen Leonard Nelson; nach Nelsons Tod 1927 Vorsitzender des ISK. Im November 1933 emigrierte E. und übernahm die Leitung der ISK-Auslandszentrale in Paris; von dort aus in Zusammenarbeit mit der "Internationalen Transportarbeiter-Föderation" Unterstützung der illegalen ISK-Gruppen in Deutschland; Herausgeber der sog. „Reinhart-Briefe" und des ISK-Organs „Sozialistische Warte"; seit Januar 1939 in London; nach dem Zusammenschluß des ISK mit der SOPADE, der SAP und der Gruppe "Neu Beginnen" zur „Union deutscher sozialistischer Organisationen in Großbritannien" im März 194I Mitglied der "Unions“-Exekutive. 1945 machte sich E. entgegen noch starken Strömungen im innerdeutschen ISK zum Fürsprecher für die Vereinigung mit der SPD; nach seiner Rückkehr nach Deutschland führende Beteiligung am Aufbau der rheinischen SPD; Chefredakteur der "Rheinischen Zeitung", 1945-1949 Herausgeber der "Sozialistischen Presse-Korrespondenz", langjähriger Schriftleiter der Monatsschrift ${ }_{n}$ Geist und Tat ${ }^{\star}$. Als Mitglied des Parteivorstandes in den Jahren 1946-1968 nahm E. maßgeblichen Einfluß auf die programmatische Entwicklung der SPD, insbesondere auf die Entstehung des Godesberger Programms von 1959. E. starb am 17. 10. I 97 I.

Biographisches Handbuch der deutschsprachigen Emigration nach 1933. Bd. I. München 1980. 
Elfein, Pauh geboren 1897 in Wechmar bei Gotha. Der Vater, ein Zimmermann, war Gewerkschafts- und SPD-Mitglied. E. wurde als neuntes von elf Kindern geboren, von denen fünf früh starben. Im Jahre $1900 \mathrm{zog}$ die Familie in einen Industrievorort von Erfurt. Seit 1911 erlernte E. das Schuhmacher-Handwerk. Er organisierte sich im „Arbeiter-Turn- und Sportbund ", in der Gewerkschaft und in der AJ. Im April 1914 ging er auf Wanderschaft, 191 5-1916 arbeitete er in einer Erfurter Schuhfabrik; 1916-1918 Soldat; 1919 Mitglied der USPD, 1920 mit dem linken Flügel der USPD zur KPD. 1923 wurde E. Vorsitzender der KPD-Ortsgruppe Hochheim bei Erfurt. Er war Mitglied des „Roten Frontkămpfer-Bundes", der „Roten Hilfe ${ }^{\alpha}$, gehörte dem Betriebsrat der Schuhfabrik, in der er arbeitete, und der Ortsverwaltung der Schuhmachergewerkschaft an. Am 29.6. 1929 erfuhr E. aus der Zeitung, daß er aus der KPD ausgeschlossen worden war. Daraufhin traten nahezu alle KPDMitglieder des Ortes zur KPO über, mit dem Ergebnis, daß die KPD im Gemeinderat seitdem nicht mehr vertreten war. E. gab die Ortszeitung der KPO heraus und war Abgeordneter im Gemeinde- und Kreisrat.

Im April 1933 wurde er verhafter, fuinf Monate KZ Esterwegen. 1934 stand er unter Polizeiaufsicht und wurde zu Notstandsarbeiten herangezogen. $\mathrm{Zu}$ seinem Lebensweg in den Jahren 1935-1948 vgl. den Brief vom 17.2. 1949, S. $212 \mathrm{f}$.

Ende September 1948 flüchtete er aus der SBZ nach Nürnberg. Um politisch arbeiten zu können, trat er der SPD bei und wurde bald Vorsitzender der SPD Nürnberg-Langwasser. Zugleich schloß er sich der Nürnberger "Gruppe Arbeiterpolitik" (GAP) um Emma und Karl Grönsfelder* an; 1952 Austritt aus der SPD. Im selben Jahr wurde er von der Leitung der GAP nach Salzgitter geholt, um sich an den dorrigen Auseinandersetzungen um die Demontage der Salzgitter-Hütte zu beteiligen. In Salzgitter arbeitete E. in der Gießerei, später im Walzwerk, politisch war er in der ungefähr einhundert Mitglieder zählenden GAP aktiv; bis zu seinem Ausscheiden aus dem Abeitsleben im Jahre 196I Betriebsrat und Mitglied der Ortsverwaltung der IG Metall; 1968 Vorsitzender des niedersächsischen Landesverbands der Freidenker. E. steht nach wie vor der GAP nahe. 1979 lebte er in Salzgitter-Lebenstedt.

K.P. Wittemann: Kommunistische Politik in Westdeutschland nach 1945. Der Ansatz der Gruppe Arbeiterpolitik. Hannover 1977. Paul Elflein: Immer noch Kommunist? Erinnerungen hrsg. v. Rolf Becker und Claus Bremer. Hamburg 1978.

Enderle, August geboren am 5.8. 1887 in Feldstetten/W uirttemberg als Sohn eines Zimmermannes. Nach der Volksschule ließ sich E. zum Mechaniker ausbilden und arbeitete als Eisendreher. 190s in Stuttgart Mitglied der SPD und des DMV. Bei Ausbruch des Ersten Weltkrieges Gegner der Burgfriedenspolitik. 191s trat er in einer SPD-Versammlung in Nowawes bei Berlin gegen den früheren SPD-Linken Paul Lensch auf, der inzwischen zu einem Befürworter der Kriegskredite und der Vaterlandsverteidigung geworden war. Daraufhin wurde E. eingezogen und war bis 1918 Soldat. Nach Kriegsende bewirtschaftete er einige Zeit die Anteile seiner Mutter an einem Bauernhof. Aus der USPD trat er 1919 zur neugegründeten KPD über. $192 \mathrm{I}$ wurde E. von Jacob Walcher* nach Berlin in die Gewerkschaftsredaktion des KPD-Zentralorgans „Die Rote Fahne" geholt. Gleichzeitig war er Mitglied der Gewerkschaftsabteilung des Zentralkomitees der KPD und 1922-1923 deutscher Vertreter in der Leitung der Roten Gewerkschaftsinternationale (RGI) in Moskau; ab 1924 wieder Gewerkschaftsredakteur der "Roten Fahne“. E., der der Mittelgruppe um Ernst Meyer zugerechnet wurde, wandte sich $1923 / 1924$ gegen die Gründung selbständiger kommunistischer Gewerkschaften. Daraufhin wurde die Abteilung nach dem vollständigen Sieg der Linken auf dem IX. Parteitag der KPD Anfang April 1924 aufgelöst. 1927 wurde E. zusammen mit Walcher* erneut in die wiedergegründete Gewerkschaftsabteilung aufgenommen. Während seiner Redaktionstätigkeit bei der "Roten Fahne “ war E. ständiger Mitarbeiter für Gewerkschaftsfragen beim theoretischen Organ der KPD „Die Internationale sowie der Komintern-Zeitschrift „Inprekorr". Für die gewerkschaftliche Bildungspolitik verfaßte er das Buch „Die Gewerkschaftsbewegung. Ein Leitfaden für proletarische Ge- 
werkschaftsarbeit " und gab mit Heinrich Schreiner, Jacob Walcher ${ }^{*}$ und Eduard Weckerle 1932 "Das Rote Gewerkschaftsbuch" heraus. Die Linkswendung der Komintern und der KPD, die insbesondere den Kurs der Gewerkschaftsspaltung einleitete, brachte E. zum zweiten Mal in Opposition gegen die Politik der Partei. Ernst Thälmann griff ihn als einen der maßgeblichen "Träger der rechten Gefahr in der Partei" an. Auf dem 4. RGI-Kongreß in Moskau im März/April 1928 opponierte E. gegen Beschlüsse, die u.a. vorsahen, „Streiks ohne Einwilligung und gegen den Willen der reformistischen (Gewerkschafts-) Führer zu leiten “. Nach dem Kongreß wurde er in Moskau festgehalten und konnte erst zurückreisen, nachdem er gedroht hatte, er werde zur Wiedererlangung seines Passes zur deutschen Botschaft gehen. Mitue Dezember 1928 stellte das ZK der KPD ihm, Jacob Walcher*, Paul Frölich* u. a. in einem Parteiordnungsverfahren sechs Bedingungen für ihre weitere Mitgliedschaft in der KPD, dazu gehörten die "vorbehaltlose Billigung und die Anerkennung der Unzulässigkeit jeglicher Propaganda gegen die Beschlüsse der Komintern und der Partei“. Nach ihrer Weigerung zu unterschreiben, wurden $E$. und fast alle führenden Rechten im Januar 1929 aus der KPD ausgeschlossen. E. wurde Gründungsmitglied der KPO und Mitglied der engeren Reichsleitung. 1930 und $193 \mathrm{I}$ kam es in der KPO zu Fraktionskämpfen, die sich an der Stellung zur Sowjetunion und zur SPD-Linken entzündeten und schließlich zur Spaltung der KPO führten. Zusammen mit sieben anderen Vertretern der KPO-Minderheit wurde E. am I2. I. 1932 wegen Geheimverhandlungen mit der neugegründeten SAP aus der KPO ausgeschlossen; mit der KPO-Minderheit trat er im März 1932 in die SAP ein; im August 1932 Redakteur des SAP-Organs „SAZ - Sozialistische Arbeiter Zeitung in Breslau.

Im Februar 1933 übernahm E. in Breslau die Leitung des Bezirks Mittelschlesien der illegalen SAP. Im Anschluß an die Verhaftung von ca. zwanzig Genossen, darunter seiner Frau, im Juli 1933 Flucht nach Berlin und, da er steckbrieflich gesucht wurde, weiter nach Amsterdam. Von dort wurde er im November 1933 unter Hinweis auf die gegen ihn in Deutschland laufende Fahndung gemeinsam mit seiner inzwischen freigekommenen Frau aus Holland ausgewiesen; illegaler Grenzübertritt nach Belgien; da er auch dort nur eine kurz befristete Aufenthaltsgenehmigung erhielt, im März 1934 unter Verwendung gefälschter Papiere Weiterreise nach Kopenhagen und nach Stockholm. In Schweden war E. maßgeblich am Aufbau einer SAP-Landesgruppe beteiligt, die schließlich etwa dreißig Mitglieder umfaßte; Mitglied der Auslandsleitung der SAP. Seinen Lebensunterhalt verdiente er als kaufmännischer Vertreter, Eisendreher und Journalist, vorwiegend in der Gewerkschaftspresse; 1936 Verfasser einer Broschüre in schwedischer Sprache über „Die Moskauer Prozesse. Gerechtigkeit oder Justizmord?". Mit Unterstützung von Edo Fimmen, dem Generalsekretär der nInternationalen Transportarbeiter-Föderation " (ITF) politische Arbeit unter deutschen Seeleuten, über diese sowie über schwedische Pfarrer Verbindung mit SAP-Freunden und Widerstandskreisen in Deutschland bis in den Zweiten Weltkrieg hinein. Zusammen mit seiner Frau spielte $E$. in den vierziger Jahren eine bedeutende Rolle bei der programmatischen Diskussion der sozialistischen deutschen Emigranten. Als Vorstandsmitglied der „Landesgruppe deutscher Gewerkschafter ${ }^{\alpha}$ in Schweden trat er mit seiner Frau und Stefan Szende nachdrücklich für das Modell einer Basisgewerkschaft mit Vorrangstellung der Betriebsräte ein. Im Rahmen der „Internationalen Gruppe demokratischer Sozialisten“, der auch Willy Brandt ${ }^{*}$ und Bruno Kreisky angehörten, beteiligte er sich an der Diskussion über Inhalte der sozialistischen Nachkriegspolitik. Zusammen mit Willy Brandt* war er die treibende Kraft bei der Annäherung der SAP an die SOPADE. Im Oktober 1944 trat E. mit vierzehn weiteren Mitgliedern der Stockholmer SAP zur SOPADE über.

Im Juni I 945 gehörten August und Irmgard E. zu den ersten Emigranten, die nach Deutschland zurückkehrten; dies war nur illegal und mit Unterstützung der ITF möglich. Sie wollten nach Berlin, blieben dann jedoch bei Adolf und Ella Ehlers ${ }^{*}$ in Bremen. In der Folgezeit widmete sich E. der Arbeit in der Bremer „Kampfgemeinschaft gegen den Faschismus ${ }^{*}$, in der SPD und den entstehenden Gewerkschaften. Wegen des Mißtrauens der ehemaligen ADGB-Funktionäre gegenüber dem alten Linkssozialisten vermochte er der Untersuchung 
Peter Brandts zufolge beim Gewerkschaftsaufbau nur eine begrenzte Rolle zu spielen. In der SPD setzte er sich bis Anfang 1946 für eine Vereinigung mit der KPD ein. Doch schon die SPD-Konferenz von Wennigsen am 5./6.10. 1945, an der er als einziger Bremer teilnahm, zeigte, daß seine Position in der Partei minoritär war; Mitbegründer und bis 1947 Gewerkschaftsredakteur des Bremer "Weser-Kurier“. 1947 übernahm E. die Redaktion der DGB-Zeitschrift für die britische Zone „Der Bund"; 1950 Chefredakteur des DGB-Funktionärsorgans „Die Quelle“. Seit seiner Pensionierung Ende 1954 arbeitete er im Auftrag des DGB-Bundesvorstandes an einer Geschichte der Gewerkschaftsbewegung nach 1945. Kurz vor Abschluß der Studie, die unter dem Titel „Die Einheitsgewerkschaften ${ }^{\star}$ (unter Mitarbeit von Bernd Heise) vom DGB als Manuskript vervielfältigt wurde, starb E. am 2. I 1. 1959.

(Literatur siehe bei Enderle, Irmgard.)

Enderle, Imgard, geb. Rasch, geboren am 28.4. 1895 in Berlin. Der Vater war Oberstudienrat. Irmgard R. besuchte das Mädchen-Realgymnasium, seit 1909 war sie in einer Mädchengruppe bei den Wandervögeln. 1917 nahm sie an Versammlungen des „Vortrupp“ teil, einer lebensreformerischen Vereinigung, bei denen sie erstmals bewußte Kriegsgegner kennenlernte; im gleichen Jahr Lehrerinnen-Examen, anschließend mehrere Semester Philosophie, Pädagogik und Volkswirtschaft an der Universität Berlin; 1918 Mitglied der USPD; unter dem Einfluß von sozialistischen Studenten Teilnahme an Arbeitsgemeinschaften der Spartakus-Jugend, Mitglied der KPD. Ab Mitte 1919 war sie Funktionărin im zentralen Apparat der KPD in Berlin, zuerst Sekretärin der Abteilung „Land“; 1922 Instrukteurin in der Gewerkschaftsabteilung des ZK; entschiedene Verfechterin der Gewerkschaftseinheit; nach Übernahme der Parteiführung durch die Linken unter Ruth Fischer und Auflösung der Gewerkschaftsabteilung "Verbannung an die KPD-Zeitung "Der Klassenkampf in Halle; 1927-1928 Redakteurin der "Roten Fahne ${ }^{\alpha}$ in Berlin. Anfang 1929 wurde sie als Mitglied der Rechtsopposition aus der KPD ausgeschlossen; seitdem arbeitslos; in der KPO aktiv, ab Mitte 1932 in der SAP. Nach ihrer Eheschließung zusammen mit ihrem Mann August Enderle im Sommer 1932 Übersiedlung nach Breslau; Mitglied der dortigen SAP-Ortsleitung, Journalistin bei der "SAZ - Sozialistische Arbeiter Zeitung“.

Im Frühjahr 1933 illegal tätig. Im Juni 1933 wurde E. verhaftet, nach einigen Tagen jedoch als „einfache Hausfrau“ entlassen. Sie stand unter Aufsicht der Polizei, die hoffte, über sie ihren flüchtigen Mann ausfindig zu machen. Am 20.8. 1933 verließ E. Deutschland ohne Papiere auf dem letzten Vergnügungsdampfer nach Arnheim. Ihr weiterer Emigrationsweg gleicht dem ihres Mannes. Seit 1934 aktives Mitglied in der SAP-Gruppe in Stockholm und in der "Landesgruppe deutscher Gewerkschafter"; Journalistische Arbeit für die schwedische und die schweizer sozialistische und Gewerkschaftspresse. In programmatischer Hinsicht arbeitete sie eng mit ihrem Mann zusammen. Ferner war sie als Deutschlehrerin und Übersetzerin tätig; im Oktober 1944 Anschluß an die SOPADE.

Im Juni 1945 Rückkehr nach Deutschland, Redakteurin beim „Weser-Kurier “. In der Bremer SPD vertrat E. eine einheitsfrontorientierte linkssozialistische Politik; 1946 Mitglied der Bremer Bürgerschaft. Im Frühjahr 1947 ging sie nach Köln und war dort bei der DGBZeitschrift "Der Bund" tätig; von 1949-195I Redakteurin der "Welt der Arbeit"; 1948-1949 Mitglied des Bizonen-Wirtschaftsrates in Frankfurt a.M.; 1950-1955 im Vorstand der IG Druck und Papier in Köln, dort auch Vorsitzende im DGB-Frauenausschuß. Von 1951 bis 1965 war E. als freie Journalistin in der Gewerkschaftspresse tätig; vorübergehende Vorsitzende der „Deutschen Journalisten-Union“, Mitglied der „Humanistischen Union“. E. lebte $198 \mathrm{I}$ in Köln.

Hermann Weber: Die Wandlung des deutschen Kommunismus. Bd. 2. Frankfurt a. M. 1969; K. H.Tjaden: Struktur und Funktion der "KPD-Opposition" (KPO). Meisenheim am Glan 1964; Hanno Drechsler: Die Sozialistische Arbeiterpartei Deutschlands (SAPD). Meisenheim am Glan 1965; Stefan 
Szende: Zwischen Gewalt und Toleranz. Zeugnisse und Reflexionen eines Sozialisten. Frankfurt a.M. 1975. Jörg Bremer: Die Sozialistische Arbeiterpartei (SAP). Untergrund und Exil 1933-45. Frankfurt a. M. 1978; Helmut Müssener: Exil in Schweden. Politische und kulturelle Emigration nach 1933. München 1974; Klaus Misgeld: Die "Internationale Gruppe demokratischer Sozialisten " in Stockholm 1942-1945. Bonn-Bad Godesberg 1976; Peter Brandt: Antifaschismus und Arbeiterbewegung. Aufbau - Ausprägung - Politik in Bremen 1945/46. Hamburg 1976; Biographisches Handbuch der deutschsprachigen Emigration nach 1933. Bd. 1. München 1980.

Euchner, Frida, geb. Dold, geboren am 16.4. 1908 in Reutlingen. Der Vater, ein der SPD nahestehender Schreiner, fiel im Ersten Weltkrieg, die Mutter drehte Zigaretten in Heimarbeit. Frida D. beendete 1922 in Stuttgart die Volksschule und arbeitete seitdem als ungelernte Arbeiterin in einer Schürzenfabrik; 1922 Mitglied der SAJ. I931 heiratete sie den 1906 geborenen Alfred Euchner. Alfred Eu. war von Beruf Lederzuschneider, gehörte seit 1924 der SPD an und trat 193 I zur kleinen Stuttgarter SAP über, die bei der Reichstagswahl vom 31.7. 1932 I 27 Stimmen erhielt.

Gemeinsam mit ihrem Mann nahm Frida Eu. 1933 an Gruppen-Wanderungen und an Schulungsabenden der illegalen SAP-Gruppe in Stuttgart teil; sie schrieben Flugblätter ab und verteilten sie. Bei der Zerschlagung der Gruppe, der u. a. Albert Schmidt*, Otto Palmer* und Wilhelm (Willy) Blind* angehörten, wurde Alfred Eu. Ende 1933/Anfang 1934 verhaftet und im September 1934 vom Oberlandesgericht Stuttgart zu acht Monaten Gefängnis verurteilt. 194I wurde er Soldat, 1944 fiel er in Frankreich. Frida Eu. arbeitete in den dreißiger Jahren in einem Textilbetrieb. Nach der Emigration des jüdischen Eigentümers und der Auflösung des Betriebs im Rahmen der NS-Arisierungspolitik 1939 Tätigkeit als Directrice in einer Schürzen- und Kinderkleiderfabrik bis Ende des Krieges.

1945 oder 1946 wurde sie Mitglied der SPD, der DAG und der „Arbeiterwohlfahrt"; 1948-1970 hauptamtliche Tätigkeit für den „Verband der Kriegsbeschädigten“ (VdK), dessen Kreis- und Landesvorstand sie zeitweilig angehörte; 1948-1950 SPD-Abgeordnete im Stadtrat; 1950-1955 Schöffin beim Amtsgericht Stuttgart, seit 1970 als Landessozialrichterin; 1971-1976 Vertreterin der Sozialrentner des Bezirks Nordwürttemberg. Frida Eu. lebte 1981 in Stuttgart.

Fabian, Ruth, geb. Loewenthal, geboren am 29.5. 1907 in Bockow bei Berlin; 1926 Abitur, Jurastudium, Referendarin am Kammergericht in Berlin, im Rahmen des ,Arisierungsprozesses “ entlassen; Mitglied der Jungsozialisten und der SPD, 193 I SAP; von 1933 bis Ende 1935 illegale Arbeit, Mitglied des Parteivorstandes der SAP in Berlin; über Prag Flucht nach Paris, Mitglied der dortigen SAP-Leitung; zusammen mit ihrem damaligen Ehemann Walter Fabian* Gründung eines Zeitungs-Ausschnittsbüros, das die französische Öffentlichkeit über die Vorgänge in Deutschland informierte; seit 1939 Fürsorgearbeit im Zusammenhang mit dem IRRC, seit $194^{\circ}$ in Marseille; nach der Besetzung Südfrankreichs Flucht in die Schweiz, Arbeit als Angestellte des IRRC im Rahmen des Schweizer „Arbeiterhilfswerks “ in Zürich; bei Kriegsende Rückkehr nach Paris, einige Jahre Fürsorgearbeit beim IRRC; mit ihrem Lebensgefährten Max Picard I95 I Gründung der deutschsprachigen Buchhandlung ${ }_{n}$ Calligrammes" in Paris; seit 1945 Vorstandsmitglied und aktive Arbeit im Rahmen der „Solidarité ${ }^{\prime}$, der Hilfsorganisation für deutsche und österreichische NS-Opfer in Frankreich; F. lebte $198 \mathrm{I}$ in Paris.

Fabian, Walter, geboren am 24.8. 1902 in Berlin; im Anschluß an das Gymnasium Studium der Pädagogik, Geschichte und Nationalökonomie, 1924 Promotion zum Dr. phil.; 1924 SPD, Mitglied des „Reichsausschusses für sozialistische Bildungsarbeit", Lektor, Redakteur; seit Ende 1928 Herausgeber der linksoppositionellen Zeitschrift „Sozialistische Infor-

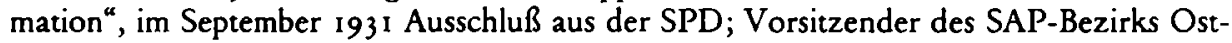
sachsen, Mitglied des SAP-Parteivorstands, Chefredakteur der „SAZ - Sozialistische Arbeiter Zeitung “; von August 1933 bis zu seiner Flucht im Januar 1935 Reichsleiter der illegalen 
SAP; 1935-1937 Mitglied der SAP-Auslandsleitung, im Februar 1937 Parteiausschluß; bis 1939 Leiter der Gruppe „Neuer Weg ${ }^{\alpha}$, die sich vor allem gegen die Moskauer Prozesse wandte und zur Solidarität mit der spanischen POUM aufrief. Trotz Notvisum für die USA blieb F. 1940 in Frankreich, 194 I-Mitte 1942 Mitarbeiter des IRRC in Marseille; Ende 1942 illegal in die Schweiz, dort journalistisch und schriftstellerisch tätig; 1957-1970 Chefredakteur des DGB-Organs "Gewerkschaftliche Monatshefte“; 1961 endgültige Übersiedlung in die Bundesrepublik; ab 1966 Honorarprofessor für Pädagogik an der Universität Frankfurt; in den sechziger Jahren aktiv in der Bewegung gegen die Notstandsgesetze und in der „Hilfsaktion Vietnam". Langjähriger Vorsitzender der „Deutschen Journalisten-Union“ und der „Deutsch-Polnischen Gesellschaft ${ }^{\prime}$, Mitglied der „Humanistischen Union ${ }^{\star}$. F. lebte 1981 in Köln.

Biographisches Handbuch der deutschsprachigen Emigration nach 1933. Bd. 1. München 1980.

Fingerle, Wilbelm, geboren am 26. 1. 1913 in Berlin. Der Vater war selbständiger Handwerker, seit 1914 SPD-Mitglied; die Mutter starb 1919; ein Bruder. Nach dem Besuch einer naturwissenschaftlich ausgerichteten Oberrealschule absolvierte F. in den Jahren 1929 bis 1932 eine Werkzeugmacherlehre in einer Telefonfabrik; in dieser arbeitete er bis zum Februar 1934 als Werkzeugmacher und Einrichter; 1929 Mitglied der SAJ im linken SPD-Bezirk Berlin-Tempelhof. Im Herbst 1931 trat er zusammen mit 800 bis 1000 von insgesamt 4000 Berliner SAJ-Mitgliedern zum SJV über.

1933 leitete F. gemeinsam mit Günther Keil und Gustav Seeger die illegale SJV- und SAPGruppe in Tempelhof. Ihre Arbeit war im wesentlichen darauf ausgerichtet, den Zusammenhalt unter den meist jugendlichen Mitgliedern aufrecht zu erhalten. Nach der Verhaftung von Keil und Seeger im Februar 1934 floh F. auf Anraten der Berliner SAP-Leitung in die CSR. In Prag lebte er zusammen mit anderen deutschen Emigranten in Notquartieren von einer kleinen Unterstützung durch die tschechischen Gewerkschaften; im September I935 illegale Rückkehr nach Deutschland. Dank der Unterstiutzung eines ehemaligen sozialdemokratischen Betriebsrats wurde er erneut in seinem alten Betrieb eingestellt. In Berlin fand F. ein relativ festgefügtes sozialdemokratisches Milieu vor. Er besuchte die Konzertabende des von führenden Sozialdemokraten wie Paul Löbe und Franz Künstler geleiteten Männerchors „Berliner Liederfreunde $1879^{\text {, }}$, an dessen Veranstaltungen bis zu seinem Verbot im Mai 1938 tausende, auch prominente, ehemalige SPD- und Gewerkschaftsmitglieder teilnahmen. Beruflich war F. seit 1937 in einer Flugzeugmotorenfabrik der Fa. DaimlerBenz tätig. Nach der Arbeit besuchte er die Abendkurse einer Ingenieurschule und begann im Frühjahr 1939 - unterstützt vom Verband des Berliner Maschinenbaus - ein Ingenieurstudium, das er jedoch im Herbst abbrach, um der Einberufung im Kriegsfalle zu entgehen. Ende des Jahres fand er eine leitende Stellung in einer Werkzeugmaschinenfabrik, bis Ende des Krieges Betriebsleiter in einem Verlagerungswerk im Sudetenland. 1940 heiratete F., der Ehe entstammen drei Kinder.

Nach Kriegsende wurde F., der als Antifaschist bekannt war, von den tschechischen Behörden zunächst aufgefordert, die Leitung des Werkes fortzuführen; wenig später jedoch mit seiner Familie ausgewiesen; in Berlin erneut Mitglied der SPD. Da es ihm in den Jahren 1946 und 1947 nicht möglich war, eine Arbeit zu finden, ernährte er sich durch Reparaturarbeiten, durch das Flicken und den Verkauf von Gebrauchsgegenständen aus den Trümmerhaufen der Stadt. Ende 1947 wurde er Preisprüfer im Bezirksamt Tempelhof, diese Stellung verlor er nach der Währungsreform im Herbst 1948, danach erneut für längere Zeit arbeitslos. Im August 1950 erhielt F. eine Anstellung als Konstrukteur für Werkzeugausrüstung in einer Bielefelder Maschinenfabrik. In Bielefeld wurde er parteipolitisch nicht mehr aktiv; von 196 I bis zu seiner Pensionierung im Jahre 1977 Leiter der Konstruktionsabteilung dieser Firma. F. lebte 1980 in Bad Rothenfelde. 
Frank, Karl, geboren am 31.5. 1893 in Wien als Sohn eines kleinen Fabrikanten; Studium der Fächer Psychologie, Biologie und Philosophie, nach Fronteinsatz als Leutnant 1916 Kriegsdienstverweigerer; 1918 einer der Führer der linksradikalen Studentengruppe um Ruth Fischer und Gerhart Eisler, 1919 KPÖ; Ende 1920 Übersiedlung nach Berlin, Mitglied

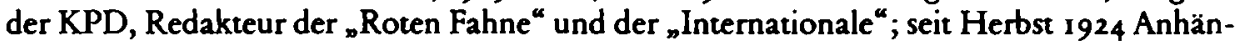
ger des rechten Parteiflügels um Heinrich Brandler*, 1928 Parteiausschluß; 929 Mitglied der KPO-Reichsleitung, 1932 Mitglied des SAP-Parteivorstands; als Mitglied der konspirativ operierenden „Leninistischen Organisation “ um Walter Lowenheim und Richard Löwenthal ${ }^{*}$, der späteren Gruppe "Neu Beginnen ${ }^{*}$, Ende 1932 Eintritt in die SPD; nach 1933 in Wien, später in Prag und Paris Auslandsleiter der Gruppe „Neu Beginnen“, deren Strategie in der Eroberung der SPD von innen und in der Organisierung von illegalen Kadern im Reich bestand; 1935 programmatisch-politische Annäherung an die Sozialdemokratie; 1939 über London in die USA. Dort widmete sich F. vor allem der Ausarbeitung programmatischer Nachkriegsrichtlinien und der kritischen Berichterstattung über die Lage in Deutschland („Inside Germany Reports ${ }^{\star}$ ). Trotz der Bemühungen von Emst Reuter um F's Rückkehr nach Deutschland war dieser bei den Alliierten politisch unerwünscht; bis zu seinem Tod im Jahre 1969 als Psychoanalytiker in New York und Connecticut tätig.

Biographisches Handbuch der deutschsprachigen Emigration nach 1933. Bd. 1. München 1980.

Frölich, Paul, geboren am 7.8. $188_{4}$ in Leipzig in eine sozialistische Arbeiterfamilie; kaufmännische Lehre, 1902 SPD; im Anschluß an ein intensives Selbststudium Volontär, Ausbildung zum Journalisten bei der „Leipziger Volkszeitung ${ }^{\prime}$, seit I 908 Redakteur an verschiedenen SPD-Zeitungen; 1914 Wechsel zur oppositionellen „Bremer Bürgerzeitung“; Mitglied der „Bremer Linksradikalen“, Delegierter auf der internationalen sozialistischen Antikriegskonferenz in Kienthal im April 1916; anschließend Kriegsdienst, wegen fortgesetzter Antikriegspropaganda bis zur Novemberrevolution Inhaftierung in einer Irrenanstalt; 1919 KPD, Mitglied der ersten KPD-Zentrale, 1921-1924 und 1928-1930 MdR. Als Angehöriger des rechten Parteiflügels 1924 gemaßregelt, wurde F. 1925 mit der Herausgabe der Gesammelten Werke Rosa Luxemburgs betraut. 1928 Ausschluß aus der KPD, Mitglied der KPO-Reichsleitung, 1932 SAP, Verfasser der programmatischen Schrift "Was will die SAP?"; nach neunmonatiger KZ-Haft Ende 1933 Emigration; 1934-1939 führender Mitarbeiter an den Exil-SAP-Publikationen in Paris ("Neue Front", "Marxistische Tribüne“); Studien zur französischen Revolution 1789 (postum veröffentlicht Frankfurt 1957), Verfasser einer Rosa Luxemburg-Biographie (1939, Frankfurt ${ }^{3}$ 1967); 1939 Internierung in Vernet, I94 I Emigration in die USA; 195 I Rückkehr nach Deutschland, Mitglied der SPD, Referent an der SPD-Heimvolkshochschule Georg v. Vollmar in Kochel/Oberbayern. F. starb am 16.3. 1953 .

Biographisches Handbuch der deutschsprachigen Emigration nach 1933. Bd. I. München 1980.

Frölich, Rose, geb. Wolfstein, geboren am 27.5. 1888 in Witten als Tochter eines jüdischen Kaufmanns; höhere Mädchenschule, kaufmännische Lehre; 1908 SPD, $1912 / 13$ Besuch der SPD-Parteischule in Berlin; 1914 Opposition gegen die Bewilligung der Kriegskredite, Teilnahme am USPD-Gründungsparteitag 1917 in Gotha und am KPD-Gründungsparteitag 1918/19 in Berlin (Schriftführerin); im November 1918 Mitglied des Arbeiter- und Soldatenrats in Düsseldorf, 1920 Delegierte zum II. Weltkongreß der Komintern, I $921-1923$ Mitglied der KPD-Zentrale, Leiterin der Parteiverlage, I921-1925 MdL Preußen; 1924 in Opposition gegen die Ruth Fischer-Führung; Mitarbeiterin von Paul Frölich bei der Herausgabe der Werke Rosa Luxemburgs, Lektorin am Malik-Verlag; im Januar 1929 Ausschluß aus der KPD, Mitglied der KPO, 1932 der SAP; im März 1933 Flucht nach Belgien, 1936 nach Paris, dort Mitglied der SAP-Auslandsleitung; von September 1939 bis 1941 interniert, dann zusammen mit Paul Frölich* Emigration in die USA; bis 1950 in New York, 
dort in engem Kontakt mit Joseph Lang und Erna Lang (-Halbe), die sie seit 1917 kannte; I95 I Rückkehr nach Deutschland, Mitglied der SPD. Rose F. lebte 198 I in Frankfurt.

Biographisches Handbuch der deutschsprachigen Emigration nach 1933. Bd. I. München 1980.

Galm, Heinrich, geboren am 23. 10. I895 in Seligenstadt/Main als jüngster Sohn eines Schreiners, drei Brüder und zwei Schwestern. Der Vater war ein aktiver SPD-Politiker, Delegierter des $W$ ahlkreises Offenbach-Dieburg auf den SPD-Parteitagen 1893 und 1895 . Die Mutter und die Schwestern waren strenggläubige Katholiken. G. ließ sich zum Sattler ausbilden und trat 1910 der Gewerkschaft und der AJ bei. Von 1916 bis Kriegsende war er Soldat. 1917 Mitglied der USPD, 1920 trat er mit dem linken USPD-Fligel zur KPD uber. Im selben Jahr wurde er als einziger Kommunist zum hauptamtlichen Sekretăr des Sattler-, Tapezierer- und Portefeuiller-Verbandes in Offenbach gewählt, zwei Jahre später wurde er I. Bevollmächtigter der Gewerkschaft und in dieser Funktion von den Mitgliedern jährlich mit großer Mehrheit bestätigt. In den Jahren $1923-1925$ wandte sich $G$. energisch gegen die Politik der linken Mehrheit der KPD, die kommunistische Richtungsgewerkschaften ins Leben rief. Seine Politik zahlte sich in den folgenden Jahren aus: als auf dem Kongreß des ADGB 1925 nur noch drei - gegenüber 192288 - kommunistische Delegierte vertreten waren, war G. einer von ihnen. Die Zahl der für die KPD in Offenbach abgegebenen Stimmen stieg kontinuierlich an, in der Reichstagswahl 1928 uberholte sie die SPD und wurde mit I 3350 (SPD I 1345 ) Stimmen stärkste Partei. Gestuitzt auf seine Anhänger unter den Lederarbeitern und den Erwerbslosen, deren Zahl aufgrund von struktureller Arbeitslosigkeit ungewöhnlich hoch war, gelang es G., den linken Flügel in der Offenbacher KPD zunehmend zurückzudrängen. Seit 1924 war er Abgeordneter im Hessischen Landtag, 1927 wurde er als Kandidat ins Zentralkomitee (ZK) der KPD gewählt. 1928 opponierte G. emeut gegen die Linkswendung der Komintern und der KPD, die Offenbacher Parteizeitung „Das Volks-

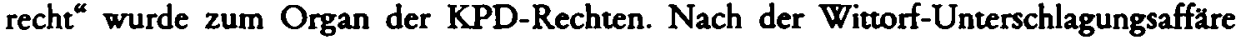
stellte G. zusammen mit dem ZK-Kandidaten Erich Hausen aus Breslau den Antrag, den KPD-Führer Ernst Thälmann aus der KPD auszuschließen. Am 20. 1 I. 1928 vom ZK seiner Funktionen enthoben, wurde die Entscheidung über seinen Verbleib in der KPD an das Exekutivkomitee der Komintern nach Moskau uberwiesen. In Moskau verteidigte G. zusammen mit Hausen den Standpunkt der rechten Opposition in der KPD; Anfang 1929 ausgeschlossen, folgte ihm die große Mehrheit der Mitglieder und Funktionäre in die KPO. Wenige Monate später errang die KPO bei der Kommunalwahl vom 17. 11.1929 in Offenbach 8908 (die SPD 1 I 729), die KPD dagegen nur 2309 Stimmen. Im November 193 I wurde G. als Kandidat der KPO erneut in den Hessischen Landtag gewählt. Alle Versuche, ihn als Bevollmächtigten des Sattler-, Tapezierer- und Portefeuiller-Verbandes abzuwählen, scheiterten, auf der letzten Verbandswahl im März 1932 erhielt er 446 Stimmen, der Kandidat der KPD 107 und der der SPD 37. Im April 1932 schlossen sich die Offenbacher KPOMitglieder mit wenigen Ausnahmen der kleinen SAP-Gruppe um Karl Hebeisen* an. Im Juni 1932 als einziger SAP-Vertreter in Hessen erneut Landtagsabgeordneter.

Im März 1933 wurde er vor dem Landtagsgebäude in Darmstadt verhaftet; bis zum I. Mai im KZ Osthofen. Im Unterschied zu anderen, meist kleineren SAP-Gruppen lehnten die Mitglieder der Offenbacher SAP jeglichen Widerstand als letztendlich wirkungslos und als zu gefährlich ab. Nach seiner Entlassung als Gewerkschaftsangestellter eröffnete $G$. einen Tabakladen, nebenbei handelte er als Reisender mit Lederwaren; seit 1933 mehrmals verhaftet. Im Juli 1944 sollte er nach Dachau kommen, glückliche Umstände führten jedoch dazu, daß er nur einige Monate in Bebra und in Darmstadt festgehalten wurde.

Bei Kriegsende ernannten die Amerikaner G. zu ihrem politischen Berater, bis zum Herbst 1945 spielte er im politischen Leben der Stadt die entscheidende Rolle. Es gelang ihm, seine politischen Freunde aus der Zeit vor 1933 sowie einige ehemalige Funktionäre der KPD um sich zu sammeln und fast alle kommunalen Ämter mit ihnen zu besetzen. Nach erfolglosen Verhandlungen mit Vertretern der SPD und der KPD über die Gründung einer Einheits- 
partei beantragte dieser Kreis im September 1945 die Lizenzierung der "Arbeiter-Partei“, deren Vorsitzender G. wurde. An der Reorganisierung des kommunalen Lebens hatte die ${ }_{n}$ Arbeiter-Partei“ (AP) bis 1947 hervorragenden Anteil. Nicht zuletzt aufgrund dieser kommunalpolitischen Erfolge erzielte sie in Offenbach 1946 17,5 und 1948 19,6 Prozent der Stimmen. Dagegen scheiterte der Versuch, die AP auf Hessen und auf $W_{\text {ürttemberg-Baden }}$ auszudehnen. Außerhalb Offenbachs blieb die Arbeiter-Partei überall Splitterpartei. Mit der Normalisierung des Lebens ging der Einfluß der AP auch in Offenbach seit 1949 kontinuierlich zurück, doch bestand sie - auch wegen der traditionellen Feindschaft zwischen $G$. und einem Teil der Offenbacher SPD-Führung - bis 1954 weiter. Im November 1954 löste G. die AP auf und trat zur SPD über. Programmatisch hatte er bereits in den vierziger Jahren in gewisser Weise die Entwicklung der SPD zum Godesberger Programm vorweggenommen: Unter seiner Führung entwickelte sich die ${ }_{\text {Adbeiter-Partei }}{ }^{*}$ seit $1947 \mathrm{zu}$ einer Partei, die alle Volksschichten ohne marxistisches Programm in einer linken Volkspartei integrieren wollte. 1956-1968 ehrenamtlicher Stadtrat. In den sechziger Jahren arbeitete G. in der Anzeigenabteilung der „Frankfurter Rundschau“. G. lebte 1981 in Offenbach a.M.

Hermann Weber: Die Wandlung des deutschen Kommunismus. Bd. 2. Frankfur a. M. 1969; K. H.Tjaden: Struktur und Funktion der „KPD-Opposition“ (KPO). Meisenheim am Glan 1964; Hanno Drechsler: Die Sozialistische Arbeiterpartei Deutschlands (SAPD). Meisenheim am Glan 1965; Bernd Klemm: Die Arbeiter-Partei (Sozialistische Einheitspartei) Hessen 1945-1954. Hannover 1980; Heinrich Galm: Ich war halt immer ein Rebell. Politische Erinnerungen von Heinrich und Marie Galm, nach Gesprächen zusammengestell von Werner Fuchs und Bernd Klemm. Offenbach a.M. 1980; Bernd Klemm (Hrsg.): „... durch polizeiliches Einschreiten wurde dem Unfug ein Ende gemacht ${ }^{*}$. Geheime Berichte der Politischen Polizei Hessen über Linke und Rechte in Offenbach 1923-1930. Frankfurt a. M. 1982.

Gardiner, Murieh geboren 1901 in Chicago als Kind einer reichen Unternehmerfamilie; College, 1922 Bachelor of Arts in Literatur und Geschichte, 1922-1924 Studien in Rom und Oxford; seit 1926 in Wien Ausbildung zur Psychoanalytikerin, 1932 Medizinstudium; seit 1934 Verbindung zu Mitgliedern der sozialistischen Partei, seitdem illegale Arbeit, Kurierfahrten zur Auslandsvertretung nach Brünn; nach dem „Anschluß“ Österreichs am 12.3. 1938 Organisatorin der Ausreise von politisch Gefährdeten; im August 1938 Promotion zum Doktor der Medizin, danach nach Paris; seit 1939 Ehefrau von Joseph Buttinger"; Ende 1939 Übersiedlung in die USA; Psychiatrische Beraterin in Kindergärten; ihr Vermögen ermöglichte $G$. eine umfangreiche Unterstützung von Emigranten und Flüchtlingen; von April bis September 1945 in Paris Koordinierung der Flüchtlingshilfe des IRRC; später Lehrtätigkeit als Psychoanalytikerin; Psychiatrische Beraterin („counselor “) an den "public schools ${ }^{*}$ des Staates Pennsylvania, dann von New Jersey.

Muriel Gardiner; Joseph Buttinger: Damit wir nicht vergessen. Unsere Jahre 1934-1947 in Wien, Paris und New York. Wien 1978.

Gerold, Karl (1906-1973), Schlosser, seit 1922 Funktionär der SAJ, später der SPD; Mitarbeiter verschiedener Zeitungen; Anfang 1933 einige Monate lang in "Schutzhaft“, nach Entlassung illegale Tätigkeit im badisch-schweizerischen Grenzgebiet; im Herbst 1933 Flucht nach Basel, Kurierdienste; im Exil schriftstellerisch tätig, als Korrespondent schweizer Zeitungen Teilnahme am Spanischen Bürgerkrieg, anschließend Internierung in schweizer Lagern; 1942 Gründer des „Bundes Deutscher Revolutionärer Sozialisten“; im Januar 1945 von einem schweizer Militärgericht wegen "Neutralitätsbruch“ und "nachrichtendienstlicher Tätigkeit“ zu einem Jahr Gefängnis verurteilt; im September 194s Rückkehr nach Deutschland; 1946-1973 Lizenzträger, Mitherausgeber und Chefredakteur der „Frankfurter Rundschau“.

Biographisches Handbuch der deutschsprachigen Emigration nach 1933. Bd. I. München 1980. 
Graber, Adolf, geboren am 15.4. 1902, Bergmann und Straßenreiniger; 1925-1931 SPD, dann SAP; als politischer Leiter der SAP-Ortsgruppe Hamborn organisierte er nach dem 30. I. 1933 die Beschaffung und Weiterverbreitung von SAP-Literatur; am 2.12. 1934 im Zuge der Aktion gegen Eberhard Brünen* verhaftet, am I 3.7. 1935 vom Oberlandesgericht Hamm zu acht Jahren Zuchthaus verurteilt, nach Verbüßung der Haft KZ Sachsenhausen.

Seine Frau Margarete Graber, Schriffführerin der SAP-Hamborn, war in den dreißiger Jahren Laborantin bei der August-Thyssen-Hütte.

Grauh Emst, geboren am 10.7. 1886 in Zeitz, USPD, seit 1920 Führer der KPD in Essen, im Januar 1925 als Rechter aus der KPD ausgeschlossen, im Januar 1926 wieder aufgenommen. Bis 1929 arbeitete G. führend in der „Roten Hilfe“. 1929 Mitglied der KPO. Nach 1933 lebte er in Merseburg; 1944 gehorrte er einer Widerstandsgruppe an; nach 1945 Mitglied der KPD und der SED, 1945 Oberbürgermeister von Merseburg.

Grönsfelder, Emma, geboren am 3. I. $188_{3}$ in München als Tochter eines Schneidermeisters, fünf Geschwister. Die Mutter starb 1888 , aus einer zweiten Ehe des Vaters gingen zwei weitere Kinder hervor. Nach der Volksschule ließ der Vater sie keinen Beruf erlernen. Mit fünfzehn Jahren ging sie außer Haus in Stellung. Dabei eignete sie sich gute Kochkenntnisse an, die es ihr später ermöglichten, als Köchin in Gaststätten zu arbeiten. 1903 zog sie nach Nürnberg und lernte dort ihren Mann kennen; 1919 aktives Mitglied der KPD, im August 1921 Delegierte des VII. Parteitags der KPD, 1930 aus der KPD ausgeschlossen; in der KPO aktiv.

Im April 1933 wurde Emma G. verhaftet, bis September 1933 war sie in "Schutzhaft" im Zuchthaus Aichach.

Nach dem Zweiten Weltkrieg trat sie der KPD bei, 1949 wurde sie zusammen mit ihrem Mann ausgeschlossen; Mitglied der ${ }_{\text {}}$ Gruppe Arbeiterpolitik “. Ende 1950 zog sich Emma G. aus gesundheitlichen Gründen aus der aktiven Politik zurück. Sie starb am 26. I I. 1967.

Grönsfelder, Karh, geboren am 18. I. 1882 in Frankfurt a.M. als Sohn eines Kutschers und Dieners und einer Köchin. Seine Kindheit und Jugend verbrachte G. in dem württembergischen Landstädtchen Bartenstein, wo er bei seinen Großeltern aufwuchs. Im Anschluß an die Volksschule absolvierte er eine Mechanikerlehre. Nachdem er in den Jahren 1900-1903 in Frankfurt a.M., Köln, Düsseldorf, Siegburg und Krefeld gearbeitet hatte, ließ er sich 1904 in Nürnberg nieder. Dort arbeitete er in einer Elektrischen Bogenlampen- und Apparate-Fabrik. 1906 heiratete er seine Frau Emma; 1908 Mitglied des DMV und der SPD, in der er als Anhänger Rosa Luxemburgs auf dem linken Parteiflügel stand. 1914 wurde er von der Fa. MAN als Facharbeiter reklamiert; im Februar 1917 Mitglied der USPD, Ende Januar 1919 Mitbegründer der KPD in Nürnberg. 1920 wurde G. zum Betriebsrat gewählt, im Februar des Jahres war er Delegierter des III. Parteitages der KPD. 192 I hielt er sich als Delegierter des III. Weltkongresses der Komintern mehrere Monate lang in der Sowjetunion auf. Auf dem VIII. Parteitag der KPD Anfang 1923 wurde er als Anhänger von Heinrich Brandler* Mitglied der Gewerkschaftskommission und der KPD-Zentrale; 192 I-1924 Vorsitzender der KPD-Bezirksleitung Nordbayern. Von 1923 bis 1928 war G. Abgeordneter des Bayerischen Landtags, 1926 wurde er Landessekretär der KPD Bayern, 1928 Sekretär für Gewerkschaftsfragen bei der Bezirksleitung. Nach der Wiederaufnahme der ultralinken Politik seit 1928 geriet G. in einen immer stärkeren Gegensatz zur politischen Linie der KPD. Im Anschluß an den I. Reichskongreß der "Revolutionären Gewerkschafts-Oppositi-

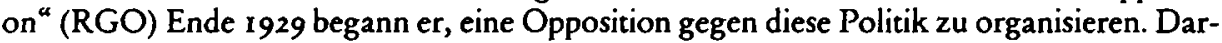
aufhin wurde er Anfang 1930 zusammen mit anderen Betriebsräten aus dem Nürnberger Gebiet aus der KPD ausgeschlossen. Wenngleich zu diesem Zeitpunkt noch keine Kontakte zur KPO bestanden, schloß sich der Großteil der Ausgeschlossenen und Oppositionellen 
bald der KPO an. G., der von 1930-1933 arbeitslos war, übernahm die Leitung der KPOGruppen in Nürnberg und in Nordbayern, der jeweils 6s-70 Mitglieder angehörten.

Am 31. 1. 1933, nach einem vergeblichen Aufruf zum Generalstreik an die Ortsleitungen der SPD, der KPD und des ADGB, stellte die Nürnberger KPO ihre Organisation auf die Bedingungen der Illegalität um, das Parteibüro wurde aufgelöst, G. bezog ein geheimes Quartier. Trotz dieser Sicherheitsmaßnahmen konnte die Gestapo die KPO-Gruppe in Nürnberg bereits im April 1933 zerschlagen. G. wurde am 12.4 . verhaftet und einen Tag später in das KZ Dachau eingeliefert; im März 1935 entlassen, bis Ende des Jahres unter Polizeiaufsicht; arbeitslos. 1937 fand er eine Anstellung als Mechaniker bei den Triumph-Werken. Am 1.9. 1939 wurde G. erneut verhaftet, doch kam er nach einer Reklamation seitens des Firmen direktors sowie Verbürgungen des Betriebsleiters und des Meisters einige Tage später wieder frei.

Nach Kriegsende war G. am Wiederaufbau der Nürnberger Metallarbeitergewerkschaft beteiligt. 1946 wurde er in den Betriebsrat gewählt, dem er bis zu seinem Ausscheiden aus dem Berufsleben im Jahre 1955 angehörte. 1946 trat er der KPD bei, 1947 Mitglied der Bezirksleitung Bayern; 1949 als "Titoist“ und Brandler-Anhänger zum zweiten Mal aus der KPD ausgeschlossen. Bereits 1947/1948 war er der „Gruppe Arbeiterpolitik“ (GAP) beigetreten, die in den Jahren 1948-1950 in Nümberg ca. so Mitglieder zählte. Zusammen mit seiner Frau Emma war er in den fünfziger und sechziger Jahren Leiter und Repräsentant der Gruppe. Als 1959 ein Teil der Mitglieder zur SPD übertrat, trug G. zur Konsolidierung der GAP in Nürnberg bei. G. starb am 20.2. 1964.

Hermann Weber: Die Wandlung des deutschen Kommunismus. Bd.2. Frankfurt a. M. 1969; Wilhelm Eildermann: Als Wanderredner der KPD unterwegs. Erinnerungen an die ersten Jahre der KPD 1919-1920. Berlin, DDR 1977; K. H. Tjaden: Struktur und Funktion der „KPD-Opposition“ (KPO). Meisenheim am Glan 1964; K. P. Wittemann: Kommunistische Politik in Westdeutschland. Der Ansatz der Gruppe Arbeiterpolitik. Hannover 1977; Helmut Beer: Widerstand gegen den Nationalsozialismus in Nürnberg 1933-1945. Nürnberg 1976.

Grunert, Karh geboren am 29.8. 1901 in Hamburg. Der Vater, ein in SPD und Gewerkschaft organisierter Hafenschiffer, starb 1912; die Mutter arbeitete als Putzfrau, Wäscherin und Schneiderin; Volksschule bis zur 8. Klasse, dann ein Jahr Selecta für begabte Schüler; Steindruckerlehre - aus finanziellen Gründen nicht abgeschlossen; von Juni 1918 bis Ende 1922 Arbeiter beim Telegrafenbauamt in Hamburg; Mitglied im "Sozialdemokratischen Jugendbund“, seit 1916 gewerkschaftlich organisiert, Ende 1918 in der Presseabteilung des Arbeiter- und Soldatenrates tätig, Spartakusbund, KPD; auf dem VII. Reichskongreß der KJD (später KJVD) im März 1923 in deren ZK gewählt, Tätigkeit in der KJD-Zentrale in Berlin; nach Übernahme der KJD-Leitung durch die Linken 1924 wegen politischer Differenzen mehrfach in die Provinz strafversetzt; wegen seiner Gewerkschaftsarbeit und seinen Kontakten zu SAJ und Gewerkschaftsjugend sollte er zur Rechenschaft gezogen werden; nachdem jedoch Anfang I92s die Komintern die Bedeutung gerade der Gewerkschaftsarbeit hervorgehoben hatte, im Herbst erneut in das ZK der KJD gewählt, von Oktober 1925 bis April 1926 Verantworticher im Ressort Presse des ZK der inzwischen in KJVD umbenannten „Kommunistischen Jugend“; 1926-1928 Besuch eines Zweijahreskurses der Internationalen Lenin-Schule der Komintern in Moskau. Beruflich war G. 1923 als Verlagsangestellter, 1924 bis 1929 als Lektor und freier Schriftsteller tätig, ab Herbst 1930 Angestellter beim Arbeitsamt Hamburg; 1930 als Versöhnler aus der KPD ausgeschlossen.

1933 wurde G. aus der Stadtverwaltung entlassen; fünf Jahre arbeitslos, aus politischen Gründen von der Arbeitsvermittlung ausgeschlossen; am 22. 10. 1933 im Rahmen einer gegen die Westermann-Gruppe gerichteten Verhaftungsaktion festgenommen, bis zum I I. 8. 1934 im KZ Fuhlsbüttel; dann erhielt er einen Prozeß wegen „Vorbereitung zum Hochverrat $^{\alpha}$, in dem er nach schweren Folterungen wegen Mangels an Beweise freigesprochen werden mußte; im Frühjahr 1937 erneut einen Monat lang im KZ Fuhlsbüttel; seit 1938 Ange- 
stellter in einer Foto-Großhandlung; 1940-1945 Soldat, ab Herbst 194I wegen Gelenkrheuma zwölf Monate im Lazarett, anschließend in der Heeresentlassungsstelle Hamburg.

Seit Dezember 1945 Regierungsinspektor beim Arbeitsamt Hamburg, 1947 in das Amt für Wiedergutmachung und Flüchtlingsfragen versetzt; seit 1950 Standesbeamter, später Vorsitzender des Landesverbandes der Hamburger Standesbeamten; 1945 Mitglied der KPD, aus dieser 1950 wegen Verbindung zu „Parteifeinden “ ausgeschlossen; Mitte der fünfziger Jahre Mitglied der SPD, da G. der Auffassung war, daß ein politischer Mensch nicht im Abseits bleiben dürfe; er engagierte sich im Ortsverein, um den linken Flügel der Partei zu stärken und für seine politischen Vorstellungen zu offnen. Etwa 1974 trat er wegen des Extremisten-Beschlusses aus der SPD aus und schloß sich später der DKP an. Seit Mitte der sechziger Jahre sammelte er Material für eine Studie über die Geschichte der Hamburger Arbeiterbewegung, half interessierten Geschichts- und Politik-Studenten, die sich regelmäßig bei ihm trafen; Mitbegründer der „Gesellschaft zur Erforschung der Geschichte der Arbeiterbewegung Hamburg e.V.", bis I 977 deren I. Vorsitzender, nach seinem krankheitsbedingten Rucktritt zum Ehrenvorsitzenden ernannt; im September 1976 Mitinitiator des Kuratoriums "Gedenkstätte Ernst Thälmann e.V. ; G. starb am 24.4. 1980 nach dreijähriger schwerer Krankheit in Kaltenkirchen bei Hamburg.

Grzeski, Hermann, geboren am 28. II. 1912 in Frankfurt a. M. Der Vater war Schlosser, die Mutrer Hausfrau. Bis 1927 besuchte G. die Volksschule. Er absolvierte eine kaufmännische Lehre, wurde aber unmittelbar im Anschluß daran 1931 arbeitslos; Tätigkeit als Bote bei einer Versicherung; 1934-1945 kaufmännischer Angestellter; 1932 Mitglied des SJV.

Nach 1933 gehörte G. einer illegalen SAP-Gruppe an, die im wesentlichen den Zusammenhalt der Organisation aufrechtzuhalten versuchte und sich in wechselnder Zusammensetzung selbst noch während des Zweiten Weltkrieges traf. Am 15.3. 1940 zum Kriegsdienst eingezogen, im Mai 1943 in Tunesien in englische Kriegsgefangenschaft. Im Juli wurde er in die USA gebracht und war dort seit 1944 zusammen mit Herbert A. Tulatz* in Fort Devens, einem Kriegsgefangenenlager für deutsche Antifaschisten, interniert; nach Teilnahme an einem Polizeilehrgang im Januar 1946 nach Deutschland entlassen. Bis 1947 war G. bei einer Versicherung tätig, dann wurde er Angestellter in einem Kölner Braunkohlenwerk; Mitglied der IG Bergbau, Betriebsrat, zeitweise Betriebsratsvorsitzender der Firma. Er arbeitete im "Kölner Kreis" (vgl. Biographie v. Ludwig A. Jacobsen*) mit und wurde 195 I Mitglied der kurzlebigen „Unabhängigen Arbeiter-Partei“ (UAP).

Später Mitherausgeber der Monatsschrift "Sozialistische Politik" (SOPO), die von November 1954 bis 1962 auf Initiative einer Gruppe linker Sozialdemokraten unter maßgeblicher trotzkistischer Beteiligung erschien. Neben der Mitarbeit im SOPO-Kreis war G. in der Gewerkschaft und später auch in der SPD tätig. Seit 1976 lebt G. im Ruhestand.

Hacks, Ilse, geboren um 1910, Studium der Fächer Deutsch, Englisch, Französisch an der Universität Breslau, 1931 SAP; nach 1933 Widerstandstätigkeit, seit 1935 Mitglied der SAPBezirksleitung in Breslau, Anfang September 1936 zusammen mit Herbert A. Tulatz* verhaftet und zu dreieinhalb Jahren Zuchthaus verurteilt; nach der Entlassung Arbeit als Sekretärin; nach 194s längere Zeit in Heilanstalten zur Auskurierung einer offenen Tuberkulose, die sie sich in der Haft zugezogen hatte; Lehrerin; seit 196r Mitglied des Landesvorstands Hessen der DFU; Ilse Hacks lebte 1979 in Wiesbaden.

Halbach, Otto, geboren am Is. 10. 1900 in Hannover. Der Vater, der seit seiner Jugend in der SPD aktiv war, starb im Alter von vierzig Jahren. Die Mutter war berufstätig, konnte die Familie jedoch nur mit Mühe ernähren; fünf Geschwister; im Anschluß an die Volksschule 191 5-1918 Ausbildung zum Bandagisten, 1918-1933 Tätigkeit als Bandagist-Geselle in ver- 
schiedenen Firmen; I9Is Mitglied der „Arbeiter-Jugend“, später des KJVD und der KPD.

Nach der Machtübernahme durch die Nationalsozialisten wurde $\mathrm{H}$. wegen illegaler Arbeit verhaftet und bis 1935 im Zuchthaus Brandenburg inhaftiert, seit der Haft litt er an blutenden Geschwüren im Magen, seine Arbeitskraft war späteren ärztlichen Untersuchungen zufolge um die Hälfte reduziert; 1935 -1937 erwerbslos; 1938 Hilfsarbeiter in einer Sattlerei; in diesen Jahren mehrere Märsche über die ngrüne Grenze " in die ČSR, um der Exil-KPD Informationen zukommen zu lassen; 1939-1942 Bleipresser in einem Blei- und Zinn-Werk. $194^{2}$ wurde $H$. zum Strafbataillon 999 eingezogen und wenige Monate später - der Grund ist nicht bekannt - vom Volksgerichtshof zu drei Jahren Gefängnis verurteilt; Einlieferung in ein $\mathrm{KZ}$.

Bei Kriegsende gelangte $H$. abgemagert und krank auf Krücken nach Hannover zurück; er wurde nie mehr gesund und war in späteren Jahren nur noch bedingt leistungsfähig.

1945 Mitglied der KPD, 1945-1948 Angestellter beim Ausschuß ehemaliger politischer Häftlinge, 1949-1955 erneut Bleipresser, Betriebsrat und Mitglied der Vertreter-Versammlung der IG Metall-Verwaltungsstelle Hannover. Ende der vierziger Jahre heiratete $H$. zum zweiten Mal; der erste Mann seiner Frau, ihre zwei Brüder und Schwestern waren seit Mitte der dreißiger Jahre als Kommunisten in Zuchthäusern und KZs inhaftiert gewesen. 1952 wurde $H$. wegen kritischer Äußerungen zum Slansky-Prozeß in der CSSR und Kritik an der Sowjetunion aus der KPD ausgeschlossen; 1955-1965 Beitragskassierer der IG Metall; 195s Eintritt in die SPD, die jedoch nicht zu seiner politischen Heimat wurde; H. starb 197 I an seinem Magenleiden.

Hammer, Walter (1888-1963), einer der führenden Köpfe der „Freideutschen Jugend“ vor dem Ersten Weltkrieg und Inhaber des Fackelreiter-Verlages, war mit Franz Bobzien ${ }^{*}$ eng befreundet. Hammer wurde 1940 von der Gestapo in Dänemark aufgespürt und wegen „literarischen Hochverrats " zu einer Zuchthausstrafe verurteilt; inhaftiert erst im KZ Sachsenhausen, dann im Zuchthaus Brandenburg-Görden. Nach Kriegsende machte Hammer die Quellensicherung über die Häftlinge des Zuchthauses zu seiner Aufgabe; es entstand ein Archiv und 1948 das Forschungsinstitut Brandenburg. Da er sich weigerte, den kommunistischen Widerstand einseitig hervorzuheben, wurde seine Arbeit behindert, im Februar 1950 mußte er unter Zurücklassung seiner Sammlungen aus der DDR fliehen. In der Bundesrepublik begann Hammer mit seiner Forschungsarbeit noch einmal von vorn. Vgl. seine Bücher: Theodor Haubach zum Gedächtnis. Frankfurt a.M. 1955; Hohes Haus in Henkers Hand. Rückschau auf die Hitlerzeit, auf Leidensweg und Opfergang deutscher Parlamentarier. Frankfurt a. M. I956.

Hebeisen, Karl, geboren 1900, SPD, Gründungsmitglied und Vorsitzender der Offenbacher SAP; nach I945 Funktionär der „Arbeiter-Partei“; Verlagsvertreter; 1948-I960 Stadtverordneter, seit $19 \$ 4$ der SPD; H. starb in den sechziger Jahren.

Heise, Lina, geboren am 28.7. 1887 in Niste bei Kassel in einem Arbeiterhaushalt, ein Bruder. Nach der Volksschule in Stellung als Hausmädchen. Im April 1906 heiratete sie Stephan H., geb. 1883 , einen Redakteur der in Duisburg erscheinenden „Arbeiterzeitung “. Seit 1910 lebten sie in Stettin, dort war Stephan H. Redakteur des „Volksboten“. Während des Ersten Weltkrieges arbeitete Lina $\mathrm{H}$. im Büro eines Lebensmittelamtes, ihr Mann war Soldat und gehörte $1918 \mathrm{dem}$ Arbeiter- und Soldatenrat in Wilna an. Seit 1917 waren beide in der USPD. Etwa 1921 verzogen sie nach Frankfurt a. M. dort traten sie 1922 mit der RestUSPD zur SPD über. Stephan H. war bis 1933 ein stark engagierter Berufspolitiker; neben seiner Tätigkeit als Redakteur der SPD- „Volksstimme“ war er u.a. Stadtverordneter und vor 1933 stellvertretender Vorsitzender der SPD-Fraktion im Stadtparlament.

1933 erhielt er als Redakteur Berufsverbot, seitdem führte er einen Zigarrenladen. Am 22.6. 
1933 für kurze Zeit verhaftet. Danach war Stephan H. illegal tätig, am 23. 10. 1935 wurde er erneut verhaftet und wegen Vorbereitung zum Hochverrat zu vierzehn Monaten Gefängnis verurteilt. Nach Verbüßung der Haft Einweisung in das KZ Buchenwald, dort bis zum 9. 11 . 1941. Von einem Freund, dem er im Winter 1942/43 von neuen konspirativen Plänen berichtete, denunziert, kam er im Januar 1943 in das KZ Sachsenhausen. 1945 kam er bei dem Todesmarsch aus dem Lager ums Leben.

Lina H. führte seit 1935 den Zigarrenladen fort. Seit Mitte 1944 war sie in der Rhön als Betreuerin von zwei älteren Frauen tätig. Nach 1945 trat sie in Frankfurt erneut der SPD bei. Sie wurde nicht mehr berufstätig. Lina H. starb am 13. 12.1971.

Heist, Walter, geboren am 4. 1. 1907 in Steinberg/Oberhessen. Der Vater, ein deutschnational eingestellter Volksschullehrer, starb im Oktober 1918. Seit 1914 lebte die Familie in Mainz. Nach dem Abitur, das er Ostern 1926 ablegte, kam H. über den SPD-Politiker Fritz Ohlhof* in Kontakt zur sozialdemokratischen Mainzer „Volkszeitung ${ }^{\alpha}$. Er begann, Theaterkritiken zu schreiben, und übernahm die Redaktion der Jugendbeilage. 1927 wurde er Mitglied der SPD; Studium der Romanistik und der Germanistik in Frankfurt a.M. und in Berlin. Im Oktober 1931 gehörte H. zu den Gründungsmitgliedern der SAP in Mainz. Bei der Hessischen Landtagswahl vom I 5.11 . 1931 stimmten 2254 Wahler $(2,6 \%)$ in der Stadt für die neue Partei, der Mainzer Kandidat Fritz Ohlhof zog neben Heinrich Galm* aus Offenbach als zweiter SAP-Abgeordneter in den Landtag ein. Ab 1931 war H. Redakteur der SAP-Organe "Mainzer Fackel" und „Arbeitertribüne" und Mitglied im Antifa-Kampfbund. Angesichts der sich zuspitzenden politischen Situation beschloß H. im Herbst 1932, sich aus der Politik zurückzuziehen und seine Dissertation über das Thema „Wege zum proletarischen Roman in Frankreich" abzuschließen und wurde im Dezember promoviert.

Im Unterschied zu anderen prominenten Mainzer SAP-Mitgliedern wurde H. 1933 nicht verhaftet; er führt das auf den Einfluß einer ihm gut bekannten Familie zurück, deren Söhne bereits vor 1933 insgeheim der NSDAP und der SS angehörten. In den Jahren 1933-1940 übte er häufig wechselnde Tätigkeiten aus, u.a. als Vertreter für Unterhaltungsromane, als Verfasser von Artikeln für populär-medizinische Zeitschriften und als Aushilfs-Abrechnungsprüfer bei der Eisenbahngastronomie „Mitropa ${ }^{“}$. Im Mai 1940 zum Kriegsdienst eingezogen, dann jedoch wegen seiner Sprachkenntnisse Zensor in einem Lager für französische Kriegsgefangene. In den Jahren 1935 bis 1944 wurde $H$. Vater von fünf Kindern, ein $193^{8}$ geborener Sohn kam zusammen mit H's Mutter und seiner Schwester 1942 bei einem Luftangriff ums Leben. Im Herbst 1944 Soldat, im Frühjahr 1945 verwundet. Von Kriegsende bis zum Januar 1947 in englischer Kriegsgefangenschaft.

Nach seiner Rückkehr wurde H. erneut journalistisch tätig. In München wurde er Redakteur der von Alfred Andersch und Hans Werner Richter herausgegebenen Zeitschrift "Der Ruf. Unabhängige Blätter der jungen Generation“. Nach dem Ausscheiden von Andersch und Richter und der damit verbundenen Änderung des politischen Kurses verließ auch $\mathrm{H}$. zusammen mit zahlreichen anderen Autoren den „Ruf ${ }^{\star}$. Er ging zunächst als Redakteur zur "Stuttgarter Zeitung “, dann war er sechs Monate lang bei der in Karlsruhe erscheinenden „Monatsschrift für Demokratie und Sozialismus“ „Volk und Zeit“ tätig. Im Juli 1948 übernahm H. auf Vorschlag von Hans Werner Richter die Redaktion der Halbmonatsschrift "Neues Europa“ in Hannoversch-Münden, in der er die programmatische Linie des alten ${ }_{n}$ Ruf ${ }^{\prime \prime}$ fortsetzte. Nach finanziellen Schwierigkeiten, an denen auch die Umbenennung der Zeitschrift in „die deutsche stimme " nichts änderte, mußte er die Zeitschrift Anfang März I 949 aufgeben. Anschließend Mitarbeit an der von einem deutsch-französischen Autorenkreis publizierten Monatsschrift ${ }_{n}$ Aussprache“. 1950-1952 Verfasser von Trivial- und Sensations-Artikeln; von November 1952 bis zu seiner Pensionierung im Jahr 1970 Pressechef der Stadt Mainz; Gründer und Redakteur der städtischen Zeitschrift "Das neue Mainz"; Initiator der „Kleinen Mainzer Bücherei“, in deren Rahmen Publikationen zu lokalhistorischen und -literarischen Themen erscheinen. Seit den sechziger Jahren beschäftigte sich $\mathrm{H}$. erneut und verstärkt mit der französischen Literatur. Ergebnis seiner Forschungen sind u.a. 
folgende Veröffentlichungen: Genet und andere. Exkurse über eine faschistische Literatur von Rang. Hamburg 1965; Die Entdeckung des Arbeiters. Der Proletarier in der französischen Literatur des 19. und 20. Jahrhunderts. München 1974; Der französische Existentialismus, in: Neues Handbuch der Literaturwissenschaft, Bd. 2 I, Wiesbaden 1979, H. lebte 198 I in Mainz.

Jérôme Vaillant: Der Ruf. Unabhängige Blätter der jungen Generation (1945-1949). München 1978.

Hennig, Elisabeth (?-1958), wurde im Frühjahr 1941 in Amsterdam verhaftet; während der Untersuchungshaft in ihrem Heimatort Gelsenkirchen erkrankte sie durch Hunger und Kälte an einer schweren Lungen- und Nierenentzündung; am 10.4. 1942 vom Volksgerichtshof in Berlin zu sechs Jahren Zuchthaus verurteilt, bis zu ihrer Befreiung am 22.6. 1945 drei Jahre im Zuchthaus Cottbus in einem Saal für Tuberkulose-Kranke; nach I945 Lehrerin, engagiertes Mitglied der SPD.

Hensel, Otto, geboren am 1 3.1. 1904 als uneheliches Kind auf dem Gut Bagnowen/Kreis Sensburg in Ostpreußen. Seine Mutter war Magd auf diesem Gutshof, sein Vater der Besitzer des Anwesens. H. besuchte bis zum zwölften Lebensjahr die Volksschule, danach arbeitete er als Knecht auf dem Gut seines Vaters. 1923 Mitglied der SAJ, 1924 der SPD, 1925 Übersiedlung nach Sterkrade/Holten, heute Oberhausen, dort als Hauer auf einer Zeche tätig. 1926 Austritt aus der evangelischen Kirche, seitdem Mitglied des Freidenkerverbandes; 1929 Heirat in Bocholt; 1930-1932 arbeitslos, dann als Brotauslieferer tätig; 193 I Mitglied der SAP.

Seit 1933 arbeitete $H$. im Rahmen der illegalen SAP; über Bocholt wurden SAP-Druckschriften und Zeitungen aus Holland eingeschleust. Im Januar 1935 verhaftet, wurde er im Juli 1935 vom Oberlandesgericht Hamm im Prozeß gegen Eberhard Brünen* und 40 weitere Angeklagte, die überwiegend aus dem Gebiet Duisburg-Hamborn kamen, zu zehn Jahren Zuchthaus verurteilt. Zu den Mitangeklagten gehörten Wilhelm Pennekamp* und Adolf Graber* aus Duisburg sowie Anna Schmitz aus Bocholt (vgl. auch S. 125 ).

Von 1935 bis 1941 war H. im Zuchthaus Münster und dann bis zum I 3. 2. 1945 im Zuchthaus Waldheim in Sachsen inhaftiert; vom I 3. 2. bis zum 6.4. 1945 im Polizeigefängnis Leipzig. An diesem Tag floh er während eines Fliegerangriffs aus dem Sammeltransport, der die Gefangenen ins KZ Sachsenhausen bringen sollte. 1945-1948 Mitglied der KPD. Nach Austritt aus der KPD Teilnahme an Bestrebungen, eine dritte "marxistische“ Arbeiterpartei zu gründen. 195 I Eintritt in die „Unabhängige Arbeiterpartei“ (UAP). I950-1969 Funktionär der IG Bau, Steine, Erden in Bocholt. Ehrenamtlicher Richter am Arbeitsgericht Coesfeld. Seit 1961 Mitglied der „Deutschen Friedens-Union“ (DFU). H. starb am 4. 8. 1979.

Henßler, Fritz (1886-1953), geboren als dreizehntes von fünfzehn Kindern einer schwäbischen Arbeiterfamilie; Schriftsetzer, seit 19 I I in Dortmund, Redakteur der „Westfälischen Allgemeinen Volks-Zeitung", 1920-1933. Bezirksvorsitzender der SPD Westfalen, führender Funktionär der Dortmunder SPD, 1930-1933 MdR; nach zweimaliger „Schutzhaft“ 1933 am 25.4. 1936 festgenommen und am 3.5. I 937 vom Oberlandesgericht Hamm wegen Verstoßes gegen das „Gesetz gegen die Neubildung von Parteien“ zu einem Jahr Gefängnis verurteilt, seit Juli 1937 im KZ Sachsenhausen; im April 1945 Teilnahme an einem zehntägigen Todesmarsch nach Mecklenburg, der 6000 Häftlinge das Leben kostete; der völlig entkräftete Henßler erlitt einen Zusammenbruch, wurde jedoch von der geheimen Häftlingsleitung gerettet; nach 1945 Oberbürgermeister von Dortmund, Vorsitzender des SPDBezirks Westliches Westfalen, Fraktionsführer im Landtag, MdB und Mitglied des Parteivorstands der SPD.

Widerstand und Verfolgung in Dortmund 1933-1945. Katalog der ständigen Ausstellung. Dortmund 1981; Kur Klotzbach: Gegen den Nationalsozialismus. Widerstand und Verfolgung in Dortmund 
1930-1945. Hannover 1969; Heinz Kühn: Aufbau und Bewăhrung. Die Jahre 1945-1978. Hamburg 1981.

Heyen, Emil (1904-1945), Dreher, trat Mitte der zwanziger Jahre der KPD bei, 1928 wurde er ausgeschlossen; bis zum Herbst 1930 Mitglied und Funktionär der KPO; 193 I SAP, zeitweise Leiter der Ortsgruppe Dortmund. Am 31. 10. 1934 wurde Heyen wegen Verdachts der Vorbereitung zum Hochverrat festgenommen, Ende Juli 1935 aber wegen Mangels an Beweisen freigesprochen. Am 9.2. 1945 geriet er erneut in Haft und wurde am 19.4. $1945 \mathrm{im}$ Rombergpark bei Dortmund, wo noch im März/April 1945 280 Menschen von der Gestapo ermordet wurden, tot aufgefunden.

Hölter, Willem geboren 1904, Graphiker, Studium an der Kunstakademie Stuttgart und an der Kunstgewerbeschule Berlin, seit 1929 freischaffend; Mitglied der KPO; nach 1933 Ausstellungs-Graphiker, Widerstand im Rahmen einer KPO-Gruppe; 1946-1950 Professor an der Hochschule fur angewandte Kunst in Ost-Berlin, 1951-1972 an der Staatlichen Hochschule für bildende Künste in West-Berlin.

Hoffmann, Dora, geboren am 25.9. 1872 in Hamburg, keine Geschwister. Der Vater war von Beruf Schneider, die Mutter Plätterin. Beide Eltern, insbesondere aber die Mutter, waren in der SPD aktiv. Dadurch geriet die Tochter schon frih in Berührung mit der Arbeiterbewegung; zur Zeit des Sozialistengesetzes schmuggelte ihre Familie in den Wäschekörben verbotenes Agitationsmaterial. 1891 nahm die Neunzehnjăhrige als eine der ersten Frauen an der Demonstration zum I. Mai teil. Im selben Jahr trat sie der SPD bei und wurde Mitglied eines Arbeiterbildungsvereins. Nach dem Besuch der Volksschule und des Lyzeums absolvierte H. eine Schneiderlehre. 1891 heiratete sie. Ihr Mann, ein Schneider, war ebenfalls in der SPD organisiert. 1892 bekam sie ihr erstes Kind, dem bis 1914 elf weitere folgten. Von diesen starben zwei im Kleinkindalter. Im Ersten Weltkrieg stand H. auf der Seite der linken Kriegsgegner. Sie unterhielt Verbindungen zum Spartakusbund und trat 1923 der KPD bei. 1920 starb ihr Mann. In der Folgezeit hielt sie ihre Familie durch Schneiderarbeiten über Wasser. 1929 Mitglied der KPO, 1932 der SAP, die in Hamburg ca. 200 Mitglieder zählte.

Von 1933 bis 1935 war H. an illegalen Kontakten beteiligt, die der Vorsitzende des Hamburger SJV, Franz Bobzien*, im Mai 1933 nach Dänemark geknüpft hatte. Dank dieser Verbindungen konnten gefährdete SAP-Mitglieder über Flensburg außer Landes gebracht und Material in die Hansestadt geschmuggelt werden. Dieser organisierte Widerstand der Hamburger SAP kam im Herbst 1934 nach mehreren Verhafungen zum Erliegen.

Nach 1945 trat $H$. keiner Partei mehr bei, politisch war sie jedoch weiterhin sehr interessiert. Sie starb am 20.6. 1957.

Hofgabe $\neq * ;$, Otto, geboren am 21.9. 1889 in Stuttgart als jüngstes von sechs Kindern. Der Vater war Fuhrmann bei einer Spedition. Nach der Volksschule machte H. eine Friseurlehre. Im Anschluß daran ging er auf mehrjährige Wanderschaft nach Frankreich und England. In England während des Ersten Weltkrieges interniert. Um 1920 kehrte H. nach Deutschland zurück. Er arbeitete zunächst als Hilfsarbeiter in einem großen Stuttgarter Metallbetrieb und gründete dann 1926/1927 ein Friseurgeschäft. Über sein politisches Engagement in den zwanziger Jahren liegen keine Informationen vor, doch geht aus seinen Briefen hervor, daß er sich zur sozialistischen Arbeiterbewegung zugehörig fühlte.

Nach 1933 in Opposition gegen das NS-Regime. Während des Krieges wurde H. zum Sicherheitshilfsdienst, einer Technischen Nothilfe, eingezogen und in Stuttgart kaserniert; ausgebombt.

Als im Herbst 1947 Albert Schmidt, Verlagsleiter der „Stuttgarter Zeitung “ und ehemaliges SAP-Mitglied, in Stuttgart die Lizenzierung der „Arbeiter-Partei“ (AP), die seit 1945 in Of- 
fenbach bestand, beantragte, gehörte $H$. zum Gründerkreis. 1948 schlossen sich Günter Eckstein* und Erich Schumacher* der Stuttgarter AP an. Die "Arbeiter-Partei“, die die "hoffnungs- und interesselosen Massen “ durch Aufklärung und Kampf gegen Mißstände in der Verwaltung, in der Lebensmittelzuteilung etc., für die sie pauschal die „alten Parteien“ verantwortlich machte, zu mobilisieren hoffue, bestand in Stuttgart bis Anfang 1949. Sie kam über ca. hundert Mitglieder, die sich überwiegend aus ehemaligen SAP-, KPO- und aus unzufriedenen KPD-Mitgliedern rekrutierten, nicht hinaus. (Vgl. auch die Biographie von Albert Schmidt*.) 1956 gab H. sein Friseurgeschäft auf. Er starb 1967.

**Dieser Name ist ein Pseudonym. Er wurde auf Wunsch der Angehörigen des Briefschreibers gewählt.

Holz, Rudolf, geboren 1906, studierte seit 1929 neuere Sprachen und Sport an der Universität Berlin und gehörte der „Sozialistischen Studentenschaft“ an. Zusammen mit Georg Kunz $^{*}$ 1931 Mitglied der SAP in Berlin-Charlottenburg. 1932 verließ er die Universität und tauchte in einer kleinen Stellung bei der Post unter; während seines Kriegsdienstes geriet er 1943 in amerikanische Kriegsgefangenschaft, in ein Lager für Kriegsgefangene aus dem Strafbataillon 999 in Mississippi; seit 1946 Berater der US-Militärregierung für Arbeitsfragen in Berlin; Holz lebte 1980 als Oberstudienrat i. R. in Westberlin.

Ils, Hans, geboren am 12.5. 1906 in Weißenhorn bei Ulm. Die Eltern betrieben ein Gemischtwarengeschäft; zwei Brüder. Nach dem Abitur, das er an einer Oberrealschule ablegte, studierte I. in Berlin Jura; neben dem Studium Tätigkeit als Pressestenograph; 1928 Mitglied der SPD und der „Sozialistischen Studentenschaft ; 1931 Gründungsmitglied der $\mathrm{SAP}$ in Berlin, seitdem intensive Tätigkeit für die Bildung einer Einheitsfront der Arbeiterorganisationen.

Im Frühjahr 1933 war I. an der Umstellung der Berliner SAP auf die Illegalität beteiligt. Die politische Arbeit beschränkte sich im wesentlichen auf das Zusammenhalten der Mitglieder, Sammeln von Nachrichten über Vorgänge in der Bevölkerung und Vorkommnisse in den Betrieben sowie auf das Verbreiten von politischen Informationen und die Einrichtung von unverdächtigen Stützpunkten. Am 24. I 2. 1933 wurde I. im Rahmen einer größeren Verhaftungsaktion gegen führende SAP-Mitglieder, die im August begonnen hatte, festgenommen. Während der Verhöre durch die Gestapo schob I. einige Tatbestände auf das SAPMitglied Hans Schuricht, von dem er wußte, daß er einige Wochen zuvor in die ČSR geflohen war. Nach der beruflichen Tätigkeit Schurichts befragt, gab er die Auskunft, dieser habe als Buchhändler bei Joseph Lang gearbeitet. Daraufhin wurde Lang am 27. I 2 . 1933 verhaftet. (Auf diesen Sachverhalt bezieht sich der Anfang des Briefes von Ils.) I. kam zunächst ins KZ Oranienburg, dann in Untersuchungshaft. Erst am I. 12. 1934 wurden 24 der verhafteten SAP-Funktionäre, darunter Klaus Zweiling*, Stefan Szende, Max Köhler, Karl Baier ${ }^{*}$ und Gustav Kleinert, vor dem II. Senat des Volksgerichtshofes abgeurteilt. Die meisten Angeklagten erhielten Gefängnisstrafen, nur drei, darunter I., je zwei Jahre Zuchthaus. Die relativ milden Urteile sind u.a. darauf zurückzuführen, daß es gelang, die Anklageschrift ins Ausland zu schmuggeln, auf deren Grundlage die SAP-Exilgruppen dann eine breite internationale Solidaritäts- und Protestkampagne organisierten. Besonders in der französischen Öffentlichkeit erregte der Prozeß Aufsehen, so forderten am 29. 10. 1934 in Paris in einer Großveranstaltung 300000 Arbeiter die Freilassung der Angeklagten; französische Schriftsteller wie Romain Rolland, André Gide, André Malraux, Henri Barbusse richteten Protesttelegramme an die deutsche Regierung.

Nach der Entlassung aus der Haft stand I. unter Polizeiaufsicht, Verbot, als Pressestenograph zu arbeiten; eine Fortührung des Studiums wurde I. verweigert; 1936-1942 Angestellter in einem feinmechanischen Betrieb; 1943 zur „Bewährung vor dem Feind“ eingezogen, wegen einer Gelbsuchterkrankung jedoch nicht frontverwendungsfähig. Kurze Kriegsgefangenschaft.

1946 Assistent eines Wirtschaftsprüfers, daneben Studium der Volkswirtschaft an der Hum- 
boldt-Universität in Berlin; Diplomprüfung, Promotion; 1950-1953 Dezernent in der Zentralstelle für Betriebswirtschaft der Deutschen Bundesbahn, 1954 Aufbau der Wirtschaftsabteilung beim Hauptvorstand der IG Metall; 1955-197 I Arbeitsdirektor bei der KlöcknerWerke-AG; seit 1946 Mitglied der SPD in verschiedenen Funktionen; $1965-1969$ Bundestagsabgeordneter; in wichtigen Fragen in Opposition zur SPD-Fraktion: öffentliches Eintreten für die Anerkennung der Oder-Neiße-Grenze und der DDR, Ablehnung des Wehretats und der Notstandsgesetze. 1980 lebte I. in Freiburg, dort ist er im SPD-Ortsverein aktiv.

Jacobsen, Ludwig A., geboren am 13. 12. 1899 in Köln. Der Vater war Bäckermeister im Arbeiterviertel Köln-Ehrenfeld, seit 1912 Abeiter in einer Brotfabrik; Volksschule, kaufmännische Lehre; 1917 zum Kriegsdienst eingezogen, an der Westfront durch einen Handgranatensplitter verwundet. Nach der Entlassung meldete er sich im Februar 1919 zum „Grenzschutz Ost“, von Juni 1919 bis Januar 1920 Soldat der "Stadtschutztruppe Bremen ${ }^{*}$. Während dieser Freikorpstätigkeit geriet J. bei Konfiskationen in Beruhrung mit marxistischer Literatur; im März 1920 Mitglied der USPD, im Dezember der KPD; 192 I Politischer Leiter der KPD Köln-Ehrenfeld, in der KPD zunächst auf dem linken Flügel in Opposition zur Parteiführung um Paul Levi. Nach dem Sieg der Linken in der KPD unter Führung von Ruth Fischer und Arkadij Maslow stellte er 1924 seine Mitgliedschaft in der Bezirksleitung der KPD zur Verfügung, nach der Übernahme der Führung durch Ernst Thälmann zog er sich aus dem Parteileben zurück. 1929 aus der KPD ausgeschlossen; Mitglied der KPO, in der er sich allerdings nicht aktiv engagierte; von Beruf seit 1920 Buchhalter in einem Installationswaren-Großhandel, der seinen späteren Schwiegereltern gehörte; 1932/33 arbeitslos, dann erneut Buchhalter in einer anderen Firma.

Nach dem 30. I. 1933 übernahm J. die Organisationsleitung des Bezirks Niederrhein der illegalen KPO. Dabei arbeitete er mit Oskar Triebel* in Duisburg und insbesondere mit Bernhard Molz in Schwelm zusammen; $1937-1939$ Soldat in den Internationalen Brigaden im Spanischen Bürgerkrieg; 1943 von der französischen Gendarmerie an die Gestapo ausgeliefert, in Deutschland zu Zuchthaus verurteilt und bis Kriegsende in Haft. (Zu den Jahren 1933-1945 vgl. die ausführliche Darstellung im Brief vom 18.9. 1946, S. 58 ff.

Nach der Befreiung durch die Amerikaner am 28. 3. 1945 kehrte J. mit der selbstverständlichen Auffassung " nach Köln zurück, sich der KPD anzuschließen; bald jedoch von deren Politik enttäuscht, unterließ er diesen Schritt. Im Herbst 1946 Beitritt zur SPD. Zugleich war J. in den Jahren 1946-1948 der theoretische Kopf des „Kölner Kreises“, einer losen Vereinigung von 25-30 Personen, die vor 1933 überwiegend der SAP und in geringerem Umfange der KPO angehört hatten; von Januar 1947 bis Februar 1948 Verfasser der Rundschreiben des Kölner Kreises, die der internen Standortbestimmung dienen sollten und darüber hinaus an befreundete Genossen im Ruhrgebiet wie Oskar Triebel ${ }^{*}$, Emil Samorei* und Bernhard Molz ${ }^{*}$ versandt wurden. Die Mitglieder des „Kölner Kreises“ verstanden sich als eine Gruppierung marxistischer Sozialisten, die eine Erneuerung der Arbeiterbewegung jenseits von Stalinismus und Reformismus anstrebten. Ihr Arbeitsschwerpunkt lag in den Gewerkschaften, die Mitgliedschaft in SPD und KPD war freigestellt. Im Laufe des Jahres 1948 kam es zu starken Spannungen und persönlichen Auseinandersetzungen, an denen der Kreis im Sommer 1948 in eine kleine Gruppe um J. und in eine größere um Hubert Pauli* zerbrach. Sachlicher Kernpunkt der Differenzen war die Beurteilung der Sowjetunion und die daraus zu ziehenden politischen Konsequenzen. Jacobsen trat gegen den „Irrglauben [auf], daß von der S.U. und der K.P.D. noch etwas wie Sozialismus kommen könnte “ und plädierte dafür, als Marxist in der SPD zu arbeiten. Dagegen lehnte Pauli, der in der Sowjetunion eine zwar bürokratisierte, aber doch nichtkapitalistische Gesellschaft sah, die SPD als ihrem Wesen nach reformistisch ab und neigte zeitweilig der Gründung einer dritten Arbeiterpartei zu.

J. war nach 1945 Angestellter beim Arbeitsamt, später Abteilungsleiter und stellvertretender Direktor des Arbeitsamtes in Brühl-Bergheim; Mitglied der OTV; 1951-1959 unter dem 
Pseudonym L.A.Jenssen Autor der von Fritz Opel* und Fritz Lamm* herausgegebenen linkssozialistischen Zeitschrift „Funken“. Nach der Verabschiedung des Godesberger Programms stellte J. seine Beitragszahlungen an die SPD ein; 1963 pensioniert. Ende der sechziger Jahre wandte sich J. scharf gegen die "Illusionen " der Studentenbewegung und wurde zunehmend zu einem Befürworter des sowjetischen Gesellschaftssystems; einen demokratischen Weg zum Sozialismus hielt er nicht mehr für möglich. J. starb am 27. 5. 1978 in Köln.

Hans Manfred Bock: Geschichte des, linken Radikalismus' in Deutschland. Ein Versuch. Frankfurt a. M. 1976; Karljosef Kreter: Funken. Aussprachehefte für internationale sozialistische Politik. Entstehung und Entwicklung einer Zeitschrifu der "heimatlosen Linken“ in der Ära Adenauer (1950-1959). Unveroffentlichte Staatsexamensarbeit. Gottingen 1980.

Jabnke, Karh geboren am 3. 10. 1898 in Hamburg. Der Vater, ein Postbeamter, starb 1908, die Mutter heiratete kurze Zeit später einen in der SPD organisierten Zigarrendreher. Nach der Volksschule absolvierte J. eine kaufmännische Lehre in einem Zigarrengeschäft. $\mathrm{Da}$ er den Eltern Kostgeld zahlen mußte, ging er im Anschluß an die I Istündige Arbeit einer Nebenerwerbstätigkeit nach; Mitglied im Hamburger Sozialdemokratischen Jugendbund; 1915 in eine Munitionsfabrik dienstverpflichtet; nach einer Antikriegsdemonstration der jugendlichen Arbeiter Mitte 1916 zum Wehrdienst eingezogen. Im Herbst kam er an die Westfront zu einem Todeskommando, das als „Feuerwehrtruppe“ eingesetzt wurde; 1917 als Sanitäter abkommandiert, wenig später verwundet und mit einer schweren Entzündung in ein Berliner Lazarett eingeliefert. In Berlin stand J. in Verbindung mit der SpartakusGruppe, nach seiner Rückkehr nach Hamburg im Frühjahr 1919 Mitglied des KJVD und der KPD, auf derem linken Flügel er stand. Nach der Parteispaltung 1920 Übertritt zur KAPD, 1921 wieder zur KPD zurück; 1919-1921 arbeitslos, 1921 Angestellter bei einer Friedhofsverwaltung. 1922 heiratete J., seine Frau Emma ernährte seit $1923 / 24$ die beiden Kinder und später auch ihren Mann durch Saubermachen, Nähen und Gelegenheitsarbeiten. Ende Oktober 1923 beteiligte sich J. aktiv an dem Aufstand der Kommunisten, der von der KPD-Zentrale ursprünglich für das gesamte Reichsgebiet geplant, wegen mangelnder Unterstützung in der Arbeiterschaft dann jedoch in letzter Minute abgeblasen worden war; der Aufstand in Hamburg am 24. 10. erfolgte in Unkenntnis dieser Entscheidung und konnte, da er isoliert blieb, von der Polizei nach wenigen Tagen niedergeschlagen werden. 1924 kurze Zeit Agitpropleiter des Bezirks Wasserkante der KPD, im gleichen Jahr Mitglied der Hamburger Bürgerschaft. 1924 wegen Beteiligung am Hamburger Aufstand zu mehrjähriger Festungshaft verurteilt, Anfang 1926 amnestiert. 1926 Mitarbeiter der Deutsch-Russischen Handelsgesellschaft (Betriebsratsvorsitzender). Im Februar 1926 griff J. in der Bürgerschaft den Justizsenator, der den Vertreter der KPD-Linken, Hugo Urbahns, einen „politischen Verbrecher ${ }^{\star}$ genannt hatte, tätlich an und schied danach aus dem Hamburger Parlament aus. Bei den Diskussionen 1926-I928 stand J. auf dem linken Parteiflügel, im Fall des Polleiters John Wittorf - Wittorf hatte Parteigelder unterschlagen und der Vorsitzende der KPD, Ernst Thälmann, hatte dies nachträglich gedeckt - vertrat er den Standpunkt Trotzkis. Deshalb Ende 1928 fristlos aus der Deutsch-Russischen Handelsgesellschaft entlassen und aus der KPD ausgeschlossen. 1929 schloß sich J. den Trotzkisten an und gehörte zur Leitung der Hamburger Gruppe. 193 I, nach einer Reise seiner Frau in die Sowjetunion, erneuter Beitritt zur KPD; 1932 Angestellter der RGO in Berlin.

Nach 1933 mehrmals inhaftiert, bis 1936 im KZ Fuhlsbüttel, zum Teil in Einzelhaft; von schweren Mißhandlungen trug J. einen Hörfehler davon. Gleich ihm wurden in den Jahren 1933 bis 1939 etwa 8500 Hamburger Kommunisten wegen „Vorbereitung zum Hochverrat" angeklagt. Nach der Entlassung aus dem $\mathrm{KZ}$ war J. erneut mehrere Jahre lang erwerbslos, 1939 fand er eine Arbeit in einer Lüneburger Knäckebrotfabrik. Seitdem lebte er von seiner Frau getrennt in Lüneburg; erst nach den Großangriffen auf Hamburg im Juli 1943, in deren Verlauf auch Emma J. ausgebombt wurde, kehrte er in die Hansestadt zurück.

1945 wieder Mitglied der KPD, Betriebsrat in einer Hamburger Firma. Zunächst Mitglied 
der DAG, dann der Ortsverwaltung HBV des DGB in Hamburg. Nach dem Verbot der KPD durch das Bundesverfassungsgericht im Jahre 1956 beteiligte er sich an illegalen Aktionen der Partei. J., der seit Anfang der fünfziger Jahre krank war, starb am 13.8. I961.

Hermann Weber: Die Wandlung des deutschen Kommunismus. Bd. 2. Frankfurt a. M. 1969.

Juchacz, Marie, geboren am 15.3. 1879 in Landsberg an der Warthe, Hausangestellte, Fabrikarbeiterin, Krankenwärterin und Näherin; 1906 nach Trennung von ihrem Ehemann Übersiedlung nach Berlin, Heimarbeiterin; 1908 Mitglied der SPD, ab 1913 hauptamtliche Frauensekretärin für den SPD-Parteibezirk Obere Rheinprovinz in Köln; seit Januar 1917 Frauensekretärin der SPD, bis 1933 Mitglied des SPD-Parteivorstandes; 1920-1933 MdR, 1919 Gründerin der .Atbeiterwohlfahr" ${ }^{*}$, die sich unter ihrer Leitung zu einer bedeutenden Organisation entwickelte; 1933 Emigration ins Saargebiet, 1935 nach Frankreich, 1941 in die USA. Im amerikanischen Exil stand J., deren Verhältnis zur SOPADE seit 1933 sehr gespannt war, der Gruppe „Neu Beginnen ${ }^{\star}$ nahe; bei Kriegsende erneute Tätigkeit auf sozialpolitischem Gebiet: Vorsitzende des Workmen's Circle, im Sommer 1946 Ubertritt zur "Arbeiterwohlfahrt USA - Hilfe für die Opfer des Nationalsozialismus ${ }^{\alpha} ; 1949$ Rückkehr nach Deutschland, Mitglied der SPD, Ehrenvorsitzende der Arbeiterwohlfahrt ; erneutes Engagement in der sozialdemokratischen Frauenbewegung; J. starb am 28. I. 1956.

Biographisches Handbuch der deutschsprachigen Emigration nach 1933. Bd. I. München 1980.

Kappius, Josef (Jupp), geboren am 3. I r. 1907 in Bochum. Der Vater, ein strenggläubiger Katholik, war von Beruf Stellmacher. Nach der Volksschule vier Jahre technische Lehre, dann Besuch der Betriebsfachschule für Werkmeister in Bochum, Vorzeichner und Konstrukteur im Stahlhoch- und Brückenbau; 1924 SAJ, 1925 DMV, später im „Bund Technischer Angestellter und Beamter “. Über seine Frau Änne, die aus einer sozialistischen Bergarbeiterfamilie stammte, erhielt $\mathrm{K}$. Verbindung zum ISK.

Ab Frühsommer 1933 Leiter der Bochumer Zelle der vom ISK geleiteten „Unabhängigen Sozialistischen Gewerkschaft" (USG). K. stand in regelmäßigem Kontakt mit Köln, dem wichtigsten ISK-Stützpunkt in Westdeutschland, über den in Zusammenarbeit mit der „Internationalen Transportarbeiter-Föderation" illegale Flugblätter aus dem Ausland eingeschleust wurden. 1935 verzog er nach Berlin, wo er u. a. eine ISK-Jugendgruppe leitete. Als Ende 1937/Anfang 1938 zahlreiche Mitglieder des ISK in einer Verhaftungswelle, die sich auf ganz Deutschland erstreckte, verhaftet wurden, gelang nur wenigen Illegalen die Flucht. Änne und Jupp K., die seit November 1937 steckbrieflich gesucht wurden, flohen in die Schweiz, dann nach Frankreich. Kurz vor Kriegsausbruch übersiedelte K. nach London, wo sich seit Januar 1939 auch der Auslandsleiter des ISK, Willi Eichler*, aufhielt; Arbeit in einer vegetarischen Gaststätte des ISK. Die Londoner ISK-Gruppe zerfiel, als die Mitglieder Ende 1939 als "feindliche Ausländer" interniert und zum großen Teil in Gebiete des Commonwealth verschickt wurden. Zusammen mit fünf weiteren ISK-Mitgliedern war K. bis $1942 / 43$ in Australien. Im Frühjahr/Sommer 1944 wurde er in Zusammenarbeit mit der internationalen Gewerkschaftsbewegung und der Abteilung „Labor Desk" des US-Geheimdienstes für einen Untergrundeinsatz in Deutschland ausgebildet, mit dem Ziel, Verbindung zu innerdeutschen Widerstandsgruppen aufzunehmen und Vorbereitungen für die Neuordnung Deutschlands zu treffen. Nach unterstützenden Kurierdiensten seiner Frau, die im April 1944 von der Schweiz aus illegal durch Deutschland reiste, sprang K. am x.9. über dem Emsland ab. Er tauchte in Bochum unter und wirkte von dort aus mit am Aufbau von Kontaktgruppen im Ruhrgebiet, die im geeigneten Moment die Führungspositionen in Betrieben und Kommunen besetzen sollten. Darüberhinaus gelang es, Verbindungen zu ISKFreunden in Hannover, Berlin, Hamburg, Köln, Kassel, Göttingen, Frankfurt/M. und Darmstadt zu schaffen. Dagegen mußten Pläne, eine militante Widerstandsorganisation aufzubauen, fallen gelassen werden. Über Änne K., die im Oktober 1944 und im Januar/ 
Februar 1945 zu zwei weiteren Kurier-Fahrten nach Deutschland kam, ließ K. Situationsberichte herausschmuggeln, die von der ISK-Auslandsleitung im Londoner Rundfunk veröffentlicht wurden. Bei Einmarsch der Amerikaner zunächst wieder nach England ausgeflogen, kehrte K. Anfang Juli 1945 nach Bochum zurück.

Nach Kriegsende bemühte er sich um den Aufbau einer neuen, einheitlichen sozialistischen Partei auf der Basis der im englischen Exil 1941 gegründeten „Union deutscher sozialistischer Organisationen in Großbritannien “ aus SPD, SAP, ISK und der Gruppe „Neu Begin-

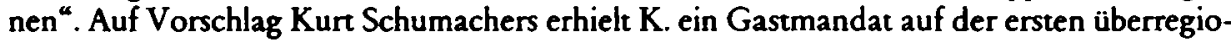
nalen sozialdemokratischen Parteikonferenz am 5./6. Oktober in Wennigsen bei Hannover. Auf dieser Konferenz sprach er sich entschieden gegen ein Zusammengehen mit der KPD aus. Ab r945 Mitglied der ÖTV. In der SPD widmete sich $\mathrm{K}$. vor allem der Bildungs- und Schulungsarbeit: 1946 Sekretär für Bildung und Kulturpolitik im Bezirk Westliches Westfalen, 1947 Mitglied des Kulturpolitischen Ausschusses. Seit 1952 im Ausschuß für Frauenfragen beim Parteivorstand der SPD. 1956 starb seine Frau Änne. 1955-1966 Mitglied des Landtags von Nordrhein-Westfalen; Vorsitzender des Zentralausschusses Sozialistischer Bildungsgemeinschaften e.V. Düsseldorf. 1965 ging er eine zweite Ehe ein. K. starb am 30. 12. 1967 .

Werner Link: Die Geschichte des Internationalen Jugend-Bundes (IJB) und des Internationalen Sozialistischen Kampf-Bundes (ISK). Meisenheim am Glan 1964; Albrecht Kaden: Einheit oder Freiheit. Die Wiedergründung der SPD 1945/46. Bonn 1980; Hartmut Pietsch: Militärregierung, Bürokratie, Sozialisierung. Zur Entwicklung des politischen Systems in den Städten des Ruhrgebietes 1945 bis 1948. Duisburg 1978; Biographisches Handbuch der deutschsprachigen Emigration nach 1933. Bd. 1. München 1980 .

Kaulich, Gerhard, geboren am 6.11. 1912 in Breslau. Der Vater war Volksschullehrer, die Mutter Hausfrau. Die Eltern standen politisch der Zentrumspartei nahe. K. besuchte bis 1932 die Oberrealschule, anschließend studierte er Jura in Breslau. 1937 Referendarexamen. Er war bei den "Sozialistischen Schülern", seit 193 I gehörte er dem SJV, später der SAP an. 1933 illegale Widerstandstätigkeit im SJV; 1937-1939 Referendarausbildung, 1939-1945 Soldat. Im Mai 1945 geriet K. im Vogtland in amerikanische Kriegsgefangenschaft, aus der er jedoch kurze Zeit später entlassen wurde. Infolge der Besetzung Breslaus durch die Polen ging er nach Görlitz, wo er eine Arbeitsstelle in der Rechtsabteilung der Stadtverwaltung fand. 1945 Eintritt in die SPD, 1946 SED-Mitglied, Tätigkeit im Volkshochschulwesen; I95 I als "Trotzkist" aus der SED ausgeschlossen; von der für das Ausschlußverfahren zuständigen Betriebsgruppe enthielten sich 26, nur 4 stimmten dafür.

Übersiedlung erst nach Westberlin, dann nach Wiesbaden. Dort durchlief K. eine Verwaltungslaufbahn vom Assessor bis zum leitenden Regierungsdirektor. Zuletzt Tätigkeit in einer Entschädigungsbehörde; 1951 SPD-Mitglied, 1954 Distriktvorsitzender im Ortsverein, Mitglied des SPD-Unterbezirks-Vorstands. 1969 trat K. zusammen mit seiner Frau aus der SPD aus. 1974 pensioniert. K. lebte 1980 in Wiesbaden.

Keun, Irmgard, geboren am 6.2. 1909 in Berlin, ein Bruder. K. wuchs in einem liberalen, großbürgerlichen Elternhaus mit Kindermädchen und privaten Sprachlehrerinnen auf. I 917 verzog die Familie nach Köln; der Vater, ein Berliner Fabrikant, übernahm dort die Leitung einer Ölraffinerie. Nach Abschluß eines evangelischen Lyzeums besuchte K. 1925 eine Schauspielschule und spielte eine Zeitlang am Stadttheater Greifswald. 1927 heiratete sie den 45 -jährigen Romanautor, Dramatiker und Regisseur Johannes Tralow. Eine zufällige Bekanntschaft mit Alfred Döblin, der sie im Anschluß an ein längeres Gespräch aufforderte: „Schreiben Sie ein Buch!", veranlaßte sie zum Schreiben. Ihr erster Roman „Gilgi, eine von uns" war 1931 ein Sensationserfolg und erreichte innerhalb eines Jahres sechs Auflagen. Ebenso der in I 8 Sprachen übersetzte Nachfolgeroman „Das kunstseidene Mädchen“ (1932), in dem sie wiederum die Träume und Lebenseinstellungen eines gerade "flügge" ge- 
wordenen Kleinbürgermädchens parodierte. „Sie hat Humor wie ein dicker Mann, Grazie wie eine Frau, Herz, Verstand, Gefühl ${ }^{\circ}$, sie ist etwas, „was es noch niemals gegeben hat, eine deutsche Humoristin“, jubelte Kurt Tucholsky in der „Weltbühne“.

Nach der Machtübernahme durch die Nationalsozialisten wurden ihre beiden Bücher als nschädliches und unerwünschtes Schrifttum" verboten. Ihre Weigerung, der NS-Reichsschriftumskammer beizutreten, zog ein Berufsverbot nach sich. Im Oktober 1935 erhob sie beim Landgericht Berlin Schadensersatzanspruch für ihre beschlagnahmten Bücher. Verhaftung und "verschärftes Verhör ${ }^{\alpha}$ durch die Gestapo. Nach dem Krieg erfuhr sie von ihrer Mutter, daß ihr Vater sie für $200000 \mathrm{RM}$ freigekauft hatte. Trennung von ihrem Mann. Sechsundzwanzigjährig emigrierte K. Ende 1935 nach Belgien. In Ostende, wo damals u.a. auch Egon Erwin Kisch, Ernst Toller und Stefan Zweig lebten, war sie lăngere Zeit mit dem österreichischen Romancier Joseph Roth befreundet. 1937 erreichte sie die Scheidung von ihrem Mann, der versucht hatte, sie nach Deutschland zurückzuholen. Auf Anraten von Roth schickte sie ihm eine Karte mit dem Inhalt: „Ich schlafe mit Juden und Negern ${ }^{\alpha}$, und wurde daraufhin wegen „schwerer Charaktermängel“ schuldig geschieden. Zusammen mit Roth ausgedehnte Reisen. Wahrend des Exils veröffentlichte $\mathrm{K}$. vier Romane in den Verlagen Querido und Allert de Lange, in denen sie wie 1931 und 1932 in salopper, alltagsnaher Sprache Unterhaltung mit pointierter Gesellschaftskritik verband: 1936 „Das Mädchen, mit dem die Kinder nicht verkehren durften ${ }^{\alpha}$, die Lausbubengeschichte eines zehnjährigen Mädchens 1919 im besetzten Koln; 1937 n Nach Mitternacht", eine psychologische Deutung des kleinen Mannes im NS-Staat; 1938 „D-Zug dritter Klasse ${ }^{\alpha . ~ D i e ~ S t a t i o n e n ~ i h r e r ~ E m i g r a-~}$ tion - Brüssel, Ostende, Amsterdam, Paris, Nizza, Salzburg, Lemberg, Warschau - liegen dem Roman „Kind aller Länder" (1938) zugrunde. Bei Kriegsausbruch Einzug ihrer Papiere durch die holländischen Behörden. Als die deurschen Truppen im Mai 1940 das Land überrannten, konnte $\mathrm{K}$. Holland nicht mehr verlassen. Mit Hilfe eines deutschen Offiziers gelang es ihr, sich unter falschem Namen einen deutschen Paß ausstellen zu lassen. Rückkehr nach Köln, dort lebte sie bis Kriegsende unentdeckt bei den Eltern. Ihr Untertauchen wurde erleichtert durch eine Falschmeldung in der internationalen Presse, in der es hieß, sie habe Mitte 1940 zusammen mit dem Dramatiker Walter Hasenclever in dem französischen Internierungslager Les Milles Selbstmord begangen.

Nach 1945 blieb K. bei ihren Eltern und pflegte sie bis zu deren Tod. 1950 Geburt einer nichtehelichen Tochter. 1947 erschien ihr Buch „Bilder und Gedichte aus der Emigration“, 1950 "Ferdinand, der Mann mit dem freundlichen Herzen ${ }^{*}$. Dieser Roman über die Nachkriegszeit - Hermann Kesten zufolge ihr bestes Buch - fand im Nachkriegsdeutschland keine Beachtung. Seitdem geriet $\mathrm{K}$. in Vergessenheit und war lange Zeit eine Schriftstellerin ohne Publikum. Erst mit der zunehmenden Erforschung des deutschen Exils seit Anfang der 7oer Jahre wurde sie von den Medien wiederentdeckt. Inzwischen liegen mehrere ihrer Romane wieder vor, zum Teil auch als Taschenbuchausgabe. K. starb am 5. 5. 1982.

David Bronson: Joseph Roth. Eine Biographie. Köln 1974; Hermann Kesten: Meine Freunde, die Poeten. München I959, ${ }^{2} 1980$; ders.: Deutsche Literatur im Exil. Briefe europäischer Autoren 1933-1949. Wien 1964; Jürgen Serke: Die verbrannten Dichter. Berichte, Texte und Bilder einer Zeit. Weinheim 1978.

Korbmacher, Willy, geboren 1897, Arbeiter, Mitglied der SPD, USPD, KPD; 1922-1929 Sekretär der "Roten Hilfe“; nach Parteiausschluß Mitglied der KPO; 1929-193 I Studium an der Deutschen Hochschule für Politik in Berlin, anschließend Fürsorger; illegale Arbeit im Rahmen der SAP, im Januar 1935 Emigration in die CSR; 1938 nach Schweden, Mitglied der SAP- und der "Landesgruppe deutscher Gewerkschafter"; K. kehrte nach dem Zweiten Weltkrieg nicht nach Deutschland zurück.

Biographisches Handbuch der deutschsprachigen Emigration nach 1933. Bd. I. München 1980. 
Komett, Albert, geboren am 5. 10. 1896 in Bortsch, Kreis Karthaus/Westpreußen als Sohn eines Arbeiters; sieben Geschwister. Die Mutter starb kurz nach der Jahrhundertwende. K. wuchs bei Verwandten auf, er erlernte den Beruf eines Schiffs- und Brückenmeisters. Bei Wiedergründung des polnischen Staates 1918 siedelte er nach Bartenstein in Ostpreußen über. Dort heiratete er 1921 . Im Dezember 1924 Umzug nach Gelsenkirchen, zunächst Hilfsarbeiter in einer Eisenhütte, ab 1926 Maurer. In der Weltwirtschaftskrise war K. ca. drei bis vier Jahre lang arbeitslos. Mitglied der KPD. Über seine politische Betätigung in den zwanziger Jahren ließen sich keine Angaben ermitteln.

Nach 1933 illegale Tätigkeit im Rahmen der von Emil Samorei* geleiteten Gelsenkirchener SAP-Gruppe. Am 5.9. 1935 verhaftet; in der Untersuchungshaft war er schweren Mißhandlungen ausgesetzt, in deren Verlauf ihm eine Niere und der rechte Arm zerschlagen wurden. Am 18.4. 1936 vom Oberlandesgericht Hamm zu drei Jahren und sechs Monaten Zuchthaus verurteilt und für wehrunwürdig erklärt. Die Strafe verbüßte K. im Zuchthaus Herford und in einem Arbeitsbataillon; nach anschließender "Schutzhaft" wurde er am 20.4. 1939 zum „Führer-Geburtstag a amnestiert. Von 1939 bis 1944 Polier in einem Baugeschäft. Anfang Juni 1944 wurde K. zum Strafbataillon 999 eingezogen, er wurde kaserniert, kam jedoch mit seiner Einheit nicht an die Front.

Nach Kriegsende in amerikanischer Kriegsgefangenschaft in Frankreich. 1946 trat K. erneut der KPD bei, später verließ er die Partei; 1947 städtischer Angestellter bei der Baubehörde; 1947-1952 1. Vorsitzender VVN Gelsenkirchen, 1952 trat er wegen der engen Bindung der Verfolgtenorganisation an die KPD aus der VVN aus. K. starb am 5. 2. I953.

Kraus, Otto, geboren am 16. I 2. 1908 in Nürnberg als Sohn eines Formers; Volksschule, dreijährige Dreher-Lehre, seit 193 I Arbeit als Mechaniker; 1923 SAJ, 193 I SAP; wegen illegaler Fortführung der SAP im Dezember 1935 verhaftet und bis Oktober 1937 im KZ Dachau; nach 1945 langjähriger Funktionär und Vorstandsmitglied der IG Metall Nürnberg.

Wolfgang Ruppert (Hrsg.): Lebensgeschichten. Zur deutschen Sozialgeschichte 18 $80-1950$. Nürnberg I980, S. 174 ff.; Hans Dieter Baroth: Gebeutelt aber nicht gebeugt. Erlebte Geschichte (ran-Buch 6). Köln 198I.

Kress, Wilhelm, geboren um 1900 in Stuttgart-Zuffenhausen als Sohn eines Tischlergesellen; zwei Brüder, drei Schwestern. 1917 als Soldat eingezogen, wurde K. durch den Krieg politisiert, Mitglied der Spartakus-Gruppe und der KPD. Seit 1919 in Berlin. Von Beruf technischer Kaufmann führte ihn seine Aktivität in der KPD in die Gewerkschaftsabteilung des ZK der KPD und in höhere Positionen der Komintern. Mitte der zwanziger Jahre (1927?) im Auftrag der Komintern in China, wahrscheinlich gemeinsam mit Heinz Neumann im Zusammenhang mit der Auslösung des Kantoner Aufstands, der in einer eklatanten Niederlage der chinesischen Kommunisten endete. Während dieser Zeit gehörte K., der Georgi Dimitroff unterstand, zum Bekanntenkreis von Ernst Thälmann. Später - ab wann ist nicht bekannt - in Opposition zum politischen Kurs der KPD, Mitglied der KPO. Nach 1933 Emigration in Frankreich, von den Nationalsozialisten ausgebürgert. Um I935 wurde $\mathrm{K}$. vom Pariser Auslandskomitee der KPO zur Unterstützung der illegalen Arbeit des Berliner Komitees der KPO nach Deutschland entsandt. Im deutschen Untergrund näherte er sich wieder der KPD an, deswegen aus der KPO ausgeschlossen. Rückkehr nach Frankreich, bei Kriegsausbruch - vermutlich für längere Zeit - interniert; nach der Besetzung Südfrankreichs durch deutsche Truppen 1943 illegal in die Schweiz.

Im September 1945 Rückkehr nach Deutschland; erneut Mitglied der KPD; einem Ausschlußverfahren, das gegen ihn nach politischen Differenzen angestrengt worden war, kam K. 1946 durch seinen Parteiaustritt zuvor; seit Mitte 1946 öffentlicher Kläger der Spruchkammer Stuttgart. K. starb am 31. I 2. 1946 an einer Herzattacke. 
Krïger, Alfred und Lotte, Alfred K. wurde um 1899 in Halle geboren, seine spätere Frau Lotte um 1904. Von Beruf war Alfred K. Bergmann, später arbeitete er als Sattler und Tischler. Seit seiner Jugend gehörte er der Arbeiterbewegung an, im Ersten Weltkrieg war er Soldat. 1918/1919 wurde er Mitglied der neugegründeten KPD, die schon zwei Jahre später im Industriegebiet des Bezirkes Halle-Merseburg die bei weitem stärkste Partei war. 1921 war dieser Bezirk Mittelpunkt der sog. März-Aktion der KPD. Die Besetzung der „unruhigen“ Provinz Sachsen durch preußische Sicherheitspolizei am 19.3. versuchte die KPD zur Auslösung einer revolutionären Aktion zu nutzen. Als nach dem 22. 3. der radikale Arbeiterführer Max Hoelz den bewaffneten Aufstand organisierte, schickte ihm die Bezirksleitung der KPD eine Gruppe junger Kommunisten, zu denen auch Alfred $\mathrm{K}$. gehörte, zu Hilfe. Diese "Hilfstruppe" wurde von der Polizei entwaffnet und gefangengenommen. Lotte war ebenfalls an den Ereignissen beteiligt; als Jugendvertreterin nahm sie an einer Sitzung der KPDBezirksleitung teil, auf der ein Vertreter der Komintem Anweisungen gab, Sprengstoffanschläge auf Einrichtungen der Arbeiterbewegung auszuüben, um so die Massen auf die Straße zu bringen. Bei den sich anschließenden Kämpfen kamen 145 Arbeiter ums Leben, 3470 wurden verhaftet. Alfred $K$. wurde wegen seiner Beteiligung an dem Aufstand, von dem sich die KPD später distanzierte, zu einer hohen Zuchthausstrafe verurteilt. Im Zuchthaus lernte er Lotte kennen, die von der KPD mit der Betreuung des ihr unbekannten politischen Gefangenen beauftragt wurde. Nachdem Alfred K. infolge einer Amnestie vorzeitig entlassen worden war, heirateten sie. Lotte $\mathrm{K}$. war in den zwanziger Jahren als Sekretärin im Parteiapparat der KPD, u.a. in der Gewerkschaftsabteilung des ZK in Berlin tätig. 1927 schlossen sich beide der rechten Opposition in der Partei an, 1929 wurden sie aus der KPD ausgeschlossen. Sie traten der KPO bei und gingen 1932 mit der KPO-Minderheit zur SAP.

Seit dem Frühjahr 1933 waren beide in der illegalen Organisation der SAP in Berlin aktiv; Alfred $K$. vervielfältigte die vierzehntägig erscheinende SAP-Zeitschrift „Das Banner des revolutionären Marxismus“. Nach der Verhaftung von fuhrenden Mitgliedern der SAPReichsleitung und der Berliner SAP-Bezirksleitung im Herbst 1933 wurden Alfred K. und drei weitere SAP-Funktionäre von Walter Fabian* wegen ihrer unmittelbaren Gefährdung aufgefordert, mit Hilfe von Hamburger und Flensburger Genossen nach Kopenhagen zu fliehen. Lotte K. blieb in Berlin zurtick und setzte die illegale Arbeit fort, bis auch sie 1935 fliehen mußte. Bei der Besetzung Dänemarks durch deutsche Truppen am 9.4. 1940 gelang ihnen mit Hilfe dänischer Fischer die Flucht nach Schweden. Wie fast alle SAP-Mitglieder in Schweden traten auch sie 1944 dem Landesverband der SOPADE bei. Zugleich waren sie in ihrem Wohnort Nyköping in der Schwedischen Sozialdemokratischen Arbeiterpartei aktiv.

1947 kehrten Alfred und Lotte K. nach Deutschland zurück; sie gingen nach Berlin, erhielten dort aber keine Zuzugsgenehmigung und zogen dann in die oberfränkische Kreisstadt Rehau. Aus Enttäuschung über die politische Situation und die fehlenden menschlichen Beziehungen sowie wegen der Schwierigkeit, eine erträgliche wirtschaftliche Existenz zu schaffen, gingen sie später nach Schweden zurück. Dort engagierten sie sich erneut in der Sozialdemokratischen Arbeiterpartei. Lotte K. starb am 16.4. 1979, Alfred K. am 19. 5. 1979.

Kübn, Heinz, geboren am 18.12. 1912, 1930 SPD, nach 1931 der SAP nahestehend; 1931-1933 Studium der Volkswirtschaft und Staatswissenschaften an der Universität Köln, Vorsitzender der örtlichen "Sozialistischen Studentenschaft"; nach kurzer Inhaftierung im Mai 1933 im Auftrag der SAP ins Saargebiet, dann Emigration in die CSR; ab 1936 in Antwerpen und Brüssel, Kontakte zum ISK; während der deutschen Besetzung Belgiens im Untergrund. Schon Ende Dezember 1945 kehrte K. über die "grüne Grenze“ nach Köln zurück und trat der SPD bei; 1946-1950 Redakteur an der von Willi Eichler" geleiteten „Rheinischen Zeitung"; 1948-1953 MdL, 1953-1962 MdB, seit 1962 erneut MdL, 1966-1978 Ministerpräsident des Landes Nordrhein-Westfalen. 
Biographisches Handbuch der deutschsprachigen Emigration nach 1933. Bd. I. München 1980; Heinz Kühn: Widerstand und Emigration. Die Jahre 1928-1945. Hamburg 1980; ders.: Aufbau und Bewährung. Die Jahre 1945-1978. Hamburg 1981 .

Kübm, Marianne, geboren am 17. I1. 1914 in Köln, Adoptivkind; Volksschule, Anwalts- und Notariatslehre, Sekretärin; 1929 Mitglied, später Vorsitzende einer Gruppe der „Roten Falken", ZdA-Jugend, 1932 SPD; 1933 illegale Kontakte und Vermittlungsarbeit für in der Emigration arbeitende SPD-Funktionäre, darunter Heinz Kühn ${ }^{*}$, ihrem späteren Ehemann; Anfang 1938 Verhöre wegen häufiger Auslandsreisen, Entzug des Reisepasses; um einer Verhaftung zu entgehen, Ende Mai Flucht nach Belgien; im August 1939 Heirat; während des Krieges einige Jahre im Untergrund; 1945/46 in Brüssel Leiterin einer CAREPaketaktion für Köln und das Ruhrgebiet, in diesem Zusammenhang Zusammenarbeit mit dem Schweizer „Arbeiterhilfswerk ${ }^{\alpha}$ und dem „Workmen's Circle ; im Spätsommer 1946 Rückkehr nach Köln, aktives Mitglied der „Arbeiterwohlfahrt“ und der SPD, Frauenarbeit im Bezirk Mittelrhein; 1952-1973 Stadträtin, Arbeitsschwerpunkte: Kultur, Schule, Erwachsenenbildung; $1952-1963$ Geschäftsführerin und stellvertretende Vorsitzende des „Sozialistischen Bildungswerks NRW“; 1956-1974 Mitglied des Programmbeirates des WDR für den Bereich Erwachsenenbildung; 1973/74 aus gesundheitlichen Gründen Rückzug aus der Politik; seit 1979 Galeristin für naive Kunst.

Kublmann, Willi [auch: Wilhelm], geboren 1902, 1923-1928 Mitglied der Bezirksleitung Ruhrgebiet des KJVD, 1929-193 I Bezirksleiter der KPO, 1931-1933 Mitglied des Bezirksvorstandes der SAP; 1933-1935 zwei Jahre lang im Gefängnis wegen „Vorbereitung zum Hochverrat “; 1942-1945 Militärdienst; 1945 zunächst KPD, dann seit September 1946 SPD.

Kuntz, Albert (1896-1945), Kupferschmied; Funktionär, Politischer Sekretär der Bezirksleitung Frankfurt-Hessen der KPD; am 1 2.3. 1933 verhaftet und 1935 zu einem Jahr und sechs Monaten Zuchthaus verurteilt; KZ Buchenwald, dort gehörte er der Leitung der illegalen antifaschistischen Organisation an; am 23. I. 1945 im Nebenlager Dora im Harz ermordet.

Hermann Weber: Die Wandlung des deutschen Kommunismus. Bd. 2. Frankfurt a. M. 1969.

Kunz, Georg, geboren am 26. I I. 1909 in Berlin. Der Vater, der im Juni i 9 Is als Soldat starb, war Berufsschullehrer; die Mutter arbeitete nach dem Tod ihres Mannes als Weißnäherin. Die Jahre I9Is bis 1917 verbrachte K. im Waisenhaus. Volksschule; 1924 - März 1928 Buchbinderlehre; Arbeit bei einer sozialdemokratischen Bücherfreunde-Organisation; längere Zeit arbeitslos; 1925 Mitglied der SAJ und des nJungbanners“, später des „Reichsbanners Schwarz-Rot-Gold“; 1927 SPD, seit Oktober 193 I SAP.

Im April 1933 als ehrenamtlicher Wohlfahrtspfleger in Berlin-Charlottenburg entlassen; 1933-1936 Angehöriger einer Widerstandsgruppe; Beteiligung an der Durchführung heimlicher Betriebsversammlungen und an der Unterstützung von Familien inhaftierter Genossen; mehrmals selbst von der Gestapo verhaftet; Gelegenheitsarbeiter; seit Oktober 1937 als Meister in einer Mappenfabrik. 1938 heiratete K.; 1942 zum Kriegsdienst eingezogen, Soldat in der Sowjetunion, dann in Italien; 1944 im Stellungskrieg bei Monte Cassino von den Engländern gefangengenommen. In der Folgezeit beteiligte sich K. als Sprecher an Programmen der deutschsprachigen Welle der BBC; im Juni 1946 aus dem englischen AntifaKriegsgefangenenlager Ascott entlassen; Rückkehr nach Berlin.

Mitglied der sich in Opposition zu dem von der SED/KPD beherrschten „Freien Deutschen Gewerkschaftsbund" herausbildenden "Unabhängigen Gewerkschafts-Organisation" (UGO) und der SPD, in der er auf dem linken Flügel stand. Seit 1950/51 vorrangiges Engagement in der Gewerkschaft ÖTV; ab 1948 Buchbinder bei der Oberfinanzdirektion Berlin. K. starb am 20. I. 1965 . 
Lamm, Fritz, geboren am 30.6. 1911 in Stettin; Mitglied des „Deutsch-jüdischen Wanderbundes Kameraden “, Buchhändler; 1929 SAJ, SPD, 1930-31 Leiter der SAJ-Gruppe Stettin; 1931 SAP, Mitglied des SJV-Vorstandes Pommern; wegen illegaler Arbeit im Mai 1933 verhaftet und zu 27 Monaten Gefängnis verurteilt, nach neuerlicher Haftandrohung im Januar 1936 mit Hilfe Richard Schmids* Flucht in die Schweiz, von dort abgeschoben nach Prag und im August 1938 nach Frankreich; in Paris als Sekretär von Frizz Sternberg* und Jacob Walcher* in der SAP-Gruppe aktiv; nach Kriegsausbruch bis Dezember I94I Internierung im Lager Vernet; Flucht, 1942-1948 Emigration in Kuba, Arbeit als Diamantenschleifer und Büroangestellter; nach seiner Rückkehr nach Deutschland im November 1948 Verlagsangestellter der „Stuttgarter Zeitung “, 1956-1974 Betriebsratsvorsitzender; 1948 SPD, zeitweise im Stuttgarter Ortsvorstand; 1949 - 1958 zusammen mit Fritz Opel* Herausgeber der Zeitschrift „Funken. Aussprachehefte für internationale sozialistische Politik"; 1963 wegen Förderung des SDS im „Sozialistischen Bund ${ }^{\alpha}$ Ausschluß aus der SPD; Bundeskulturreferent des „Touristenvereins Die Naturfreunde“, in den siebziger Jahren Mitglied des „Sozialistischen Büros ${ }^{\alpha}$ Offenbach a. M.; L. starb am I s. 3. 1977.

Heinrich Schwing (Hrsg.): Fritz Lamm. Stuttgart 1979; Karljosef Kreter: Funken. Aussprachehefte für internationale sozialistische Polirik. Entstehung und Entwicklung einer Zeitschrift der „heimatlosen Linken" in der Ära Adenauer (1950-1959). Unveroffentlichte Staatsexamensarbeit. Göttingen 1980.

Lang, Ema, geb. Demuth, verw. Halbe, geboren am 30.6. 1892 in Hamburg als jüngstes von drei Kindern. Ihr Vater, ein Kürschner (Zurichter), war SPD-Funktionär und Schriftführer im Vorstand des Kürschnerverbands. Im Januar 1912 starb er an Schwindsucht. Erna Demuth wollte nach Abschluß der Volksschule 1907 Lehrerin werden, jedoch langte dazu das Einkommen ihrer Eltern nicht. Ausbildung zur Kindergärtnerin im privaten „Fröbel-Institut $^{\star}$, aktives Mitglied im Sozialdemokratischen Jugendbund, von 1908-1913 Dienstmädchen und Erzieherin erst auf einem Gutshof in Schleswig-Holstein, dann bei einer deutschen Offiziersfamilie in Straßburg. 1913 Rückkehr nach Hamburg, im selben Jahr heiratete sie Max Halbe, einen Funktionär des Jugendbunds, 1914 Geburt ihrer Tochter Herta, später verheiratete Thielcke*. Zusammen mit ihrem Mann engagierte sich Ema Halbe in der SPD, der sie 1910 beigetreten war. Wegen ihrer Ablehnung der Bewilligung der Kriegskredite wurden beide aus der SPD ausgeschlossen. In den folgenden Jahren gehörte Erna Halbe zu den Funktionären der kleinen, aber aktiven Gruppe der Hamburger Linksradikalen, deren ca. 200 Mitglieder sich vor allem aus Werft- und Hafenarbeitern sowie aus Jugendlichen zusammensetzten. Wie zwei weitere Gruppen in Berlin und Braunschweig orientierten sich die Hamburger Linksradikalen an den politischen Positionen der in Bremen von Karl Radek, Johann Knief und Paul Frölich* herausgegebenen Wochenzeitung ${ }_{n}$ Arbeiterpolitik $^{\prime}$; in ihrem Kampf gegen den Krieg und gegen die kapitalistische Gesellschaftsordnung lehnten sie den Parlamentarismus, Parteien und Gewerkschaften ab und sprachen sich für eine Einheitsorganisation und ein konsequentes Rätesystem aus. Auf dem Gründungsparteitag der USPD Ostern 1917 in Gotha begründete Erna Halbe als Delegierte die Ablehnung der Hamburger Linksradikalen, der USPD beizutreten. Wenige Wochen später, Ende Mai, verhaftet und drei Monate lang in sogenannter Sicherungshaft. Nach ihrer Entlassung wandte sie sich erneut der Herstellung und Verbreitung revolutionärer Flugblätter zu, die zum Massenstreik aufriefen. Im März 1918 mit fünf weiteren Genossen verhaftet und als Rädelsführerin zu zweieinhalb Jahren Zuchthaus verurteilt. Ihr Mann, Max Halbe, starb Ende Juni 1918 an den Folgen einer Kriegsverwundung. Ende Oktober aus der Haft entlassen, nahm sie an den Revolutionsereignissen in Hamburg teil und gehörte bis zum April I 9 19 als einzige Frau dem unter Führung der Linksradikalen stehenden 30-köpfigen Arbeiter- und Soldatenrat an. Seit Gründung der KPD in Hamburg Mitglied der Bezirksleitung Wasserkante, ab April 192 I hauptamtliche Angestellte für die Frauenarbeit. Im November 192 I ging Erna Halbe auf Wunsch der KPD-Zentrale nach Magdeburg und übernahm bis I 924 die politische Leitung der KPD in diesem Industriebezirk. Politisch stand sie auf dem 
linken Flügel der KPD, arbeitete eng mit Ruth Fischer und den Hamburger Linken Hugo Urbahns und Ernst Thälmann zusammen. Nach Übernahme der Parteiführung durch die Linken wurde sie 1924 auf dem LX. Parteitag der KPD in Frankfurt a. M. auf Vorschlag von Ruth Fischer zur Reichsfrauenleiterin der KPD gewählt. Die Organisations- und Personalpolitik wie auch die Gründung kommunistischer Richtungsgewerkschaften, die Ruth Fischer während der anderthalb Jahre ihrer Führung propagierte, brachten Erna Halbe eigenen Angaben zufolge zunehmend in Opposition zur linken Fraktion und führten dazu, daß sie sich 1925/26 dem sich herausbildenden rechten Flügel der KPD um Paul Frölich*, Rose (Frölich-)Wolfstein ${ }^{*}$, Hans Tittel*, Heinrich Galm* und Robert Siewert* anschloß. Ende 1927 schied sie aus der Frauenabteilung aus und übernahm die Leitung eines Kinderheims der Roten Hilfe in Eldersburg/Thüringen. Anfang 1929 Ausschluß aus der KPD, dadurch Verlust ihrer Arbeit; von 1930 bis 1932 verdiente sie sich ihren Lebensunterhalt, indem sie in Berlin in Warenhäusern oder von Haus zu Haus für Staubsauger warb. In der KPO mehrfach Mitglied der Reichsleitung, seit 1930 zur Minderheitsfraktion zugehörig, Anfang März 1932 Übertritt zur SAP, auf dem im März 1933 in der Illegalität stattfindenden SAP-Parteitag in Dresden Wahl in die SAP-Reichsleitung. Seit Ende Januar 1933 illegale Arbeit in Berlin, nach einer Haussuchung am 30.5. 1933 verhaftet und bis zum 2.8. "Schutzhaft" im Frauengefängnis in der Ballinstraße. Seit ihrer Freilassung war Erna Halbe zusammen mit Walter Fabian ${ }^{*}$ und Joseph Lang an der Koordinierung der illegalen Abeit der SAP beteiligt, im Juni 1934 wegen unmittelbarer Gefährdung Emigration nach Prag. In der ČSR, wo sie zusammen mit Joseph Lang lebte, leistete Erna Halbe illegale Abeit an der tschechischdeutschen Grenze. Durch die Verhaftung mehrerer Freunde in Berlin erhielt die Gestapo davon Kenntnis und verlangte von der tschechischen Regierung ihre Auslieferung; dies wurde zwar abgelehnt, aber sie wurde „gebeten“, das Land so schnell wie möglich zu verlassen. Daraufhin 1938 über Wien und Zürich nach Paris. Im Mai 1940 interniert, wenig später auf einem Sammeltransport, der in das südfranzösische Lager Gurs führen sollte, freigelassen. Obwohl Erna Halbe und Joseph Lang im Herbst 1940 als politisch Verfolgte und unmittelbar Gefährdete ein amerikanisches Visum erhielten, gestaltete sich die Ausreise als sehr schwierig. Erna Halbe besaß keinerlei Papiere und auch keine Ausreiseerlaubnis. Joseph Lang fuhr im November 1940 nach Lissabon ab, Erna Halbe folgte ihm nach kurzer Zeit, indem sie die Pyrenäen mit einer gefälschten Geburtsurkunde zu Fuß überquerte. Am 14. 12. 1940 trafen beide mit dem Schiff in New York ein. In den USA, wo sie später heirateten, eröffneten Erna und Joseph Lang nach anfänglichen Gelegenheitsarbeiten ein kleines Textilgeschäft. Seit Sommer 1945 zusammen mit politischen Freunden Organisatoren einer Hilfsaktion für verfolgte deutsche Sozialisten. Ende I950 kehrte Erna Lang zusammen mit ihrem Mann nach Deutschland zurück, bis 1954 beruflich beim IRRC Frankfurt tätig. Seit Januar 195 I Mitglied der SPD, war sie bis vor wenigen Jahren politisch aktiv. Erna Lang lebte $198 \mathrm{I}$ in einem Altersheim der Arbeiterwohlfahrt am Frankfurter Stadtwald.

Volker Ullrich: Die Hamburger Arbeiterbewegung vom Vorabend des Ersten Weltkrieges bis zur Revolution 1918/19. 2 Bde. Hamburg 1976; Hermann Weber: Die Wandlung des deutschen Kommunismus. Bd. 2 Frankfurt a.M. 1969; K. H.Tjaden: Struktur und Funktion der „KPD-Opposition" (KPO) Meisenheim am Glan 1965; Hanno Drechsler: Die Sozialistische Arbeiterpartei Deutschlands (SAPD). Meisenheim am Glan r 965 s.

Lang, Joseph, geboren am 5.4. 1902 in einer deutschsprachigen jüdischen Familie in Ungarn. Nach dem Tod seiner Mutter kam er als dreijähriges Kind nach Mainz, wo ihn der Bruder der Mutter an Kindesstatt aufnahm. Er wuchs in einem orthodoxen jüdischen Haus auf und besuchte bis 1918 die Oberrealschule. Anschließend absolvierte er in Frankfurt eine Buchhändlerlehre, seit 1922 in diesem Beruf tätig. 1920 Beitritt zur ultralinken Kommunistischen Arbeiterpartei (KAPD), in der sich in Frankfurt zu dieser Zeit ein großer Teil der kommunistisch gesinnten Jugendlichen organisierte. Später auf dem rechten Flügel der KPD, Funktionär; am I6. I. I929 in Frankfurt aus der KPD ausgeschlossen, in der KPO gehörte er zum 
Führungskreis der Minderheitsfraktion. 1930 ging Joseph Lang nach Berlin und machte sich dort als Buchhändler selbständig. Am 12.1. 1932 zusammen mit sieben anderen maßgeblichen Vertretern der Minderheit wegen Geheimverhandlungen mit der SAP aus der KPO ausgeschlossen, Beitritt zur SAP, 1932 Vorsitzender der Berliner SAP-Ortsgruppe Schöneberg-Friedenau. Nach der Gleichschaltung der Gewerkschaften bildete er eine der ersten legalen Gewerkschaftsgruppen des Zentralverbands der Angestellten in Berlin, im Herbst 1933 - nach Verhaftung der meisten Mitglieder der SAP-Reichsleitung und der Berliner SAP-Bezirksleitung - zusammen mit Walter Fabian* und Ema Halbe Koordinator der illegalen Aubeit der SAP. Am 27. 12. 1933 verhaftet, schwebte Joseph Lang als Jude in großer Gefahr; seine ungarische Staatsangehorigkeit bewahrte ihn jedoch vor der Einweisung in das berüchtigte Columbiahaus. Kurz nach seiner Entlassung pauf Ehrenwort ${ }^{*}$ - seine Teilhaber hatten ihn erfolgreich als Geschäftsinhaber reklamiert -, ging er im Februar 1934 illegal über die tschechische Grenze nach Prag, dort zusammen mit Erna Halbe und Stefan Szende Leiter der 20-30-köpfigen SAP-Gruppe. Berufliche Tätigkeit als Buchhändler, Vertreter der deutschsprachigen Verlage Oprecht-Zürich, Allert de Lange-Amsterdam und Bermann-Fischer-Stockholm in der CSR und im westeuropäischen Ausland, durch beruflich bedingte Reisen in direktem Kontakt mit der SAP-Auslandszentrale in Paris. 1938 Übersiedlung nach Paris, dort verdiente er seinen Lebensunterhalt, indem er mittels eines Bauchladens Bücher an deutsche und osterreichische Emigranten verlieh. Im November 1940 mit einem amerikanischen Notvisum Ausreise aus Frankreich, zusammen mit Erna Halbe über Lissabon in die USA. In New York Inhaber eines kleinen Textilgeschäfts, politisch aktiv in der deutschsprachigen Abteilung des "Workmen's Circle .

I950 Rückkehr nach Deutschland, Anfang 195 I in Frankfurt Mitglied der SPD, 1952 Leiter der Buchhandlung des Bund-Verlages im Frankfurter Gewerkschafishaus, die unter seiner Führung zum Treffpunkt von Gewerkschaftern, Verlegern und Politikern weit über Frankfurt hinaus wurde. Seit 1957 ununterbrochen im Vorstand des SPD-Unterbezirks Frankfurt, davon viele Jahre als stellvertretender Vorsitzender neben Walter Möller, zugleich leitete er den SPD-Ortsverein Frankfurt-Sachsenhausen. Seit 1967 im Ruhestand, spielte Joseph Lang bis zu seinem Tod am 10.9. 1973 in der Frankfurter und in der südhessischen SPD eine maßgebliche Rolle.

Hanno Drechsler: Die Sozialistische Arbeiterpartei Deutschlands (SAPD). Meisenheim am Glan 1965; Jörg Bremer: Die Sozialistische Arbeiterpartei Deutschlands (SAP). Untergrund und Exil 1933-45. Frankfurt a. M. 1978; Joseph Lang 1902-1973 (Reden aus Anlaß der Trauerfeier am 18.9. 1973). Broschüre, hrsg. vom Unterbezirk Frankfurt der SPD. Frankfurt a.M. o. J. [1973].

Lewy, Fritz, der Bruder von Ruth Seydewitz, gehörte in den zwanziger Jahren der „Klassenkampf"-Gruppe in der SPD an . I93 I Mitbegründer der SAP und leitender Redakteur der SAP-Wochenzeitschrift „Das Kampfsignal“. I 933 floh Lewy in die CSR, später wurde er bei einer Kurierfahrt in Deutschland festgenommen und im KZ Hohenstein inhaftiert. I940 Emigration in die USA.

Lewinski, Erich (1899-1956), Rechtsanwalt in Kassel, Mitglied des ISK; nach 1933 Emigration nach Frankreich, in Paris Inhaber eines vegetarischen Restaurants, u. a. zur Finanzierung der ISK-Exilgruppe; 1940/1941 organisierte Lewinski mit Fritz Heine und in Zusam-

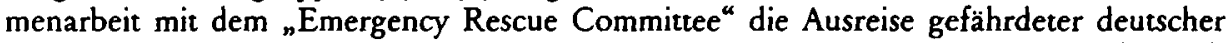
Emigranten in die USA; seit 1941 Büroangestellter in New York; 1947 Rückkehr nach Deutschland; 1949-1956 Landesgerichts-Präsident in Kassel.

Biographisches Handbuch der deutschsprachigen Emigration nach 1933. Bd. I. München 1980.

Linder, Willi, geboren am 15. I. 1902 in Gräfrath bei Solingen. Der sozialdemokratisch eingestellte Vater war von Beruf Schleifer, die Mutter Hausfrau. Im Anschluß an die Volks- 
schule begann L. eine Lehre als Ausmacher. Wegen des Kriegsdienstes seines Lehrmeisters konnte er diese jedoch nicht beenden. Er arbeitete als Schleifer in der Solinger Metallwarenindustrie. Seit 1919 im DMV, Branchenleiter der Schenkelspließter, Obmann der Erwerbslosen im ADGB; 1923-1929 KPD, Mitglied der Ortsleitung Solingen. Neben seinem gewerkschaftlichen und parteipolitischen Engagement gehörte L. dem Vorstand der Allgemeinen Ortskrankenkasse und dem KPD-nahen „Internationalen Bund der Opfer des Krieges und der Arbeit “ an, im Rahmen des „Bundes“ war er Sachbearbeiter für Invaliden- und Unfallangelegenheiten; Mitglied des Arbeitergesangvereins „Zukunft“. 1929 wurde L. aus der KPD ausgeschlossen und trat der KPO bei. 1928 erkrankte er an Tuberkulose und wurde erwerbsunfähig, bis 1933 stand er in ärztlicher Behandlung. Danach erwerbslos, ab 1936 Pflicht- und Fürsorgearbeit, seit 1938 Beschäftigung als Teerstraßenarbeiter. Am 23.8. 1938 wurde L. wegen des Verdachts der Vorbereitung zum Hochverrat festgenommen. Der einzige Anklagepunkt bestand darin, daß er im Sommer 1933 illegale Schriften von einer für die KPD tätigen Person gekauft und sie an seinen Gartennachbarn weitergegeben hatte. Wegen dieses „Delikts“ wurde er am 24. 10. 1938 vom Oberlandesgericht Hamm zu einem Jahr und dreí Monaten Gefängnis verurteilt. Nach der Entlassung aus der Haft Arbeit als Gärner; seit April 1942 Soldat.

1945 Rückkehr nach Solingen; Mitglied der Gewerkschaft Landwirtschaft und Forsten, Ende der vierziger Jahre der SPD. 1946 machte sich L. als Gärtner selbständig. Wegen einer Magenerkrankung konnte er jedoch bald nicht mehr arbeiten und gab die Gärtnerei 195I auf. L. starb r959.

Löwendahl Hans, geboren r9os, jüdischer Herkunf, Jurist, gehörte seit Mitte der zwanziger Jahre der "Kommunistischen Studentenfraktion “ in Frankfurt a. M. an; in den Jahren 1933-1935 maßgeblich am Aufbau der illegalen KPO-Organisation im Rheinland beteiligt, danach als Mitglied und Kurier der KPO-Reichsleitung tätig; am 23. I. 1937 verhaftet; die Gestapo fand heraus, daß er homosexuell war und legte einen anderen Homosexuellen in seine Zelle, der ein Spitzel war. Über diesen und durch Erpressungen gewonnene Angaben war es der Gestapo möglich, die KPO-Reichsleitung sowie eine größere Zahl von Bezirksleitungen und illegal tätige Mitglieder in ganz Deutschland zu verhaften. L. wurde am IO. I I. 1937 vom 2. Senat des Volksgerichtshofes zu einer hohen Freiheitsstrafe verurteilt, er kam später in einem $\mathrm{KZ}$ ums Leben.

Löwenthal Fritz, geboren am i5. II. 1888, Rechtsanwalt; 1928 Mitglied der KPD; 1930-1932 MdR; 1933 Emigration in die Sowjetunion; 1946 Leiter der Abteilung Justizaufsicht der Zentralverwaltung für Justiz in der SBZ; im Mai 1947 Flucht nach Westdeutschland, SPD, Mitglied des Parlamentarischen Rates.

Löwenthal, Richard (Pseudonym: Paul Sering), geboren am 15.4. 1908 in Berlin als Sohn eines Handelsvertreters, 1926-1931 Studium der Nationalökonomie und Soziologie; 1926 Mitglied, 1928 Reichsleiter der „Kommunistischen Studentenfraktion“; 1929 Abwendung von der KPD und Parteiausschluß, I929-1931 KPO; nach 1933 als Theoretiker und Berliner Leitungsmitglied maßgeblich am Aufbau illegaler Kader der Gruppe „Neu Beginnen“ beteiligt, im August 1935 Emigration in die CSR, in Prag zusammen mit Karl Frank" Leiter des „Neu Beginnen“-Auslandsbüros; $1936 / 37$ in London und 1938 in Paris vollzog L. durch die Aufgabe des Konzepts eines „demokratischen“ Zentralismus und einer Erziehungsdiktatur des Proletariats eine Annäherung an den Austromarxismus und an traditionelle politische Positionen der linken Sozialdemokratie; im Sommer 1939 mit dem „Neu Beginnen“Büro nach London, nach Kriegsausbruch einer der Redakteure der "Reports from Inside Germany". Im Hinblick auf die Kriegsziele der Alliierten propagierte L. I94 I die "deutsche Revolution zwischen den Weltmächten“ und die Beteiligung der UdSSR an der Neuordnung Europas, um eine Restaurierung der kapitalistischen Gesellschaftsordnung zu verhin- 
dern. Die Polenpolitik der Sowjetunion $1943 / 44$ bewirkte dann eine Revision seiner politischen Perspektiven; in der 1946 unter dem Pseudonym Paul Sering erschienenen einflußreichen theoretischen Studie über einen demokratischen Sozialismus "Jenseits des Kapitalismus " trat er für tiefgreifende Strukturreformen in Zusammenarbeit mit und in Anlehnung vor allem an die britische und amerikanische Arbeiterbewegung ein. 1945 Mitglied der SPD, 1948-1958 Deutschlandkorrespondent verschiedener englischer Agenturen und Zeitschriften; 1961 Professor für Politikwissenschaft am Otto-Suhr-Institut Berlin, später Direktor des Osteuropa-Instituts der Freien Universität Berlin; Ende der sechziger Jahre einer der Initiatoren, 1970-1973 Vorstandsmitglied des konservativen „Bundes Freiheit der Wissenschaft", seit seiner Emeritierung 1974 freier Publizist, Mitglied der Grundwerte-Kommission der SPD.

Biographisches Handbuch der deutschsprachigen Emigration nach 1933. Bd. I. München 1980.

Lüscher, Erwin, geboren 1905, ein schweizer Lehrer und Sozialdemokrat, unterstlitzte die SAP-Gruppe in Basel bei der illegalen Arbeit; am 27. 5. 1939 wurde er von einem Verräter auf deutschen Boden gelockt und verhaftet; am 18 . 5. 1940 vom Oberlandesgericht Stuttgart zu funf Jahren Zuchthaus verurteilt; wie Richard Schmid war Lüscher im Zuchthaus Ludwigsburg inhaftiert.

Märten, Lu, geboren am 24.9. 1879 in Berlin-Charlottenburg. Der Vater, der jüngste Sohn einer Bauernfamilie, war Berufssoldat und später kleiner Beamter bei der Reichsbahn. Als einziges von fünf Kindern übertebte M. eine Tbc. Der Besuch einer Schule war ihr aufgrund ihrer Krankheit nur sporadisch möglich. Ohne Schulabschluß, bildete sie sich autodidaktisch weiter, besonders in den Bereichen Philosophie, Kunsttheorie, Geschichte der Arbeiterbewegung, Marxismus. 1898 trat M. der SPD bei. Vom Krankenbett aus begann sie, Artikel für linksbürgerliche und sozialdemokratische Zeitschriften und Zeitungen zu schreiben. Sie hatte schnell Erfolg; seit 1902 veroffentlichte sie Beiträge überwiegend zu literarischen Themen und zur proletarischen Frauenbewegung im "Vorwärts", in der "Neuen Zeit ${ }^{*}$, im Wiener ${ }_{n} \mathrm{Kampf}^{*}$, in der "Gleichheit ${ }^{*}$ und in der in München und Leipzig erscheinenden „Frauen-Zukunft". Neben Gedichten erschien 1909 ihr Arbeiterdrama "Bergarbeiter", das von Vertretern der SPD-Linken wie Franz Mehring und Clara Zetkin überschwenglichpositiv rezensiert wurde, im selben Jahr der autobiographische Roman „Torso ${ }^{\text {, }}$, der ein beeindruckendes Bild von ihrer Kindheit und Jugend vermittelt. Die Fülle der von ihr verfaßten Zeitungs- und Zeitschriftenartikel läßt vermuten, daß sie sich ihren Lebensunterhalt als freie Journalistin verdiente. Vor 1914 heiratete sie den Bildhauer Wilhelm Repsold. Während des Ersten Weltkrieges lebte sie aus Gesundheitsgründen längere Zeit in der Schweiz. 1920 wurde M. Mitglied der KPD. In den folgenden Jahren veröffentlichte sie Artikel im KPD-Zentralorgan "Die Rote Fahne ${ }^{\star 1920-1921), ~ i n ~ d e r ~ " A r b e i t e r-L i t e r a t u r ~}{ }^{4}$ Wien (1924), in der von Franz Pfemfert herausgegebenen Zeitschrift "Die Aktion" (1925-1927) sowie seit 1927 in „Die Bücherwarte und in "Die neue Bücherschau“. 1924 erschien ihre bedeutende, 1973 in der Bundesrepublik neu aufgelegte literatursoziologische Studie „Wesen und Veränderung der Formen (Künste). Resultate historisch-materialistischer Untersuchungen", in der sie sich um eine eigenständig-kritische Anwendung marxistischer Untersuchungsmethoden auf die Kunst bemühte. Eine sozialistische Tendenzkunst lehnte $M$. vehement ab. Um 1927 geschieden. Seit Mitte der zwanziger Jahre war M. im Rahmen einer Hilfsaktion der Stadt Berlin für notleidende Künstler beschäftigt, von 1928 bis zum März 1930 in verschiedenen städtischen Bibliotheken. Seitdem arbeitete sie an einer „Bibliographie des gesamten Sozialismus aller Länder von I 547 bis zur Gegenwart ${ }^{\alpha}$, die 1933 mit finanzieller Unterstützung der Stadt Berlin gedruckt werden sollte. Die Machtübernahme durch die Nationalsozialisten verhinderte dies, doch konnte das Manuskript nach Schweden in Sicherheit gebracht werden. 
I 933 gehörte M. zu den Autoren, deren Bücher verbrannt wurden. Ihren Lebensunterhalt verdiente sie sich in den dreißiger Jahren durch Zimmervermittlung an in- und ausländische Studenten sowie durch Hauskurse über Marxismus, Kunst etc. Vor 1939 mehrere Aufenthalte in Schweden. Ohne an eine Veröffentlichung zu denken, schrieb sie Filmmanuskripte, Schauspiele und einen Roman; 1943-1944 wissenschaftliche Hilfskraft in der Berliner Staatsbibliothek.

1945 trat M. erneut der KPD bei. Wie lange sie Mitglied der KPD/SED blieb, ist nicht zu kJären. Seit 1946 arbeitete sie als externe Gutachterin für den Ostberliner Verlag „Volk und Wissen“. Zugleich überarbeitete sie ihr in der Weimarer KPD nicht unumstrittenes Buch „Wesen und Veränderung der Formen (Künste)", das Karl August Wittfogel 193 I in der Literaturzeitschrift "Die Linkskurve" als "trockistisch", „undialekrisch" und als "formalistische Barbarei “ abqualifiziert hatte, für einen studentischen Leserkreis. Die veränderte Neuauflage erschien 1949 in Weimar. Danach kaum noch Veröffentlichungen. Die „Bibliographie des gesamten Sozialismus", die Arbeit "Die Stellung der Frau in der Geschichte. Vom Mutterrecht bis zur Gegenwart", eine Biographie des Naturkundlers und Mainzer Revolutionärs Georg Forster, auf deren Bedeutung 1956 in der DDR-Zeitschrift „Neue Deutsche Literatur" noch einmal hingewiesen wurde, blieben unveröffentlicht. Bis zu ihrem Tode am 1 2.8. I 970 lebte M. fast völlig isoliert in Westberlin. Erst neuere wissenschaftliche Untersuchungen über die sozialistische Literatur und Arbeiterdramatik in Deutschland versuchen, die „bedauernswerte Vernachlässigung dieser außergewöhnlichen sozialistischen Schriftstellerin und Denkerin “ (Trempenau) zu überwinden. Der Nachlaß von Lu Märten, der zahlreiche Romane, Erzählungen, Gedichte u.a. enthält, befindet sich im Internationalen Institut für Sozialgeschichte in Amsterdam.

Lu Märten. In: Lexikon deutschsprachiger Schriftsteller von den Anfängen bis zur Gegenwart. 2 Bde. 2. überarbeitete Auflage Leipzig 1972-1974; Lu Märten-Bio-Bibliografie. In: alternative, H.89, April 1973; Gertrud Meyer-Hepner: Lu Märten. In: NDL Neue Deutsche Literatur, 4.Jg. 1956, H.4, S. I 5 I-1 53 ; Helga Gallas: Marxistische Literaturtheorie. Kontroversen im Bund proletarisch-revolutionärer Schriftsteller. Neuwied 1971; Manfred Brauneck: Die Rote Fahne, Kritik. Theorie, Feuilleton 1918-1933. München 1973; Frank Trommler: Sozialistische Literatur in Deutschland. Ein historischer Überblick. Stuttgart 1976; Dietmar Trempenau: Frühe sozialdemokratische und sozialistische Arbeiterdramatik (1890-1914). Stuttgart 1979; Lu Märten: Formen für den Alltag. Schriften, Aufsätze, Vorträge. Auswahl, Kommentare, Bibliographie und Nachwort v. Rainhard May. Dresden 1982.

Mager, Otto Wemer, geboren am 7. 1 2. 1914 in Dresden als ältester Sohn eines sozialdemokratischen Maurers; ein Bruder. M. besuchte die Volksschule und begann 1929 eine Schlosserlehre im Reichsbahn-Ausbesserungswerk in Dresden. 1929 Mitglied der SAJ, I 93 I ausgeschlossen, Beitritt zum SJV, der mit fast I 000 Mitgliedern die SAP in Dresden zahlenmäßig übertraf; 1932 Vorsitzender der Eisenbahnerjugend Dresden.

Wegen seiner feindlichen Einstellung gegenüber den Nationalsozialisten wurde $M$. nach Ablauf der Lehrzeit im März 1933 von der Reichsbahn entlassen; arbeitslos; im August wegen illegaler Arbeit verhaftet und von einem Sondergericht in Freiberg/Sachsen zu einer 16-monatigen Gefängnisstrafe verurteilt. Nach Verbüßung der Haft in Dresden und Bautzen stand er unter polizeilicher Aufsicht. 1935 Arbeitsdienst, 1936-1937 Werkzeugschleifer in einer Nähmaschinenfabrik. Im November 1937 wurde M. zur Militärausbildung eingezogen, 1939-1945 Soldat.

Bei Kriegsende wurde $M$. in Oberbayern von den Amerikanern kurz interniert. Seit Juni I 945 arbeitete er als Landarbeiter.

Angesichts des Zerstörungsgrades seiner Heimatstadt entschied er sich gegen eine Rückkehr nach Dresden. Er fand eine Anstellung in einem Bamberger Elektrobetrieb und war bis 1948 Betriebsratsvorsitzender. 1946 oder 1947 wurde M. Mitglied der KPD. 1948 heiratete er. Im Februar 1948 1. Vorsitzender der Ortsverwaltung der IG-Metall, seit November Bevollmächtigter und Kassierer. I950 trat M. zur SPD über. In den fünfziger, sechziger und 
siebziger Jahren übte er neben seinem Beruf mehrere ehrenamtliche Tätigkeiten aus: seit 1952 war er Arbeitsrichter beim Arbeitsgericht Bamberg, seit 1955 Landessozialrichter beim Bayerischen Landessozialgericht, seit 1957 im Verwaltungsausschuß des Arbeitsamtes Bamberg. Weiterhin führte er den Vorsitz im Ortsausschuß der Allgemeinen Ortskrankenkasse (AOK). M. starb am 1.9. 1977.

Markscheffel Günter, geboren am 16. I I. 1908 in Gleiwitz; Journalist, bis 1933 Lokalredakteur der SPD-Zeitung „Waldenburger Bergwacht ${ }^{\text {; }}$ i 933 nach einem Zusammenstoß mit der SA Flucht ins Saargebiet; seit 1936 Emigration in Frankreich, in Paris Montagelehre, 1936-1938 Vorsizzender der SAJ Paris, ab Januar 1938 Vorstandsmitglied des „Landesverbandes Deutscher Sozialdemokraten “ in Frankreich; 1939 interniert, 1940-1944 in Südfrankreich im Untergrund; 1945 als Sekretär der neugegrlindeten SPD-Landesgruppe in Opposition zu Einheitsfrontbestrebungen mit der KPD. Im Dezember 1945 Rückkehr nach Deutschland; ab 1947 Chefredakteur der SPD-Zeitung „Die Freiheit " in Mainz, 1948-1957 SPD-Bezirksvorsitzender Rheinhessen, MdL, 1957-1970 Chefredakteur des "Sozialdemokratischen Pressedienstes ${ }^{\alpha}$; $1970-1974$ persönlicher Referent von Bundespräsident Gustav Heinemann. M. lebte 1977 in Bonn.

Biographisches Handbuch der deutschsprachigen Emigration nach 1933. Bd. 1. München 1980.

Marx, Franz, geboren am 26. 1. 1903 in Köln. Der Vater, ein gelernter Kesselschmied, war Angestellter des DMV, Sekretär der SPD in Bonn und Abgeordneter des Preußischen Landtags; drei Geschwister; 1917 Beginn einer Lehre als Maschinenschlosser in Düsseldorf. Mit vierzehn Jahren trat er dem DMV bei, 1917/1918 war er einer der Gründer der Düsseldorfer Gewerkschaftsjugend; seit 1919 Maschinenschlosser in Bonn, Mitglied der AJ und der SPD. 1920 wurde er Vorsitzender der AJ, 1923 der Bonner Jungsozialisten. Im selben Jahr mußte M. Bonn verlassen, da er von der französischen Militärpolizei als Gegner der Besatzungspolitik und der Separationsbestrebungen im Rheinland gesucht wurde. Daraufhin ging er nach München, dort war er erneut in seinem Beruf tätig. Anfang 1924 nahm er an einem sechsmonatigen Kursus der Heimvolksschule Tinz in Thüringen teil; anschließend ehrenamtlicher Jugendleiter der Münchener Gewerkschaften. 1925 schied M. noch einmal aus dem Arbeitsleben aus. Bis zum Frühjahr 1927 hörte er Vorlesungen an der Universität Bonn, seinen Lebensunterhalt finanzierte er während dieser Zeit durch Vortragstätigkeit. Von 1927 bis 1930 arbeitete er bei der Fa. Maffei, danach war er arbeitslos, bis er 1932 eine Anstellung bei den Bayerischen Motoren Werken fand. Nachdem er Anhänger des Göttinger Philosophen Leonard Nelson kennengelernt hatte, trat M. 1927 aus der SPD aus und übernahm die Leitung der 10-20 Mitglieder starken Münchener ISK-Gruppe. 193 I schloß er sich der SAP an, die in München ebenfalls nur wenige Mitglieder zählte.

Seit dem Frühjahr 1933 war M. illegal tätig. Wenige Wochen nach einer Feier zum I. Mai 1933 im Perlacher Forst, zu der die SAP-Gruppe einige hundert Exemplare der Zeitung "Der Marxist" verteilt hatte, wurde er zusammen mit neun weiteren SAP-Mitgliedern verhaftet. Er kam ins KZ Dachau, wurde aber nach einigen Monaten von einem Sondergericht mit der Begründung freigesprochen, das am 14.7. 1933 erlassene „Gesetz gegen die Neubildung von Parteien" dürfe nicht rückwirkend angewandt werden. Die Münchener SAPGruppe setzte ihre illegale Arbeit bis 1937/1938 fort. Über Albert Heinzinger und Josef Hermannsthaler, die der fünfköpfigen Leitung angehörten, bestanden Verbindungen zu anderen SAP-Gruppen und zur SAP- ${ }_{-} Z_{\text {Zntrale }}{ }^{*}$ für Südwestdeutschland in Mannheim (vgl. die Biographie von Gustav Roos*). Öffentliche Aktionen lehnte die Münchener SAP als wenig erfolgversprechend und als zu gefährlich ab. Trotz dieser Vorsicht gelang es der Gestapo 1935, einen Spitzel einzuschleusen; aufgrund seiner Informationen wurden 1937 mehrere SAP-Mitglieder festgenommen. Mit der Verhaftung Heinzingers und Hermannsthalers - im Anschluß an die Zerschlagung der SAP Mannheim - im November 1938 hörte die illegale Gruppe auf zu bestehen. 
M. war im Juli 1934 aufgrund einer Denunziation zum zweiten Mal verhaftet und acht Wochen lang festgehalten worden. In dieser und auch in späteren nicht ungefährlichen Situationen kam ihm seine berufliche Qualifikation zugute. 1934 opponierte die Gestapo gegen seine Wieder-Einstellung bei BMW, wegen des akuten Facharbeitermangels konnte sie sich jedoch nicht durchsetzen. 1937 wurde M. entlassen und für alle Rüstungsbetriebe gesperrt, doch fand er einige Monate später eine Tätigkeit als Spezialist für amerikanische Werkzeugmaschinen bei den Ford-Werken in Köln. In dieser betrieblichen Schlüsselstellung war er gegen Repressalien relativ gesichert und im Krieg unabkommlich. Erst im Dezember 1944 erhielt er einen Einberufungsbefehl, er befolgte ihn jedoch nicht und tauchte bis zum Einmarsch der Amerikaner Anfang März 1945 unter.

Bereits im Mărz/April bemühte sich M. zusammen mit den Gewerkschaftern Hans Böckler und Werner Hansen um einen organisatorischen Zusammenhalt der Sozialdemokraten im rechtsrheinischen Köln. Im Juli 1945 wurde er Bezirkssekretär der SPD Oberrhein, als solcher nahm er am 5./6. 10. an der ersten überregionalen Nachkriegskonferenz der SPD der Westzonen in Wennigsen teil. 1946 kehrte M. nach München zurück. Er wurde Sekretär und 1948 geschäftsführender Vorsitzender der SPD München. 1946-1949 Abgeordneter im Bayerischen Landtag. Seit Ende der vierziger Jahre gehörte M. zur Führungsgruppe der bayerischen SPD: er war Mitglied des Landesausschusses und 1952-1976 Vorsitzender des SPD-Bezirks Südbayern. 1949-1973 Mitglied des Deutschen Bundestages, langjähriger Abgeordneter des Europaparlaments, danach wieder in der Münchener SPD aktiv. M. lebte 1980 in München.

Möller, Hans (1908-1978), Heizer, 1928-1930 ISK; seit Oktober 1931 Mitglied des Dortmunder SJV und der SAP. I 933 übernahm Moller die Leitung der illegalen SAP im Bezirk Westfalen. Am 30.10. 1934 wurde er verhaftet und am 29.7. 1935 vor dem Oberlandesgericht Hamm wegen Vorbereitung zum Hochverrat zu acht Jahren Zuchthaus verurteilt; nach Verbüßung der Haft in verschiedenen KZs; im Sommer 1944 Soldat in der Strafeinheit SS-Division Dirlewanger, ging er im Dezember 1944 zur Roten Armee über. Im Herbst I945 kehrte er über russische und amerikanische Gefangenschaft, noch knapp achtzig Pfund wiegend, nach Dortmund zurück. Nach 1945 SPD-Funktionär.

Widerstand und Verfolgung in Dortmund. 1933-1945. Katalog der ständigen Ausstellung. Dortmund 1981 .

Molz, Bembard, geboren am I I. I. 1905 in Elberfeld. Der Vater leitete in den zwanziger Jahren eine Druckerei der KPD, die Mutter war Hausfrau. Als dreijähriges Kind kam M. mit einer schweren Kinderlähmung ins Krankenhaus, seitdem mußte er eine Schiene am linken Bein tragen. Volksschule, Friseurlehre, im Anschluß daran verschiedene Tätigkeiten als Friseur, Leimsieder und Rohrzieher; 1920 Mitglied des KJVD, 1924 der KPD. Durch die KPD erhielt er eine Anstellung als Inseratenbuchhalter bei der kommunistischen Zeitung „Arbeitertribüne ${ }^{\alpha}$ in Krefeld. Diese Stelle verlor er 1926, als der Verlag aufgelöst wurde; im Frühjahr 1928 Filialleiter der KPD-Zeitung "Volksstimme " in Koblenz. Im Sommer 1929 wurde M. aus der KPD ausgeschlossen, Ende des Jahres verzog er nach Köln und trat dort der KPO bei; seit 193 I erwerbslos, 1932 Umzug nach Schwelm.

Seit dem Frühjahr 1933 arbeitete M. in der illegalen KPO im Ruhrgebiet unter der Leitung von Dagobert Lubinski, Düsseldorf. Als Leiter der Gruppe Schwelm unterhielt er regelmäBige Kontakte u.a. zu Ludwig A. Jacobsen* in Köln. Wie Lubinski näherte sich M. 1936 der $\mathrm{KPD}$ an und befürwortete die Rückgliederung der KPO in die KPD. Bei der Zerschlagung der illegalen $\mathrm{KPO}$ im Ruhrgebiet wurde auch M. am 28.4. 1937 verhaftet. Am 3.6. 1938 wurde er vom Oberlandesgericht $\mathrm{Hamm}$ im Prozeß gegen Lubinski und 57 weitere Angeklagte zu sieben Jahren Zuchthaus verurteilt. Konzentrationslager Buchenwald. Nach Kriegsende fand M. eine Arbeit als Angestellter im Bauamt der Stadt Schwelm. In den fünfziger Jahren qualifizierte er sich für die Beamtenlaufbahn und wurde später Steuerober- 
inspektor. Mitglied der KPD, später der SPD, gewerkschaftlich war er in der ÖTV organisiert. 1967 wurde M. wegen einer Erkrankung an Magenkrebs vorzeitig pensioniert. Er starb am 12.6. 1975.

Müller, Georg (1902-1967), Rohrleger und Klempner, Bruder von Karl Müller*; in der Weimarer Republik Mitglied der KPD und der KPO; nach 1933 Widerstand im Rahmen der Gruppe „Neu Beginnen“, zweieinhalb Jahre im Zuchthaus. 1945/1946 Schulungssekretär beim FDGB in Berlin-Lichtenberg, war Müller 1947 und 1948 maßgeblich an der Gründung einer SED-unabhăngigen Gewerkschaftsopposition beteiligt; 1948 Vorsitzender der Arbeitsgemeinschaft der „Unabhăngigen Gewerkschaftsopposition (UGO) und Betriebssekretär der Berliner SPD, spăter Rechtsbeistand beim DGB in Berlin-West.

Müller, Karh geboren am 16.8. 1903 in Rathenow/Havel als drittes von fünf Kindern. Der Vater war Klempner. M. besuchte die Volksschule. 1917 kam er von Berlin aus, wo die Familie inzwischen lebte, mit einem Kindertransport zur Erholung ins neutrale Dänemark, dort wurde er von einer dänischen Familie aufgenommen. Die finanzielle Forderung seitens dieser Familie ermöglichte ihm später den Besuch einer Privatschule für Bauingenieure. Ausbildung zum Zahnradtechniker, seit 1923 Tätigkeit in diesem Beruf. Als Jugendlicher gehörte M. dem KJVD an, 1921 Mitglied der KPD, 1929 der KPO. Ob er sich später der SAP anschloß, ließ sich nicht ermitteln. 1931 -1934 arbeitslos.

Seit dem Frühjahr 1933 fanden bei M. illegale Zusammenkünfte statt. Nach zwei Hausdurchsuchungen wurden diese 1934 als zu gefährlich abgebrochen. Seit 1934 Arbeit als technischer Angestellter, seit 1936 als Ingenieur. Wegen seiner Beschäftigung in einer Akkumulatorenfabrik wurde $M$. im Krieg unabkommlich gestellt; seine Frau und seine zwei Kinder wurden 1943 wegen der Luftangriffe nach Schlesien evakuiert.

1945 Mitglied der KPD, seit 1945/1946 Angestellter bei der Fahrbereitschaft der Sowjetischen Militäradministration (SMA) in Berlin-Treptow. Obwohl er im Ostsektor der Stadt wohnte und arbeitete, schloß sich M. 1947 in Westberlin der SPD an. 1948 verlor er seinen Arbeitsplatz bei der SMA, da er sich weigerte, eine Erklärung gegen die Währungsreform in den Westzonen zu unterschreiben. Seit Mărz 1949 Tiefbauingenieur bei der Westberliner Stadtentwässerung, 1953 als Beamter; 1956 fluchtartige Ubersiedlung in die Westsektoren Berlins; Anfang der sechziger Jahre Austritt aus der SPD. 1964 wurde M. nach einem Schlaganfall pensioniert. Er starb am 28.6. 197 I.

Nageh, Fritz, geboren am 27.9. 1897 in Brieg/Schlesien. Der Vater war Arbeiter in einer Drahtseilerei und politisch kaisertreu-national eingestellt, die Mutter arbeitete als Wäscherin und Putzfrau; neun Geschwister. Nach der Volksschule erlernte N. in einer vierjährigen Lehre das Buchdrucker-Handwerk. Von 1914 bis 1918 war er Soldat bei der Artillerie in Flandern. Unter dem Eindruck des Krieges, in den er 1914 mit Begeisterung gezogen war, wurde N. Sozialist. 1919 trat er der SPD bei und wurde Mitglied des „Zentralverbands proletarischer Freidenker" ${ }^{\text {“ }} 1922$ heiratete er, aus der Ehe gingen bis 1927 drei Kinder hervor; von 1924 bis 1933 Stadtverordneter in Brieg. Wegen seiner politischen Tätigkeit mußte er schwere berufliche Benachteiligungen hinnehmen; die Qualifizierung zum Meister wurde ihm verweigert, Mitte der zwanziger Jahre verlor er im Anschluß an einen Streik, den er geleitet hatte, seine Arbeit. Danach war er mehrere Jahre arbeitslos, bis ihn die Gemeinde Brieg als Gasableser einstellte. Neben der Kommunal- und Parteiarbeit engagierte sich $\mathrm{N}$. vor allem in der Jugend- und Arbeiterbildung. Die Gründung der Brieger Volkshochschule ging im wesentlichen auf ihn zurück. 1931 Mitglied der SAP. Nach der Machtübernahme durch die Nationalsozialisten wurde N. als Gemeindeangestellter entlassen und war bis 1936 arbeitslos. Etwas Geld verdiente er als Hausierer und Obstverkäufer. Seit 1933 führte er die SAP in Brieg und Umgebung in enger Zusammenarbeit mit der illegalen Bezirksleitung in der SAP-Hochburg Breslau fort.

Dort hatten sich im Oktober 1931 große Teile der SPD der neugegründeten SAP ange- 
schlossen : der langjährige Breslauer SPD-Vorsitzende Dr. Ernst Eckstein*, der Parteisekretär Max Rausch, der Breslauer Reichstagsabgeordnete Hans Ziegler", 16 von 34 Stadtverordneten sowie fast alle Mitglieder der SAJ und der Jungsozialisten. Nach der Verhaftung

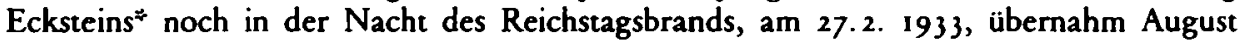
Enderle $^{*}$ die Leitung des rund 3000 Mitglieder zählenden Bezirksverbands. Seit dem Verbot der Parteizeitung „SAZ - Sozialistische Arbeiter Zeitung " am 28. 2. gab die illegale SAP ein Mitteilungsblatt heraus, von dem wöchentlich 3-5 $\infty$ Exemplare erschienen. Diese breite und wenig konspirative Massenarbeit mit ihrem Höhepunkt nach der Ermordung Ernst Ecksteins* am 7.5. 1933 wurde der Breslauer SAP zum Verhängnis. Erkenntnisse, die die Gestapo mittels Folterungen gewonnen hatte, führten Mitte Juli zur Verhaftung von etwa 20 SAP-Funktionären; August Enderle gelang die Flucht. Das Mitglieder-Reservoir der SAP war in Breslau jedoch so groß, daß die illegale Arbeit nach einer kurzen Unterbrechung unter Leitung des Buchdruckers Willi Kalinke fortgesetzt werden konnte. Das Ende des organisierten Widerstandes der SAP in Schlesien kam 1936: In Breslau wurden Anfang 193622 Stadtteil- und Gruppenleiter verhaftet. Auch N. wurde im Zusammenhang mit dieser Verhafungswelle am 2.4. 1936 festgenommen und im Frühjahr I 937 in einem SAP-ProzeB vor dem Oberlandesgericht Breslau zu drei Jahren Zuchthaus und "Ehrverlust" verurteilt. Bis zum April 1939 war er im Zuchthaus Brandenburg-Görden und im Arbeitslager Dessau-Rosslau inhaftiert. Seine Frau Helene entging 1936 nur wegen ihrer Kinder der Verhaftung, bis 1939 wurde sie ständig überwacht. In dieser Zeit erhielt sie von staatlichen Stellen pro Monat RM I 4,20 Unterstützung. Nach dem 20. Juli 1944 wurde $\mathrm{N}$. erneut verhaftet und in das KZ Groß-Rosen gebracht. Bei der Evakuierung des Konzentrationslagers im Februar I945 wurde er in ein Lager des SS-Arbeitskommandos Hersbruck bei Nürnberg überstellt. Von dort kam er nach Dachau, wo er am 29.4. I945 zusammen mit mehr als 30000 Häftlingen aus 3 I Ländern von amerikanischen Truppen befreit wurde. Da er an Hungertyphus litt und wegen einer Zertrümmerung des Schambeins, die er sich während seiner Haft in den Jahren 1936-1939 zugezogen hatte, schwer körperbehinder war, wurde er in ein Bamberger Krankenhaus eingewiesen.

In Bamberg traf er im Frühjahr 1946 seine Familie, die aus Schlesien ausgewiesen worden war, wieder. N. wurde Kassenleiter im Arbeitsamt. Trotz seiner körperlichen Behinderung - er konnte sich nur mit Hilfe von Krücken fortbewegen - war er äußerst aktiv. Seine Frau fuhr ihn im Rollstuhl zur Arbeit und zu den politischen Versammlungen. In kurzer Zeit wurde N. führendes Mitglied der Bamberger SPD und der Gewerkschaften. Neben der Partei- und Gewerkschaftsarbeit widmete er sich dem Auf- und Ausbau der „Arbeiterwohlfahrt" und der Flüchtlingsbetreuung. Auf seine Initiative hin wurde in Bamberg eine Volkshochschule gegründet. N. starb am 6.5. 1948 an den Folgen einer im KZ nicht behandelten Knochenverletzung, die eine bösartige Geschwulst nach sich zog. Außer der SPD und den Gewerkschaften rief auch die KPD Bamberg ihre Mitglieder dazu auf, sich zahlreich an dem Begräbnis dieses „überzeugten Kämpfers für die Sache des Sozialismus“ zu beteiligen.

Nelke, Günter, geboren am 31. I 2. 1908 in Stettin. Der Vater war Textilkaufmann. In den zwanziger Jahren engagierte sich $\mathrm{N}$. im „Deutsch-jüdischen Wanderbund Kameraden“. Nach dem Abitur 1928 absolvierte er eine dreijährige Kaufmannslehre; Mitglied des ZdA; im Frühjahr 1930 Beitritt zur SPD, 193 I SAP. Als stellvertretender Bezirksvorsitzender und Kassierer von Pommern betreute N. die wenigen SAP-Stützpunkte in Greifswald, Stralsund und Köslin. 1933 war er an der Herausgabe des illegalen SAP-Informationsblattes „Trotz alledem" beteiligt. Anfang September zerschlug die Gestapo die meisten SAP-Gruppen in Pommern, Ende des Monats floh N. über das Riesengebirge in die ČSR. In Prag war er seit 1934 Angestellıer der „Demokratischen Flüchtlingsfürsorge“, die von Kurt Grossmann, dem ehemaligen Generalsekretär der „Deutschen Liga für Menschenrechte “, geleitet wurde und die sich insbesondere der Emigranten annahm, die nicht den beiden großen Arbeiterparteien angehörten. Mitte der dreißiger Jahre lebten in Prag etwa 20-30 SAP-Mitglieder. Im April 1934 stellte N. zusammen mit neun weiteren SAP-Mitgliedern ein Eintrittsgesuch 
an die SOPADE; dieses wurde mit der Begründung abgelehnt, daß in der Emigration keine Aufnahmen vollzogen würden. Dagegen wurde er in die Jugendorganisation der sudetendeutschen "Deutschen Sozialdemokratischen Arbeiterpartei ${ }^{*}$ aufgenommen und arbeitete illegal im Rahmen der Gruppe „Neu Beginnen“. Am 23. 5.1938 verließ Kurt Grossmann die CSR und übergab N. die „Demokratische Flüchtlingsfürsorge “. Obwohl er als Jude und Sozialist doppelt bedroht war, reiste N. erst am 4.3. 1939, elf Tage vor dem Einmarsch der deutschen Truppen, fast als letzter von Prag nach Frankreich aus. Die geplante Weiterreise nach England, wo seine Freundin Marianne in der Emigration lebte, scheiterte infolge des Kriegsausbruchs. Im November 1939 Meldung als Frejwilliger zur französischen Armee; am 4.6. 1940 schwer verwundet, einen Tag später in deutsche Kriegsgefangenschaft. Bei den sich anschließenden Verhören gelang es N., sich in französischer Sprache als gebürtiger Pole mit Wohnsitz im unbesetzten Marseille auszugeben; im Sommer 1941 als Schwerverwundeter aus der Kriegsgefangenschaft entlassen; Verleihung des französischen Ordens "Croix de guerre ${ }^{\alpha}$. Seine Eltern wurden 1940 in das polnische Ghetto Piaskj deportiert, dort kamen sie später beide ums Leben. Seit 1942 arbeitete N. in einem Arbeitslager für Ausländer, die in der französischen Armee Dienst getan hatten, erst bei Montauban, später in der Corrèze. Trotz zahlreicher Kontrollen seitens der Gestapo blieb seine Identität verborgen. Zusammenarbeit mit der Résistance; Beteiligung an Waffentransporten. Zwei Tage vor der Landung der Alliierten in der Normandie tauchte er zusammen mit anderen im Maquis der Correze unter, um deutsche Truppentransporte durch dieses Gebiet zu verhindern. Im Oktober 1944 als Angehöriger der Résistance demobilisiert; anschließend in Paris als Beauftragter des IRRC Betreuung von überlebenden Emigranten.

Nachdem er im Frühjahr 1946 seine Freundin in England geheiratet hatte, kehrte er mit ihr im September nach Deutschland zurück. In Hannover Mitarbeiter der KZ-Betreuungsstelle im Regierungspräsidium; Mitglied der SPD; gewerkschaftlich in der DAG, später in der ÖTV organisier; seit 1947 Sachbearbeiter, später Leiter der Betreuungsstelle für Flüchtlinge aus der DDR beim Parteivorstand der SPD, der im Juni 195 I seinen Sitz von Hannover nach Bonn verlegte. Nach einem Herzinfarkt 1969 war N. lange Zeit krank, 1971 ging er in den Ruhestand. Seitdem arbeitet er im Bonner Ortsverein der SPD mit, er ist im Vorstand der "Arbeitsgemeinschaft für Bildung und Kultur " und ehrenamtlicher Buchhalter der „Deutsch-Israelischen Gesellschaft ${ }^{\star}$. N. lebte 1980 in Bonn.

Jörg Bremer: Die Sozialistische Arbeiterpartei Deutschlands (SAP). Untergrund und Exil 1933-45. Frankfurt a.M. 1978; Kurt R. Grossmann: Emigration. Geschichte der Hitler-Flüchtlinge 1933-1945. Frankfurt a. M. 1969; Biographisches Handbuch der deutschsprachigen Emigration nach 1933. Bd. I. München 1980.

Neumann, Siggi (Siegmund) (1907-1960), Buchhändler und kaufmännischer Angestellter; 1926 Mitglied der KPD, Anhänger der sog. Versöhnler-Gruppe; 1933 Emigration, 1934 in Paris aus der KPD als „Bucharinist“ ausgeschlossen; Mitglied der Exil-KPO; 1937 Freiwilliger im Spanischen Bürgerkrieg, verwundet; 1938 nach Stockholm; in der „Landesgruppe deutscher Gewerkschafter "in Schweden Vertreter der linken Opposition, die das von der SPD und der KPD getragene Konzept einer künftigen Einheitsgewerkschaft ohne marxistisch-revolutionäre Festlegung ablehnte; im April 1946 Rückkehr aus dem Exil, unter dem Eindruck der Deutschlandpolitik der Sowjetunion Eintritt in die SPD; 1947 kurze Zeit Leiter des Ostbüros beim Parteivorstand (PV) der SPD, das sich um eine konspirative Fortführung der SPD-Parteiarbeit in der SBZ bemühte; 1947-1954 Betriebsgruppenreferent beim PV der SPD, dann beim Hauptvorstand der IG Metall in Frankfurt a. M.

Ohlhof, Fritz (1889-1946), Redakteur der sozialdemokratischen Mainzer „Volkszeitung ${ }^{c}$, 1931-1932 zusammen mit Heinrich Galm* SAP-Abgeordneter im Hessischen Landtag; 194I-1945 im Konzentrationslager, $1946 \mathrm{kam}$ O. bei einem Autounfall ums Leben. Vgl. auch die Biographie von Walter Heist. 
Opel Fritz, geboren am 26.8. 1912 in Hindenburg/Oberschlesien, sein Vater fiel 1916 im Krieg, seine jüdische Mutter war Redaktionssekretärin; 1930/3 I Beginn eines Jurastudiums, 1933 Exmatrikulation; im Sommer 1933 Mitglied der illegalen KPD, im November 1934 verhaftet; im Februar 1937 vor dem 3. Strafsenat des Volksgerichtshofes in Berlin unter Anrechnung der Untersuchungshaft zu drei Jahren Zuchthaus verurteilt, im Dezember 1937 entlassen; Mitte 1938 Flucht über den Bodensee nach Zürich, dann Paris; dort Anhänger der ehemaligen Versöhnler-Fraktion der KPD; 1940 interniert; 1941 über Oran und Trinidad in die USA; 1943 amerikanischer Staatsbürger und zur Armee eingezogen, ab Herbst 1944 als GI erst in Frankreich und dann in Deutschland; 1946 ausgemustert; 1948-1954 Angestellter des IRRC in Frankfurt; gemeinsam mit Fritz Lamm* Herausgeber und Redakteur der Zeitschrift „Funken. Aussprachehefte für internationale und sozialistische Politik ${ }^{\alpha}$; nach der Wiedererlangung der deutschen Staatsbürgerschaft 1953 Mitglied der SPD; Studium der Politik, Soziologie und öffentliches Recht, 1956 bei Wolfgang Abendroth* promovier; seit Dezember 1956 Vorstandssekretär der IG Metall, 1957 Leiter der Auslandsabteilung, später Leiter der Abteilung Grundsatzfragen; Verantwortlicher der IG Metall-Kampagne gegen die Notstandsgesetze; 1968-1972 Beisitzer im Unterbezirksvorstand der SPD in Frankfurt, ehrenamtlicher Stadtrat; O. starb am 14. 10. 1973.

Karljosef Kreter: Funken. Aussprachehefte für internationale sozialistische Politik. Entstehung und Entwicklung einer Zeitschrift der "heimatlosen Linken “ in der Ära Adenauer (1950-1959). Unveröffentlichte Staatsexamensarbeit. Göttingen 1980.

Oppler, Kurt, geboren am 24. I I. 1902 in Breslau, jüdischer Herkunft, katholisch. Der Vater, der 1930 starb, war Kaufmann. Seit 1921 studierte O. an der Universität Breslau Philosophie und Kunstwissenschaften, von 1924 bis 1926 war er in einem Textilbetrieb kaufmännisch tätig. Von 1926 bis 1929 studierte er Rechts- und Staatswissenschaften, 1930 wurde er zum Dr. jur. promoviert. Seit 1929 war er Referendar bei dem Breslauer SPD-Vorsitzenden, Ernst Eckstein ${ }^{*}$, der als "Anwalt der Armen “ in der Stadt großes Ansehen genoß. In dieser Zeit arbeitete $O$. als Strafverteidiger vorwiegend in politischen Prozessen; zugleich war er aber auch politischer Mitarbeiter Ecksteins. Anfang Oktober 1931 nahm O. an der Gründung der ersten SAP-Ortsgruppe in Breslau teil. Mitte Oktober konstituierte sich unter seinem Vorsitz ein provisorischer Hauptvorstand des "Sozialistischen Studentenverbands" (SStV), der Studentenorganisation der SAP. Nennenswerte Gruppen des SStV, der über ein- bis zweihundert Mitglieder nicht hinauskam, entstanden jedoch nur in Breslau und in Berlin. Im November 1932 legte O. sein Assessorexamen ab. Da in Breslau für zwei SAPRechtsanwälte keine Existenzgrundlage bestand, eröffnete er ein Anwaltsbüro im oberschlesischen Gleiwitz. Dadurch entging er den Verfolgungen, die in Breslau im Frühjahr 1933 unter Leitung des neuen Polizeipräsidenten, des Feme-Mörders und SA-Gruppenführers Edmund Heines, einsetzten.

Obwohl O. den NS-Bestimmungen zufolge Jude war, konnte er aufgrund des Genfer Abkommens über den Minderheitenschutz in Oberschlesien sein Anwaltsbüro in den ersten Jahren der Diktatur fortführen. Er engagierte sich als Verteidiger politisch Verfolgter und war Rechtsanwalt vor dem Internationalen Schiedsgericht in Kattowitz. Nach Ablauf des Genfer Abkommens 1937 wurde ihm die Ausübung seines Berufes aus rassischen Gründen verboten. Danach wurde O. erneut kaufmännisch tätig. 1938 emigrierte er zusammen mit seiner Frau Rosa nach Holland. Er erhielt ein Einreisevisum für die USA, doch wurde im Mai 1940 das für die Überfahrt vorgesehene Schiff versenkt. Gezwungenermaßen blieb $O$. in Belgien, seinen Lebensunterhalt verdiente er durch Übersetzungen und Privatunterricht. Während des Krieges arbeiteten $O$. und seine Frau mit der belgischen Résistance zusammen; dreimal ausgebombt. Seit Kriegsende war O. in Namur (Belgien) in einem amerikanischen Büro für Schadensfeststellungen beschäftigt. Im Anschluß an eine Reise durch die US-Zone im April 1946 kehrte er nach Deutschland zurück; seit Mai 1946 Ministerialdirektor und Leiter der Abteilung für öffentliches Arbeitsrecht im hessischen Justizministerium 
unter Georg August Zinn. 1947 war er u. a. an der Ausarbeitung des Betriebsverfassungsgesetzes beteiligt; Mitglied der VVN, im Herbst 1946 trat er der SPD bei. Im Oktober 1947 übernahm O. die Leitung des Personalamts der Bizonen-Verwaltung in Frankfurt a. M.. Im März 1952 wechselte er in den Auswärtigen Dienst über, seit 1953 vertrat O. die Bundesrepublik als Botschafter in Island, Norwegen (1956), Belgien (1959) und Kanada (1963). Seit 1966 im Ruhestand, O. starb am 29.4. 1981 in Baden-Baden.

Biographisches Handbuch der deutschsprachigen Emigration nach 1933. Bd. I. München 1980.

Osner, Karh geboren am 26. 5. $190 \mathrm{I}$ in Griesheim a.M. als Sohn eines sozialdemokratischen Metallarbeiters; gelernter Feinmechaniker; 1919 KPD; Mitte der zwanziger Jahre Angestellter in einer KPD-Buchhandlung in Krefeld; um 1926/27 Ruckkehr nach Frankfurt; 1928 Arbeiter in einer Schreibmaschinenfabrik, Betriebsrat; 1928 Austritt aus der KPD; KPO, dann SAP, Organisationssekretär; seit 193 I arbeitslos; 1933 Leiter der illegalen SAPGruppe in Frankfurt; im Juli von befreundeter Seite gewarnt, daB ein Haftbefehl gegen ihn vorliege; zusammen mit seiner Frau Carola Flucht nach Frankreich, von der NS-Regierung ausgebürgert; O's Schreibmaschinenreparaturbüro in Paris und nach $194 \mathrm{I}$ in New York war ein Treffpunkt der politisch-literarischen Emigration; O. starb 1972 in den USA.

Karl Osner, in: Arbeiterjugendbewegung in Frankfurt 1904-1945. Gießen 1978, S. I63.

Ostermann Franz, geboren am 9.3. 1899 in Sallgast/Niederlausitz. Der Vater war Maurer, beide Eltem gehörten der SPD an; drei Geschwister, vier weitere Kinder starben im Säuglingsalter. Nach der Jahrhundertwende verzog die Familie nach Berlin. Im Anschluß an die Volksschule ließ sich O. zum Schneider ausbilden. 1913 Mitglied, später Vorsitzender der AJ in Berlin-Kreuzberg. 1916 trat er dem später kommunistisch geführten Berliner Turnverein "Fichte" bei. Seit 1914 gewerkschaftlich organisiert. Am 1. Mai 1916 beteiligte sich $O$. zusammen mit mehreren tausend Menschen an der ersten größeren Antikriegsdemonstration der Spartakus-Gruppe auf dem Potsdamer Platz, in deren Verlauf Karl Liebknecht verhaftet wurde. Von 1917 bis zum März 1919 Soldat, Mitglied des Soldatenrats seiner Kompagnie in Eisleben. Im April 1919 Mitglied der USPD, 1921 der KPD. In dieser übernahm er die Funktion eines Literaturobmanns, zugleich war er in der „Roten Hilfe a aktiv. Seit 1920 engagierte er sich in der Freien Sportbewegung, er wurde Mitglied der $x$ I. Männerabteilung (Berlin-Kreuzberg) des „Arbeiter- Turn- und Sportbundes“, später Jugendleiter und in den Jahren vor 1933 deren 2. Vorsitzender. 1924 trat $O$. aus der KPD aus, vermutlich veranlaßt durch die nahezu vollständige Beherrschung der Berliner KPD-Organisation durch den linken Parteiflügel, danach war er parteilos. In den zwanziger Jahren Schneider in einer $\mathrm{Fa}$ brik, von 1926 bis 1929 Betriebsrat; nach einem Streik 1929 entlassen und daraufhin bis 1934 arbeitslos; 1931 Eintritt in die SAP, Organisationsleiter einer SAP-Gruppe.

Wegen Fortführung des Arbeitersports wurde O. im August 1933 verhaftet und zwei Monate lang in der Gestapo-Zentrale Prinz-Albrecht-Straße und im berüchtigten ColumbiaHaus der SS verhört. Bei zwei Haussuchungen wurde kein belastendes Material gefunden. Nach seiner Entlassung konnte $O$. seine Genossen warnen, er wechselte die Wohnung, lebte in der Illegalität und zog 1935 nach Buchholz, einem Außenbezirk von Berlin. Seit 1934 arbeitete er bei der Fa. Peek \& Cloppenburg, die im Krieg Uniformen herstellte. Im Oktober 1944 eingezogen. Bei Kriegsende geriet O. in sowjetische Gefangenschaft, wegen einer Erkrankung an Ruhr wurde er jedoch bereits wenige Monate später nach Berlin entlassen. 1950 wurde O. nach einer zweijährigen Kandidatur Mitglied der SED. 1949 und $1950 \mathrm{Be}-$ triebsgruppenleiter in der Textilfabrik „VEB Fortschritt ${ }^{*}$. Von 1950 bis 1964 arbeitete er als Lehrlingsausbilder, später als Lehrmeister in der Lehrwerkstatt dieses Betriebes. Für seine Verdienste im Berufsleben wurde er mehrfach ausgezeichnet. O. starb am 3.9. 1970. 
Palmer, Otto, geboren am 17.7. 1914 in Stuttgart. Der Vater war Buchdrucker beim DMV, die Mutter Hausfrau und Heimarbeiterin. P. besuchte die Realschule, 1929 begann er eine dreieinhalbjährige Lehre als Tapezierer; in diesem Beruf arbeitete er bis 1945 . Unter dem Eindruck der Stimmengewinne der Nationalsozialisten in der Wahl vom I4.9. 1930 trat P. der SAJ bei, im Oktober 1931 schloß er sich dem SJV an.

In der illegalen SAP-Gruppe Stuttgan stellte P. 1933 verschiedene interne Informationsschreiben zusammen, die vervielfältigt wurden. Nachdem ein von ihm mit synthetischer Tinte geschriebener Briefwechsel mit Mitgliedern der illegalen SAP in Berlin entdeckt worden war, wurde er am 16.12. 1933 verhaftet. Im September 1934 zu einem Jahr und acht Monaten Gefängnis verurteilt; im Anschluß an die Haft häufig arbeitslos, später erneut einige Monate inhaftiert. Infolge der "Wehrunwürdigkeit", zu der er verurteilt worden war, wurde P. im Krieg nicht als Soldat eingezogen.

1945 trat P. der SPD bei. Von 1946-1948 war er öffentlicher Kläger und Spruchkammervorsitzender in Entnazifizierungsverfahren. Von Dezember 1947 bis 1975 Abgeordneter im Stuttgarter Stadtrat, ca. zehn Jahre Vorsitzender der SPD-Fraktion; 1948-1968 Vorsitzender der Dritten Kammer des Arbeitsgerichts Stuttgart; seit 1969 kaufmännischer Vorstand bei den Technischen Werken der Stadt Stuttgart, Ende 1979 pensioniert. P. lebte 1980 in Stuttgart.

Pauli, Hubert, geboren am 20.5. 1908 als einziger Sohn in einem bürgerlichen Elternhaus. Der Vater war Möbelfabrikant; 1927 Abitur, Studium an der Universität Köln; ein Semester Theologie, dann Nationalökonomie, Soziologie und Philosophie. Die politische Situation im Köln der zwanziger Jahre war geprägt vom Dominieren des politischen Katholizismus und der Existenz einer traditionalistischen, ausgesprochen reformorientierten SPD. Dagegen fielen linkssozialistische Gruppierungen wie die "Sozialistische Studentenschaft ${ }^{\text {, }}$, der ISK und die "Roten Kämpfer", die im Vergleich zu anderen Städten in Köln verhältnismäBig stark waren, zahlenmäßig nicht ins Gewicht, hatten aber als Stützpunkte junger Intellektueller eine gewisse Bedeutung. P. wurde - wie der spätere Politische Leiter der illegalen KPO im Bezirk Niederrhein Hans Mayer - aktives Mitglied der „Sozialistischen Studentenschaft" und 1931 der SAP, die in Köln bei der Reichstagswahl vom 31.7. 1932586 Stimmen erhielt. Nach Auseinandersetzungen mit den Nationalsozialisten an der Universität ging er 1932 nach München. Dort begann er ein Medizinstudium und widmete sich dem Aufbau einer konspirativen Gruppe.

Im Kölner Widerstand spielten die Mitglieder der linkssozialistischen Gruppen und Parteien, insbesondere der SAP und ihres Jugendverbandes SJV, eine bedeutende Rolle. Motor des SAP-Widerstandes war bis 1934 Erich Sander, der Sohn des berühmten Fotografen August Sander. Im zweiten Halbjahr 1934 wurden I 8 SAP-Mitglieder verhaftet und zu hohen Zuchthausstrafen verurteilt. P. kehrte 1935 nach Köln zurück und schloß sich der illegalen SAP an, in der auch Lotte und Ernst Singer" arbeiteten. Über Karl Völker" und die 1934 emigrierte Hilde Singer" wurde illegales Material beschafft und verteilt. P. war einer der aktivsten, er leistete Fluchthilfe für bedrohte Juden, hielt sich mehrfach illegal in Holland auf. Im Juni 1936 bei der Verhaftung von Lotte und Ernst Singer war ihm die Gestapo unter seinen Decknamen "Thomas", „Tom" und "John" dicht auf der Spur. 1937 Examen, 1938 Vertreter eines Arztes in einer Klinik; mit Zustimmung seiner Genossen und mit notarieller Beglaubigung eines befreundeten Anwalts Eintritt in die SS, Mitglied der SS-Ärzteschaft; 1938 zweimalige Verhaftung wegen seiner Beziehung zu Juden und wegen des Verdachts illegaler Arbeit; im Dezember 1939 zur Waffen-SS eingezogen; Internist in einem SS-Lazarett bei München; 1942 Leiter eines Flecktyphus-Lazaretts in Finnland. Während des Heimaturlaubs malte er in Uniform NS-feindliche Parolen auf den Kölner „Ring“. Im selben Jahr heiratete er. 1943 erklärte er seiner Frau, daß er nicht mehr in das finnische Lazarett zurückkehren könne. Auf dem Rückflug ließ er sich aus dem landenden Flugzeug fallen und mußte in ein Krankenhaus eingewiesen werden. Versetzung nach Meran, als Internist Chef eines Lazaretts; während des ganzen Krieges illegale Kontakte; im März 1945 
Versetzung als Standortkommandant nach Leipzig. P. setzte sich ab und blieb bis Kriegsende in München im Untergrund. Nach der Befreiung durch die Amerikaner widmete er sich der medizinischen Betreuung der Überlebenden des $\mathrm{KZ}$ Dachau.

Leitende Position in der Ärztekammer München. Nach 1945 erhielt P. Urkunden von Emigranten aus Israel und den USA, daß er als Antifaschist in der SS tätig war; 1949 Inhaber eines Ausweises für politisch, rassisch und religiös Verfolgte; 1946 Rückkehr nach Köln. P. war ein führendes Mitglied des „Kölner Kreises“ (vgl. S. 341). Er trat nach 1945 keiner Partei bei. Beruflich arbeitete er als Werksarzt und als Vertrauensarzt der Landesversicherungsanstalt Rheinland. P. litt jahrelang an Depressionen; er starb 1954 an den Folgen einer Morphiuminjektion.

Pennekamp, Wilhelm, geboren 1894, SPD-Mitglied, dann SAP-Funktionär, vor 1933 Wirt im Duisburger Gewerkschaftshaus; wegen illegaler Arbeit wurde Pennekamp im August 1935 in Dortmund im Prozeß gegen Eberhard Brünen* zu achtzehn Monaten Zuchthaus verurteilt. Nach 1945 Mitglied der SPD, Angestellter bei der ÖTV (Vgl. auch die Biographie von Oskar Triebel*).

Pfaffenbäuser, Franz, geboren am 30. I 1. 1895 in Monreal/Eifel. Der Vater war Seifensieder, die Mutter Sammetweberin in Heimarbeit. Pf. lernte Hutmacher in Mayen. Aus Gesundheitsgrinden gab er den geplanten Beruf auf und trat in die Mobelwerkstatt seines Schwagers in Bonn ein. Um 1913 AJ; 1918/1919 Mitglied der KPD. 1923 beteiligte sich Pf. am sog. Ruhrkampf der KPD gegen die französische Besatzungsmacht. Dem Zugriff der Polizei konnte er sich durch Flucht in das unbesetzte Gebiet entziehen. 1925 ermöglichte die Londoner Amnestie Pf. die Rückkehr nach Bonn. Im selben Jahr übernahm er die KPD-Buchhandlung in Frankfurt a. M. 1928 geriet er in Konflikt mit der politischen Linie der KPD. Zusammen mit seiner Frau Änne trat er aus der Partei aus und verlor dadurch seine Arbeit. Beide wurden aktive Mitglieder der KPO. Später mietete Pf. eine Werkstatt in einem Frankfurter Vorort, er arbeitete gebrauchte Möbel auf und handelte mit Antiquitäten und Kunstgegenständen aller Art.

Seit der Machtübernahme durch die Nationalsozialisten arbeitete Pf. illegal im Rahmen der KPO. Zunächst beteiligte er sich an der von Philipp Pless ${ }^{*}$ geleiteten Gruppe „Einheit ${ }^{\text {, }}$, der in Frankfurt ungefähr zwanzig, in Offenbach zehn Mitglieder angehörten. Bis zum November 1933 gab diese Gruppe zehn Nummern einer Zeitschrif gleichen Namens heraus, einen Monat später hörte sie mit der Flucht von Philipp Pless ins Saarland auf zu bestehen. Anfang 1937 kam die Gestapo durch Angaben des 1936 im Rheinland verhafteten KPO-Kuriers, Hans Löwendahl*, auch der Frankfurter Organisation der KPO auf die Spur. Pf. wurde am 3. 5.1937 verhaftet und am I 5.7. 1938 in Kassel zu zweieinhalb Jahren Zuchthaus verurteilt, die er u.a. in Ludwigsburg absaß. Nach Verbüßung der Haft wurde er im April 1940 zu erneuten Verhören nach Frankfurt gebracht. Bis zum 23. I2. 1940 in Einzelhaft. Danach Transport in das KZ Dachau. Zu seinem Lebensweg bis Ende des Krieges vgl. seinen Brief S. $293 \mathrm{ff}$.

Nach 1945 arbeitete Pf. bis zu seiner Pensionierung 1960 in der Rentenabteilung der Bundesbahn. Politisch unorganisiert; Pf. bezeichnete sich selbst als einen "heimatlosen Linken“. Am I0. 5. 1977 verunglückte er auf einer Reise in Israel tödlich.

Wolfgang Abendroth: Ein Leben in der Arbeiterbewegung. Gespräche, aufgezeichnet und hrsg. von B. Dietrich und J. Perels. Frankfurt a. M. 1976, S. 174 f.

Pilz, Louis, geboren am 6. 2. 1900 in Osterwieck/Harz. Der Vater, der gewerkschaftlich organisiert war und der SPD nahestand, war ein gelernter Korbmachermeister, arbeitete aber als Maschinenwart. 1903 verzog die Familie nach Braunschweig. In dieser Industriestadt, in der die Gegner der Burgfriedenspolitik seit 1914 die große Mehrheit der SPD-Mitglieder, die SPD-Parteiorganisation und die Gewerkschaften hinter sich hatten, machte P. seine 
ersten politischen Erfahrungen. I916 trat er der Gewerkschaft und der AJ bei, die ihren $800-1000$ aktiven Mitgliedern auch im Krieg ein breitgefächertes Vortragsprogramm über naturwissenschaftliche, völkerkundliche und politische Themen in wöchentlichen Versammlungen anbieten konnte; Verteiler der illegalen "Spartakusbriefe". 1917 wurde P. in Zusammenhang mit Antikriegsunruhen verhaftet. Gegen Ende des Krieges kurze Zeit Soldat; Anfang der zwanziger Jahre Mitglied der KPD. 1922 anläßlich der Ermordung des Außenministers Walther Rathenau nahm P. an einer Protestkundgebung sowie an dem anschließenden Versuch einer Erstürmung des Braunschweiger Gefängnisses teil, um Genossen zu befreien; zusammen mit anderen verhaftet, jedoch im Prozeß freigesprochen; als Maurer in einem Ruhrbergwerk Arbeit unter Tage; Mitglied eines Sprechchors; im Rahmen offentlicher Veranstaltungen, u. a. auf der Ruine Scharzfeld am Harz, Deklamation revolutionärer Gedichte als Mittel kollektiver Agitation; 1922-1924 Wanderschaft durch Deutschland und die Schweiz. Seit Ende 1924 lebte P. in Stuttgart, dort arbeitete er als Maurer. 1928 wurde er wegen seines Protests gegen die RGO-Politik aus der KPD ausgeschlossen, danach Mitglied der KPO.

1933 sechs Wochen "Schutzhaft" im KZ Heuberg. Seit 1936 arbeitete P. mit der SAPGruppe um Richard Schmid* zusammen. Am 20. 11.1938 verhaftet, wegen Vorbereitung zum Hochverrat zu anderthalb Jahren Gefängnis verurteilt, davon vier Monate in einem Lager bei Dieburg; anschließend bis Ende des Krieges Soldat, Kriegsgefangenschaft im Elsaß; im Mai 1946 Rückkehr nach Stuttgart; 1947 Eintritt in die SPD; ab 1947 hauptamtliche Jugend- und Bildungsarbeit im DGB; ca. acht Jahre DGB-Kreisvorsitzender von Stuttgart; seit 1965 pensioniert, 1980 lebte $P$. in Stuttgart.

Pless, Philipp (1906-1973), Dreher, seit 1922 Mitglied der Bezirksleitung Hessen-Frankfurt des KJV, im November 1928 Ausschluß aus der KPD; 1929-1931 zusammen mit Heinrich Galm* KPO-Bezirksleiter; 1933 Widerstandstätigkeit, Leiter der Frankfurt-Offenbacher Gruppe „Einheit" (vgl. die Biographie von Franz Pfaffenhäuser*); Ende 1933 Emigration ins Saargebiet, später nach Frankreich; 1946-1948 Parteisekretär der Offenbacher ArbeiterPartei. 1952 Mitglied der SPD, 1958 Abgeordneter im Hessischen Landtag; 1967-1972 Vorsitzender des DGB Hessen.

Biographisches Handbuch der deutschsprachigen Emigration nach 1933. Bd. 1. München 1980.

Rabbich, Heinrich, geboren am 3.10. 1888, Mechaniker, führender KPD-Funktionär in Essen, zeitweise im militärischen Apparat der Partei; nach der Machtübernahme durch die NSDAP an der Organisierung des kommunistischen Widerstands beteiligt; vom 1.3. 1933 bis Ende Januar 1934 "Schutzhaft" in den KZs Kleve und Brauweiler; während dieser Zeit stürzte sich seine Frau, die zu Aussagen gegen ihren Mann gezwungen werden sollte, aus dem Fenster; sie überlebte, war seitdem aber seelisch völlig gebrochen; $R$. wurde am 28. 2. 1934 aus der Haft entlassen und am 2.6. 1934 in einem Prozeß vor dem Oberlandesgericht Hamm von der Anklage der Vorbereitung zum Hochverrat wegen Mangels an Beweisen freigesprochen; vom 16.6. 1934 bis I.4. 1935 erneut in Haft, 1935 und Anfang 1936 wieder vernommen und gefoltert, dann am 22.9. 1936 verhaftet und zu vier Jahren Zuchthaus verurteilt; nach seiner Freilassung 1940 wurde seine schwermütig gewordene Frau im Rahmen der Euthanasie-Aktion ermordet; am 22.9. 1944 verhaftet, konnte R. im Oktober aus dem Gefängnis fliehen; im März 1945 schloß er sich in Essen einer Widerstandsorganisation an, in der deutsche NS-Gegner und russische Kriegsgefangene zusammenarbeiteten; nach Kriegsende am Wiederaufbau der KPD im Ruhrgebiet beteiligt, 1945 Mitarbeiter des KPDBezirksvorstandes.

Detlev Peukert: Ruhrarbeiter gegen den Faschismus. Dokumentation über den Widerstand im Ruhrgebiet 1933-1945. Frankfurt a. M. 1976. 
Regenbogen, Georg ${ }^{* 4}$, geboren 1906 in Potsdam. Der Vater, ein Zuschneider, machte sich mit einem Konfektionsbetrieb selbständig, die Mutter war Hausfrau. Beide Eltern waren politisch gegen nautoritäres Preußentum “ eingestellt. Nach der Mittleren Reife ließ sich $\mathbf{R}$. zum Feinmechaniker ausbilden. Seit 1922 arbeitete er an einem wissenschaftlichen Institut in Berlin, dann in der Industrie. Durch den Kontakt zu gewerkschaftlich und politisch organisierten Facharbeitern verstärkte sich sein Interesse an politischen Fragen. Er wurde Mitglied des DMV, 1930 - nach dem Erfolg der NSDAP in der Septemberwahl - trat er der SPD bei. Er beschloß, sich weiterzuqualifizieren, und holte 1932 das Abitur an der Berliner KarlMarx-Schule nach. Danach begann er mit Hilfe eines Stipendiums der Studienstiftung des deutschen Volkes ein Ingenieurstudium an der Universităt Berlin 1932/1933 arbeitete er im Arbeitskreis junger Sozialdemokraten mit.

1934 wurde er aus politischen Grïnden vom Studium ausgeschlossen. Daraufhin bewarb er sich als Ingenieur in der Industrie. $\mathrm{Da}$ ihm Berlin zu nationalsozialistisch geprägt war, verzog R. 1937 in das , liberalere ${ }^{\star}$ Schwaben. In Stuttgart arbeitete er als Ingenieur in einem großen Betrieb der Metallindustrie. 1943 Tytigkeit in einem Verlagerungsbetrieb in Berlin. Im Fruhjahr 1945 kehrte R. nach Stuttgart zurlick. Bei Kriegsende engagierte er sich in den Arbeitsausschüssen, einer Antifa-Organisation, die in Stuttgart seit 1945/1946 auf Stadtteilebene auch Verwaltungsfunktionen wie Beschaffung von Wohnraum, Nahrungsmitteln und Brennstoffen sowie Trümmerbeseitigung ubernahm und bis ins Jahr 1948 bestand. Er fand erneut Anstellung bei seiner alten Firma, wurde Mitglied des Betriebsrats und beteiligte sich am Aufbau der Gewerkschaften. Aus Sympathie mit den Russen und aus der Überzeugung, daß sich der Reformismus disqualifiziert habe, schloß sich $R$. der KPD an. Er betätigte sich im „Kulturbund zur demokratischen Erneuerung Deutschlands“, organisierte Jugendlesekreise und bemühte sich um Kontakte zu den Kirchen. Im Mai 1947 äußerte er sich auf dem ersten Bundeskongreß des „Kulturbundes ${ }^{\alpha}$ in Berlin sehr kritisch über die Entwicklung in der SBZ. 1949 wurde er wegen seines Eintretens für eine eigenständige, von der Sowjetunion unabhängige Politik aus der KPD ausgeschlossen. 1969 pensioniert.

7* Dieser Name ist ein Pseudonym. Er wurde auf Wunsch des Briefschreibers gewählt.

Reisner, Else, geboren 1910; Ehefrau von Konrad R., Sekretärin und Journalistin, Mitglied der Jungsozialisten; von April bis November 1933 in Schutzhaft; 1934 Flucht ins Saargebiet, im Januar 1935 nach Frankreich; Mitglied der „Revolutionắren Sozialisten Deutschlands “ und der „Jeunesse Socialiste Française"; Mitatbeiterin der Deutschlandberichte der SOPADE und des „Neuen Vorwärts"; im September 1940 Flucht nach Südfrankreich; über Spanien und Portugal im Oktober 1940 in die USA; nach 1945 Mitorganisatorin einer $\mathrm{Pa}$ ket-Hilfsaktion für Deutschland.

Reisner, Konrad, geboren am 2. I. 1908 in Breslau; Studium der Rechtswissenschaften; Mitglied der SPD, dann der SAP; Sekretär der "Deutschen Friedensgesellschaft" in Breslau sowie Regionalsekretär der „Deutschen Liga für Menschenrechte“ (DLM); im März 1933 Flucht nach Prag, von dort einen Monat später über die Schweiz nach Frankreich; in Paris Mitglied der SAP-Exilgruppe; Delegierter der DLM bei der Internationalen Liga für Menschenrechte; hauptamtlich für französische und deutsche Flüchtlingsorganisationen tätig; einer der Initiatoren der Friedens-Nobelpreisverleihung an Carl von Ossietzky; 1936 in Paris einer der SAP-Vertreter im Ausschuß zur Vorbereitung der deutschen Volksfront; September 1940 Flucht über die Pyrenäen nach Spanien und Portugal, im Oktober in die USA; dort tätig als Sozialarbeiter. R. lebte 1980 in Centerville/Ohio.

Biographisches Handbuch der deutschsprachigen Emigration nach 1933. Bd. I. München 1980.

Restle, Stefie, geboren am 24. I 2. I901 in Beuron/Hohenzollern als achtes von zehn Kindern. Der Vater war Oberförster und stand im Dienst der Fürsten von Hohenzollern. R. 
besuchte zunächst die Volksschule und dann die Klosterinternatsschule in Tutzing/Oberbayern. Danach ließ sie sich auf einer kaufmännischen Fachschule in Tuttlingen als Kaufmannsgehilfin und Kontoristin ausbilden. Von 1921 bis 1925 berufliche Tätigkeit in Norwegen. Seitdem im württembergischen Landesdienst, im Innenministerium und in den Landesarbeitsämtern Karlsruhe und Stuttgart.

1933 wurde R. wegen ihrer Mitgliedschaft in der SPD aus dem Landesdienst entlassen und zeitweise inhaftiert. In der Folgezeit war sie arbeitslos. In den dreißiger Jahren arbeitete sie weiterhin, wenn auch unter schwierigsten Bedingungen, für die SPD. Von 1935 bis 1947 Buchhalterin und Leiterin des Lohnbüros eines Stuttgarter Großhandels- und Werkstättenbetriebs.

1945-1947 Betriebsratsvorsitzende; 1947-195 I SPD-Abgeordnete im Stuttgarter Stadtrat, Mitglied der Verfassunggebenden Landesversammlung; von 1950 bis 1968 Abgeordnete in den Landtagen von Württemberg-Baden und Baden-Württemberg. Im Dezember 1966 wurde R. für ihre Verdienste mit dem Großen Verdienstkreuz der Bundesrepublik Deutschland ausgezeichnet. Ihr besonderes Engagement galt Jugend-, Sozial-, Kultur- und FrauenFragen, dabei nahm sie sich vor allem der Probleme der Blinden an. R. starb am 8. 10. 1978.

Röbrig, Hugo, geboren am 31. S. 1906 in Solingen-Wald in eine seit zwei Generationen sozialdemokratische Familie. Der Vater war ungelernter Packer, die Mutter Hausfrau; Volksschule, 1920 Angestellter in einer Konsumgenossenschaft. Seit 1927 besuchte R. Kurse zur Vorbereitung von Arbeiterkindern auf die Reifeprüfung, die in Berlin von den Schulreformern Kurt Kerlow-Löwenstein und Fritz Karsen eingerichtet worden waren. Nach dem Abitur Anfang 1930 Studium an der Universität Köln in den Fächern Rechts- und Staatswissenschaften mittels eines Stipendiums der Studienstiftung des deutschen Volkes. R. trat aus der evangelischen Kirche aus und wurde aktives Mitglied der „Sozialistischen Studenten-

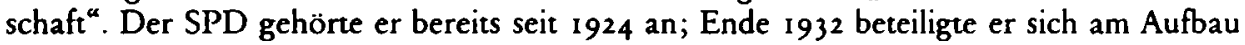
einer illegalen SAP-Gruppe.

Nach dem 30. 1. 1933 Ausschluß aus der Studienstiftung mit der Verpflichtung, alle erhaltenen Mittel zurückzuzahlen. Im Frühjahr vorübergehend verhaftet. Unter größten Schwierigkeiten absolvierte $R$. sein erstes juristisches Staatsexamen; die bereits vorbereitete Promotion mußte unterbleiben, da er Hausverbot an der Universität erhielt. Seit 1933 umfangreiche illegale Tätigkeit im Rahmen der SAP. Vom juristischen Vorbereitungsdienst wurde R. zunächst zurückgewiesen, doch dann erreichte er 1937 die Zulassung zum zweiten juristischen Staatsexamen. Strafversetzung in den Oberlandesgerichtsbezirk Kassel. Dem Drängen der Staatsführung auf aktive Betätigung in der NSDAP und in anderen NS-Organisationen vermochte er durch freiwillige Meldungen zu Wehrübungen auszuweichen. 1939 zum Wehrdienst eingezogen; bis Kriegsende Soldat, immer an der Front; 194 I Ernennung zum Amtsgerichtsrat in Korbach/Waldeck, ohne dort tätig zu werden; bei Kriegsende in amerikanische Gefangenschaft.

1946 konnte R. erstmals seinen Beruf ausüben. Er wurde Amtsgerichtsrat, dann ab November 1949 Leiter des Amtsgerichts in Solingen; Ende 1945 Mitglied der SPD. Wegen politischer Differenzen wurde R. eigenen Angaben zufolge einige Jahre später nicht mehr kassiert, womit seine Mitgliedschaft endete. 1964 Präsident im Entschädigungssenat beim Oberlandesgericht Düsseldorf; I97 I pensioniert; Mitglied der "Humanistischen Union“ (HU), später Austritt aus Protest gegen die Politik des HU-Mitglieds Innenminister Maihofer. R. lebte 1980 in Solingen.

Roos, Gustav, geboren am 6.11. 1904 in Mannheim-Seckenheim. Der Vater war als Arbeiter bei der Stadt beschäftigt. Nach der Volksschule absolvierte R. in den Jahren I 9 19-1 922 eine Elektromechaniker-Lehre bei der Fa. Brown, Boveri \& Cie, verbunden mit einer theoretischen Ausbildung in einer Gewerbeschule. Seit Oktober 1919 war er Mitglied des DMV, 
1920-1922 dessen Jugendsprecher. 1923 trat er dem "Reichsbanner Schwarz-Rot-Gold bei, 1924 der SPD; 1928-1929 Vorsitzender der Mannheimer Jungsozialisten; 1923-1928 Betriebsmonteur in einer großen Gummiwarenfabrik. 1928 wurde er nach einem Streik gemaßregelt und verlor seinen Arbeitsplatz. In all diesen Jahren qualifizierte sich $R$. nach der Arbeit fachlich weiter, u. a. auch in Fremdsprachen; 1929 legte er seine Meisterprüfung als Elektromechaniker ab. 1928-1938 als Monteur für Kräne und Aufzugsanlagen im In- und Ausland. 193 I trat R. zur SAP über; soweit feststellbar, nicht als Anhänger des linken Flügels der SPD, sondern aus Enttäuschung über die Untätigkeit der Partei in der Ära Brüning. 1931-1933 Vorsitzender der kleinen Gruppe der Mannheimer SAP, die nicht mehr als fünfzig Mitglieder zählte und in der Reichstagswahl vom 31.7. 1932 nur 199 Stimmen erhielt. Am 20. 2. 1933 leitete er die letzte Betriebsräte-Vollkonferenz in Mannheim, die mit großer Mehrheit - jedoch zu spät - den Generalstreik gegen die Nationalsozialisten beschloß.

Von 1933-1938 war R einer der Leiter der illegalen SAP und des SJV in Mannheim und Südwestdeutschland. Seit 1933 wurde Mannheim zum Zentrum des südwestdeutschen Widerstands der SPD, KPD und der SAP. Bis 1936 bestanden in der Stadt sowohl starke KPDals auch SPD-Gruppen. Den relativ unbekannten und in konspirativen Techniken geschulten Mitgliedern der SAP, deren Zahl in den Jahren nach der Machtübernahme durch die Nationalsozialisten auf 80 bis 100 anwuchs, darunter auch Mitglieder des linkskommunistischen „Lenin-Bundes“, gelang es, im Mannheim-Ludwigshafener Industriegebiet eine rege Öffentlichkeitsarbeit zu entfalten. Im Abstand von acht bis vierzehn Tagen vertrieben sie seit Februar 1933 unter den Titeln „Das Fanal“, „Die Avantgarde“, „Die Einheit", „Die Vorhut", „Die Tribüne“ selbstgedruckte Zeitungen. Sie organisierten Flugblattaktionen, versahen bei öffentlichen Ereignissen Straßen mit Klebezetteln. Seit 1934 bestand zwischen der illegalen Mannheimer SAP und dem SAP-Stützpunkt in Basel, der von dem Braunschweiger (SAP-) Emigranten Max Steinmüller geleitet wurde, eine enge und kontinuierliche Verbindung. Leitende Mitglieder der Mannheimer SAP, darunter auch $R$., nahmen in den Jahren 1934-1936 wiederholt an Zusammenkünften in Basel teil und trafen sich mit Mitgliedern der Pariser SAP-Auslandsleitung wie Paul Frölich*, Jacob Walcher ${ }^{*}$ und mit Fritz Stemberg*, der bis zum Februar 1936 in Basel lebte. Seit 1936 kamen SAP-Zeitschriften, aber auch die sozialdemokratische "Sozialistische Aktion", ausschließlich auf diesem Wege nach Südwestdeutschland. Unmittelbar von Mannheim aus gingen die politischen Schriften und Nachrichten durch Kuriere und Verbindungsleute an die illegalen SAPGruppen in Frankfurt a.M., Freiburg, Heidelberg, Heilbronn, Kaiserslautern, Ludwigshafen, Pforzheim und Stuttgart. Über Stuttgart bestanden Kontakte zur illegalen SAP in München.

1936 wurde $R$. zusammen mit einem anderen SAP-Funktionär verhaftet, mangels Beweisen jedoch wieder auf freien Fuß gesetzt. Das Ende des organisierten SAP-Widerstands in Baden und Württemberg kam 1938; Ende April setzten Verhaftungen ein, die in mehreren Wellen erfolgten, fast alle SAP-Gruppen erfaßten und erst im Spätherbst abgeschlossen wurden. Allein in Mannheim wurden dabei 25-30, in Südwestdeutschland Ios SAP-Mitglieder festgenommen. R. wurde am 20. 5. 1938 verhaftet und am 7.6. 1939 in einem Prozeß, der im Auftrag des Volksgerichtshofes Berlin in Karlsruhe stattfand, zu vier Jahren Zuchthaus und Ehrverlust verurteilt. Nach seiner Entlassung im Jahr 1942 arbeitete er erneut als Monteur.

1945/1946 Betriebsrats-Vorsitzender. Nach Kriegsende trat ein Teil der ehemaligen SAPMitglieder in Mannheim der KPD und der SPD bei. R. schloß sich Anfang 1946 trotz gewisser Bedenken der KPD an. Zugleich beteiligte er sich 1946 und 1947 an Verhandlungen, die - von Heinrich Galm*, Offenbach, initiiert - den Zusammenschluß der ${ }_{n}$ Arbeiter-Partei“" Offenbach, der „Sozialistisch-Demokratischen Vereinigung Mosbach“ und ehemaliger SAP-Kreise zu einer "Sozialistischen Union“ zum Ziel hatten. Als Mitglied des daraus entstandenen "Siebener-Ausschusses" nahm er am 22.3. 1947 an einer Konferenz der „Arbeitsgemeinschaft sozialistischer Parteien und Gruppen Süddeutschlands“ in Offenbach a. M. teil, die jedoch ergebnislos verlief. Als er sich daraufhin wegen seiner Teilnahme vor 
der Mannheimer KPD-Leitung rechtfertigen sollte, trat $\mathrm{R}$. aus der Partei aus. Anfang Oktober 1947 wurde er Mitglied der SPD. 1946-1969 Betriebsingenieur im Mannheimer Werk der Fa. Daimler-Benz; 1949-1963 Betriebsratsmitglied, 1963-1970 2. Vorsitzender; Vorsitzender der DAG-Ortsgruppe Mannheim, Mitglied des engeren Landesvorstandes der DAG Wurttemberg-Baden; 1956-1969 Arbeitsrichter beim Arbeitsgericht Mannheim. R. lebte 1980 in Mannheim.

Jörg Schadt/Wolfgang Schmierer (Hrsg.): Die SPD in Baden-Würtemberg und ihre Geschichte. Stutugart 1979. Volker Berghahn/Reinhard Schiffers: Die Sozialistische Arbeiterpartei (SAP) in Mannheim und Sudwestdeutschland 1933-1938. 19-seitiges Manuskript. Stadtarchiv Mannheim.

Roth, Hans (1892-1959): Portefeuiller. KPD, 1924-1928 KPD-Stadtverordneter in Offenbach, bis 1933 Mitglied der KPD. 1933 mehrere Monate im KZ Burg Hohenstein in der Sächsischen Schweiz. Selbständiger Kaufmann. 1945 Funktionär der „Atbeiter-Partei“, 1951 Übertritt zur SPD. 1946-1959 Stadtverordneter in Offenbach a.M.

Rudolph, Frieda, geboren am I s. 1 2. 1889 in Mainz. Der Vater war von Beruf erst Schmiedemeister, dann Geschäftsinhaber, die Mutter Hausfrau. Ihre Eltern waren aktive Sozialdemokraten, zur Zeit der Bismarckschen Sozialistengesetze waren sie konspirativ tätig. Als junges Mädchen begeisterte sie sich für die Friedensbewegung und führte einen Briefwechsel u. a. mit Bertha von Suttner. Mitglied der SPD. 1918 heiratete sie den Berliner Schriftsteller Alwin R., der für die deutsche („Der wahre Jacob ${ }^{\text {") }}$ ) und für die schweizer sozialistische Presse schrieb. Ein Jahr zuvor war sie nach Offenbach a. M. verzogen, wo sie Leiterin des vor allem von Arbeiterkindern besuchten städtischen Jugendhorts wurde. Die Jugendarbeit war ihr auch in den folgenden Jahren ein besonderes Anliegen. Zusammen mit dem späteren hessischen Innenminister Wilhelm Leuschner gründete R. nach 1919 die Arbeiterjugendverbände in Stadt und Kreis Offenbach. Sie setzte sich für den Bau von Jugendheimen und Erholungsplätzen ein und war die treibende Kraft der Offenbacher Kinderfreunde-Bewegung. 1923-1933 Stadtverordnete. 1932 schloß sich R. der SAP an. Anfang der dreißiger Jahre war sie als Rednerin und Verfasserin von Zeitungsartikeln gegen die Nationalsozialisten aktiv. 1933 wurde $\mathrm{R}$. verhaftet und war mehrere Wochen in ${ }_{n}$ Schutzhaft ${ }^{*}$, meist in Einzelhaft. Es folgten Haussuchungen, die Konfiskation ihrer Bücher und Polizeiaufsicht.

Bei Kriegsende wurde sie sofort wieder aktiv als Leiterin einer vom Roten Kreuz errichteten Tageserholungsstätte für schwer unterernährte Kinder, einer Gemeinschaftsküche und einer Wärmehalle für ältere Bürger. Vorsitzende des überparteilichen Frauenverbandes. Sie mobilisierte Firmen zu Spenden und Handwerker zur freiwilligen Arbeit am Bau eines später nach ihr benannten Rentnertagesheimes, das in den fünfziger Jahren als vorbildlich galt. 1945 Mitbegründerin der "Arbeiter-Partei ${ }^{*}$ und in den folgenden Jahren deren Funktionärin, 1946-1960 Stadtverordnete. Enttäuscht über die erneute Spaltung der Arbeiterbewegung bemühte sich R. seit $1947 / 48$ um Kontakte mit der SBZ/DDR; sie nahm an internationalen Frauentreffen teil und war später Mitveranstalterin der „Arbeitnehmergespräche mit Menschen aus dem anderen Deutschland“. I95 I verließ sie mit vier anderen führenden Funktionären die Arbeiter-Partei und trat zur SPD über. I 962 wurde ihr auf Beschluß der Offenbacher Stadtverordnetenversammlung der Ehrentitel "Stadtälteste" verliehen. R. starb am 18.3. 1966.

Rubnau, Fritz, geboren am 25. I1. 1896 in Hamburg als fünftes von sieben Kindern. Die Mutter starb 1900; der Vater, ein Gastwirt, 1904. R. wuchs bei einer Tante auf, seit 1900 litt er an Asthma. Nach der Volksschule Ausbildung zum Handlungsgehilfen, dann Kostenberechner in einer Anwaltspraxis. Von 1915 bis Kriegsende war R. Soldat. Vor 1914 Mitglied im Sozialdemokratischen Jugendbund, 1917 USPD, 1920 KPD; 192 I Angesteilter im KPDBezirksbüro Wasserkante in Hamburg; 1922 bei der Deutsch-Russischen Handelsvertretung; 1923 Beteiligung am Aufstand der KPD in Hamburg. In der KPD war R. 1921-1923 
ein Anhänger von Heinrich Brandler* und August Thalheimer*. 1930 wurde er wegen seiner Kritik an der RGO-Politik aus der KPD ausgeschlossen. Daraufhin verlor er auch seine Arbeit. Seit 1930 arbeitslos. Im selben Jahr schloß sich R. der KPO an und wurde bald örtlicher Organisations-Leiter der Partei, die in Hamburg 1931 60 Mitglieder zählte.

1933 illegale Fortführung der KPO. R. vertrieb die KPO-Zeitschriften "Gegen den Strom ${ }^{\text {“ }}$ und "Juniusbriefe ${ }^{\alpha}$ und hielt Verbindung zur Inlandsleitung in Berlin. Am I9. I I. 1933 wurde er verhaftet und von der Gestapo schwer mißhandelt. Im Februar 1934 aus einem Lazarett entlassen, wenige Tage später mit der Mehrheit der Mitglieder der KPO-Gruppe jedoch erneut verhaftet; im September 1934 zusammen mit 19 Mitangeklagten in einem Prozeß vor dem Hanseatischen Oberlandesgericht wegen Vorbereitung zum Hochverrat Verurteilung zu zweieinhalb Jahren Zuchthaus, wehrunwürdig. Seine Verlobte Frieda Boutcher erhielt zwei Jahre Gefängnis. Zuchthaus Oslebshausen bei Bremen; nach Verbüßung der Haft ins KZ Fuhlsbütuel bei Hamburg; auf Grund zahlreicher Interventionen seiner Verlobten, die beim Standesamt ein Aufgebot bestellt hatte, am 30. 10. 1936 entlassen; kurzfristige Gelegenheitsarbeiten. Seit 1937 war R. wegen seines Asthmas immer wieder im Krankenhaus, der längste Aufenthalt dauerte von November 1941 bis April 1943, seitdem war er arbeitsunfähig; im Juli 1943 bei den Großangriffen auf Hamburg ausgebombt und danach zusammen mit seiner Frau nach Weiden i.d. Oberpfalz evakuiert.

Kurz nach Kriegsende Eintritt in die KPD. Im Mărz 1946 kehrte R. nach Hamburg zurück. Er hielt engen Kontakt zu ehemaligen Mitgliedern der KPO, mit denen er sich in der „Gruppe Arbeiterpolitik ${ }^{\alpha}$ (GAP) zusammenschloß. 1948 Ausschluß aus der KPD. Wegen politischer und persönlicher Differenzen zog er sich wenig später auch aus der GAP zurick. Von 1949-1959 unterstützte er Heinrich Brandler*, der seit seiner Rückkehr aus dem kubanischen Exil bei ihm lebte, bei dessen politischer Tätigkeit. R. starb am 14. 5. 1980.

Samorei [auch: Samoray], Emil geboren am 29.7. 1891 in Rotthausen bei Gelsenkirchen. Der Vater war Bergmann, die Mutter Hausfrau, Volksschule, Schlosserlehre, 1908 Mitglied der Arbeiter-Jugend, wenig später der SPD. Im Ersten Weltkrieg erlitt S. schwere Verwundungen, mit mehreren Lungendurchschüssen lag er zwei Jahre im Krankenhaus; seit diesem Zeitpunkt Lähmung des linken Beines und des rechten Armes, zu hundert Prozent kriegsbeschädigt. Nach dem Krieg Verwaltungsangestellter der Gemeinde Rotthausen, 1918 Vorsitzender des dortigen Arbeiter- und Soldatenrates; USPD-Mitglied, vermutlich $1920 \mathrm{KPD}$, USPD- und KPD-Stadtverordneter in Gelsenkirchen. 1923 wurde S. wegen antimilitaristischer Arbeit im von französischen Truppen besetzten Rheinland interniert. Delegierter des VIII. Parteitages der KPD im März 1923 in Leipzig; 1924/25 Opposition gegen die linke Führung der KPD. Die Bezirksleitung warf ihm vor, er beabsichtige eine Parteispaltung mit dem Ziel einer neuen USPD-Gründung. S. wurde aus der Partei ausgeschlossen, die KPD in Gelsenkirchen verlor im Zusammenhang mit diesen Auseinandersetzungen 900 Mitglieder. Beamter im Wohlfahrtsamt der Stadt Essen; Rechtsschutzobmann der „Roten Hilfe“, Mitglied des Freidenkerverbands; $1931 / 32$ aktives Mitglied der SAP.

Am 2 1. I1. 1933 wegen seiner politischen Einstellung als Stadtsekretär entlassen; in der Folgezeit arbeitslos. Im Frühjahr 1933 bildete S. einen Kreis von SAP- und SPD-Mitgliedern um sich, zu dem zunehmend Kommunisten stießen. Bis 1935 Anlaufstelle für die SAP; am 5.9. 1935 verhaftet und als Rädelsführer wegen Verbreitung illegaler Schriften vom Oberlandesgericht Hamm am I 4.4. $1936 \mathrm{zu}$ vier Jahren und sechs Monaten Zuchthaus verurteilt. Von den acht Mitangeklagten wurden die drei KPD-Mitglieder Fritz Melchers, Albert Kornett* und August Rogge zu zwei bis dreieinhalb Jahren Zuchthaus verurteilt, die übrigen Angeklagten kamen mit geringfügigen Gefängnisstrafen davon. Über den Ort und die Dauer der Inhaftierung von S. liegen keine Informationen vor. Einer schriftlichen Notiz von ihm zufolge hielt er sich von 1942 bis 1944 in Lothringen auf; dort verteilte er Flugblätter für die KPF.

Nach 1945 Beamter der Stadt Essen, zuletzt Oberinspektor im Wohlfahrtsamt. 1948/49 trat 
S. für die Gründung einer dritten „marxistischen“ Arbeiterpartei ein; später war er vermutlich Mirglied der SPD; gewerkschaftlich organisiert in der ÖTV, aktives Mitglied im Freidenkerverband. Ehrenamtlicher Schöffe. 1955 heiratete S. 1959 wurde er pensioniert. Er starb 1967.

Beatrix Herlemann: Kommunalpolitik der KPD im Ruhrgebiet 1924-1933. Wuppertal 1977.

Sauter, Willi, geboren am 13.8. 1903 in Ulm als Sohn eines gewerkschaftlich organisierten Bierbrauers; fünf Geschwister. Im Anschluß an die Volksschule absolvierte S. eine Sattlerund Tapezierer-Lehre und war später als Tapezierer tätig. Mit sieben Jahren Mitglied des

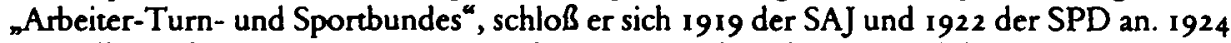
Jugendleiter der SAJ Ulm, 1925 Leiter des SAJ-Unterbezirks. Mitglied des ADGB-Ortsvorstands und des „Reichsbanners Schwarz-Rot-Gold“. Im Herbst 1931 Mitbegriinder der SAP, der in Ulm ca. zehn bis fünfzehn Mitglieder angehörten. Im Frühjahr I 933 war S. daran beteiligt, Verbindungen zwischen den konspirativ arbeitenden kleinen SAP-Gruppen in Ulm, Göppingen und Stuttgart zu knüpfen; er unterhielt regelmäßige Kontakte zur SAPReichsleitung in Berlin und zu SAP-Emigranten, insbesondere zu Fritz Sternberg*, in Basel. Im Januar 1934 verhaftet, war S. im Juli 1934 Hauptangeklagter im Prozeß gegen elf SAPMitglieder vor dem Oberlandesgericht Stuttgart und wurde zu zwei Jahren Zuchthaus verurteilt; im Anschluß daran drei Jahre im KZ Dachau; 1939-1945 Soldat.

1945 Mitglied der SPD, 1946 Gewerkschaftssekretär der ÖTV in Ulm; 1949-1964 Geschäftsführer der SPD in Stuttgart. S. starb am 29. 12. 1967 in Ulm.

Scblör, Jakob (1888-1956), Kellner, I91 I Mitglied der SPD, 1919 der KPD; 1926-1929 Generalsekretär der „Roten Hilfe“. Im Mai 1929 aus der KPD ausgeschlossen; Funktionär der $\mathrm{KPO}$; nach sechsmonatiger Inhaftierung in einem KZ 1934 Emigration, zuletzt in Schweden. 1945 kehrte Schlör nach Berlin zurück und schloß sich wieder der KPD und dann der SED an. Mitglied des Vorstandes der Gewerkschaft „Nahrung, Genuß und Gaststättengewerbe" der SBZ; 1950/195 I abgelöst und aus der SED ausgeschlossen, I955 erneut aufgenommen.

Hermann Weber: Die Wandlung des deutschen Kommunismus. Bd. 2. Frankfur 1969.

Scblott, Johann Georg, geboren am 6. I I. 1891 in Frankfurt a. M. als ältester Sohn eines Pakkers. 1906 beendete Sch. die Volksschule mit dem „Fleißpreis“. Eine von der Schule angebotene Ausbildung zum Volksschullehrer mit Hilfe eines staatlichen Stipendiums lehnte der Vater ab. Sch. machte eine Schlosserlehre, konnte jedoch auch in den folgenden Jahren keine innere Beziehung zu diesem Beruf finden. Er trat dem DMV bei und wurde aktives Mitglied der Freien Turnerschaft. Nach der Gesellenprüfung Wanderschaft durch Deutschland. I 9 I I wurde er bei Streikunruhen in Berlin festgenommen und zum Militär eingezogen. Bis zum Herbst 1913 Militärdienst in Neu-Ulm. 1914-1918 Soldat. Seit 1916 verheiratet, zwei Söhne 1919 und 1920. Nach dem Ersten Weltkrieg arbeitete Sch. als Schlosser in mehreren Frankfurter Großbetrieben. Mitglied der USPD, 1920 der KPD. 1922 zum Betriebsrat gewählt; wegen seiner gewerkschaftlichen Aktivitäten wurde er später entlassen und fand in keinem anderen Betrieb Anstellung. Nach längerer Arbeitslosigkeit gründete er eine kleine Schlosserei. Mitte der zwanziger Jahre wurde Sch. beim ersten öffentlichen Auftreten der SS in Frankfurt durch eine Handgranate schwer verwundet. Hauptkassierer der KPD und der Freien Turnerschaft, Rechnungsführer der „Roten Hilfe“. Als Schöffe und Geschworener sowie beim Mieteinigungsamt tätig. Seit 1928 war er KPD-Stadtverordneter und Sekretär der sozialen Beratungsstelle der kommunistischen „Arbeiter-Zeitung“.

Im April 1933 wurde Sch. verhaftet und in der Frankfurter SA-Kaserne mißhandelt, mehrere weitere Festnahmen und Verhöre schlossen sich an. 1934 arbeitslos, als NS-Gegner bis Ende 1936 von der Arbeitsvermittlung ausgeschlossen. 1937 Beifahrer in einer Packerei. 
Weil er die Familie eines inhaftierten Genossen finanziell unterstützt hatte, wurde Sch. 194I erneut verhaftet und wegen Vorbereitung zum Hochverrat zu neun Monaten Gefängnis verurteilt. Nach der Entlassung bei Außenarbeiten eingesetzt. Im Herbst 1944 KZ Dachau. Zusammen mit 7000 anderen Häftlingen nahm Sch. am 26.4. 1945, zwei Tage vor der Befreiung des Lagers durch amerikanische Truppen, an dem Todesmarsch teil, der hunderten von Menschen das Leben kostete. Zu diesem Zeitpunkt war Sch. an Typhus und an einer Rippenfellentzündung erkrankt und hatte einen schweren Knochenbruch. Nach der Befreiung im Seuchenlazarett Starnberg, im Juni Nervenzusammenbruch in einem Frankfurter Krankenhaus. Aus der Haftzeit resultierten körperliche und psychische Schäden, eine ärztliche Diagnose erkannte später auf traumatische Epilepsie.

1945/1946 schloß sich Sch. der KPD, der Arbeiterwohlfahrt und der „Vereinigung der Verfolgten des Naziregimes ${ }^{\alpha}$ (VVN) an. 1946 Leiter des Entnazifizierungsausschusses der Oberpostdirektion Frankfurt; von 1949 bis zu seiner Pensionierung 1959 Postangestellter beim Fernmeldeamt; aktives Gewerkschaftsmitglied; seit Anfang 1948 SPD. Sch. starb am 28. I. 1964 .

Schmid, Richard, geboren am 31.3. 1899 in Sulz am Neckar; Studium der Rechtswissenschaften an den Universitäten Tübingen, Freiburg und München; 1923 Promotion, 1924 Assessorexamen. Nach kurzer Tätigkeit als Richter Rechtsanwalt in Sturtgart, vorwiegend in Zivilsachen. Sch. stand zwar in diesen Jahren der SPD nahe, im engeren Sinne politisch aktiv wurde er eigenen Angaben zufolge jedoch erst nach den großen Stimmengewinnen der NSDAP bei der Reichstagswahl vom 14.9. 1930.

Im Jahre 1934 übernahm er die Verteidigung des schwer belasteten SAP-Bezirksleiters für Südwestdeutschland Alfred Merck im Prozeß gegen Willi Sauter*, Alfred Euchner (vgl. die Biographie von Frida Euchner*), Otto Palmer*, Wilhelm Blind* und sieben weitere SAPMinglieder vor dem Oberlandesgericht Stuttgart. 1935 und 1936 unterhielt er auf beruflich motivierten Auslandsreisen Kontakte zu KPO- und SAP-Emigranten in Zürich, Paris und Kopenhagen, so zu August Thalheimer*, Fritz Bauer, Walter Fabian* und Jacob Walcher*. Durch sie wurde er unmittelbar in die Widerstandstätigkeit einbezogen. Er übernahm den Auftrag, die SAP in Stuttgart neu aufzubauen und organisierte illegale Grenzübertritte gefährdeter Sozialisten in die Schweiz, so von Fritz Lamm* und nach Dänemark. Zur Tarnung illegaler Zusammenkünfte annoncierte er im Frühjahr 1935 in einer Stuttgarter Zeitung die Gründung einer Esperanto-Gruppe. Nach der Zerschlagung der SAPOrganisation in Mannheim (vgl. die Biographie von Gustav Roos*), die Hinweise auf das Bestehen einer SAP-Gruppe in Stuttgart erbracht hatte, kam die Gestapo Sch. auf die Spur. Im November 1938 wurden Sch., sein Schwager Eugen Krautwasser und Louis Pilz* verhaftet.

Während der Untersuchungshaft sechs Wochen strenge Isolierhaft im KZ Welzheim. Im Januar 1940 vom 2. Senat des Volksgerichtshofs in Berlin wegen Vorbereitung zum Hochverrat zu drei Jahren Zuchthaus verurteilt und für wehrunwürdig erklärt; im Juli 194I unter Anrechnung der Untersuchungshaft aus dem Zuchthaus entlassen. Daß er anschließend nicht in ein KZ kam, glaubt Sch. dem Umstand zu verdanken, daß die Gestapo-Stelle in Stuttgart in der $Z$ wischenzeit ganz neu besetzt worden war. Den Rest der Kriegszeit verbrachte er als landwirtschaftlicher Arbeiter in einem Dorf bei Herrenberg. $1945-1953$ Generalstaatsanwalt in Württemberg-Baden, später Baden-Württemberg; außerdem Leiter einer Abteilung im Justizministerium. 1953-1964 Oberlandesgerichtspräsident in Stuttgart. Seit 1945 Mitglied der SPD, 1968 trat Sch. wegen der Zustimmung der SPD zu den Notstandsgesetzen aus der Partei aus. Zahlreiche Vorträge, Rundfunksendungen und Artikel in Fachzeitschriften, Zeitschriften ("Merkur $\left.{ }^{*}\right)$ und Zeitungen ( ${ }_{\text {DDie Zeit }}{ }^{\circ}$ ) über zeitgeschichtliche, politische und juristische Themen. Seit seiner Pensionierung veröffentlichte er folgende Bücher: Einwände. Kritik an Gesetzen und Gerichten. Stuttgart 1965; Justiz in der Bundesrepublik, Pfullingen 1967; Unser aller Grundgesetz? Praxis und Kritik, Frankfurt a.M. 1971 ; Das Unbehagen an der Justiz, München 1975. Sch. lebte 1981 in Stuttgart. 
Hans Schueler: Der Justiz den Spiegel vorgehalten. Ein konsequenter und unbequemer Mahner. In: Die Zeit vom 30. 3. 1979; Richard Schmid: ${ }_{m}$ Am meisten Schweiß und Tinte habe ich für die Meinungsfreiheit vergossen“. In: Stuttgarter Zeitung vom 3 I. 3. 1979.

Schmidt, Albert, geboren am 3.8. 1909, Bezirksleiter des SJV Württemberg. Bis zu seiner Verhaftung Anfang Juni 1933 organisierte er die Aktivitäten der regionalen SAP und gab die illegale Parteizeitschrift „Der Aufrechte“ heraus. Am 27.7. 1933 wurde er deswegen zu zwei Jahren Zuchthaus verurteilt. Seit seiner Rückkehr aus sowjetischer Kriegsgefangenschaft im Jahre 1946 hielt Schmidt, der Verlagsleiter der „stuttgarter Zeitung ${ }^{\alpha}$ wurde, enge Verbindung zur Offenbacher „Arbeiter-Partei“. Im Herbst 1947 grtindete er in Stuttgart nach dem Offenbacher Vorbild die „Arbeiter-Partei ${ }^{\alpha}$, die im Laufe des Jahres 1948 auf ganz Württemberg-Baden ausgedehnt werden sollte. Es bildeten sich einige Ortsgruppen, die zum Teil aus unzufriedenen SPD-Mitgliedern bestanden, in Göppingen, Neckarzimmern und Mosbach; Ende 1948/Anfang 1949 mußte die Arbeiter-Partei wegen mangelnden Interesses jedoch ihre Aktivitäten einstellen. „Der Unabhängige “, ein Mitteilungsblatt der Partei, erschien in Stuttgart in einer größeren Auflage vom März 1948 bis zur Wăhrungsreform. Zur Politik der Arbeiter-Partei vgl. auch die Biographie und den Brief vom 22.7. 1948 von Otto Hofgabe* S. 258 .

Schmidt, Alfred, geboren 1891, Eisenbahnarbeiter, 1909 SPD, USPD, 1919 KPD, Gewerkschaftssekretär, 1924-1928 Leiter des KPD-Unterbezirks Erfurt, 1928-1932 Abgeordneter des Preußischen Landtags. 1929 KPO, Mitglied der KPO-Reichsleitung. Nach dem 30. I. 1933 Widerstandstätigkeit in Erfurt und im Bezirk Thüringen; aufgrund einer Namensverwechslung Ende Mai 1934 festgenommen und einen Monat lang in Untersuchungshaft; Mitte August 1935 erneut verhaftet, Überführung in das KZ Esterwegen, nach dessen Auflösung von Juni 1936 bis Mai 1939 im KZ Sachsenhausen; bis Kriegsende Kohlenträger, Bauarbeiter und Hilfsschweißer. 1945 trat Schmidt in Thüringen der KPD und dann der SED bei. Er wurde Landesleiter der Gewerkschaft „Nahrung, Genuß und Gaststättengewerbe“. 1947 wegen nantisowjetischer Einstellung “ aus der SED ausgeschlossen, am 6.7. 1948 von sowjetischer Militärpolizei verhaftet und am 2. 1 2. 1948 durch ein sowjetisches Militärtribunal wegen „antisowjetischer Propaganda“ zum Tode verurteilt. Das Urteil wurde später in 25 Jahre Arbeitslager umgewandelt. Bis zum Juni 1956 in der Strafanstalt Bautzen, dann in die Bundesrepublik entlassen. In Salzgitter, wo er in den Hüttenwerken Arbeit fand, schloß er sich der "Gruppe Arbeiterpolitik" an. Schmidt lebte $198 \mathrm{I}$ in Frankfurt a. M.

Hermann Weber: Die Wandlung des deutschen Kommunismus. Bd. 2. Frankfurn a. M. 1969.

Schmitz, Josef(Jup): Siehe den selbstverfaßten politischen Lebenslauf im Briefteil S. i $26 \mathrm{ff}$.

Schoemann, Hans, geboren am 7.7. 1906 in Köln in einem jüdischen Elternhaus; 191 s-1922 Realgymnasium, 1922-1926 Angestellter in der Metallindustrie, 1926-1933 Handlungsbevollmächtigter, dann Prokurist in einer Kölner Schuhfabrik; 1923-1929 Mitglied und Funktionär des KJVD und der KPD; 1929 nach Parteiausschluß KPO, 193 I SAP. Im Oktober 1933 konnte sich Sch. der bevorstehenden Verhaftung durch seine Flucht nach Belgien entziehen; dort erhielt er später eine Aufenthaltsgenehmigung als Kaufmann. Da es ihm materiell besser ging als den meisten deutschen Flüchtlingen, organisierte er Hilfsaktionen und unterstützte den Matteotti-Fonds der Exil-SAP. Nach Kriegsausbruch lebte Sch. illegal mit belgischen und französischen Papieren, 1942 tauchte er in Paris unter; nach Kriegsende in Belgien naturalisiert; 1944 Mitgründer, später Vorsitzender des ${ }_{n}$ Comité Israélite des Réfugiés victimes des lois raciales“ in Brüssel, Vertreter des IRRC, Mitglied des „Council of Jews from Germany“, Verwaltungsratsmitglied der "Centrale d'Oeuvres Sociales Juives“. I952 Mitglied der „Parti Socialiste Belge“. Sch. lebte 1980 in Brüssel. 
Biographisches Handbuch der deutschsprachigen Emigration nach 1933. Bd. I. München 1980.

Schöneseiffen, Max, geboren am 15. 3.1888 in Bonn. Der Vater war Arbeiter in einer Brauerei, die Mutter Hausfrau. Nach der Volksschule ließ sich Sch. zum Anstreicher und Lackierer ausbilden. 1910 heiratete er. Während des Ersten Weltkrieges verzog er nach Köln, dort war er nach 1918 zuerst als Metallschleifer, dann als Lackierer in einer Transformatorenfabrik tätig. Mitglied der USPD, seit 1919 der KPD. Mitte der zwanziger Jahre verlor Sch. wegen engagierter Gewerkschaftstätigkeit seinen Arbeitsplatz. Seitdem war seine wirtschaftliche Existenz ungesichert. Einige Jahre machte er sich als Lackierer selbständig, später erhielt er wegen eines Asthmaleidens eine geringfligige Wohlfahrtsunterstlitzung. Zugleich trat er nebenberuflich als Musiker, Komiker und Humorist auf. 193 I oder 1932 Mitglied der SAP. Uber seine politischen Aktivitaten in den zwanziger und dreißiger Jahren konnte nichts Näheres in Erfahrung gebracht werden.

Nach 1933 wurde Sch. als Notstandsarbeiter in der Kolner Stadtverwaltung eingestellt und einige Jahre später, obwohl kein Mitglied der NSDAP, als Verwaltungsangestellter ubernommen. Im Juni 1942 ausgebombt und nach Crimmitschau in Sachsen evakuiert.

1945 trat er dort der SPD bei. 1950 kehrte er illegal nach Köln zurück. Da ihm das Arbeitsamt wegen seines Alters keine Stelle mehr vermitueln konnte, wurde er im selben Jahr vorzeitig Rentner. Mitglied im Freidenkerverband. Seit 195 I schwer krank, starb Sch. am 7. 10. 1953.

Schöttle-Thalheimer, Berta, geboren am 17.3. 1883 in Affaltrach/Wurttemberg, jüdischer Konfession. Der Vater war ein wohlhabender liberaler Viehhändler und Kaufmann. Ein Jahr nach ihr wurde ihr Bruder August Thalheimer geboren, zu dem sie ihr ganzes Leben lang eine enge persönliche und politische Bindung hatte. Nach Absolvierung eines Realgymnasiums für Knaben ging Berta Th. Anfang 1900 nach Berlin und begann dort, Nationalökonomie zu studieren. Sie fand Anschluß an die Arbeiterbewegung, wurde Mitglied der SPD und trat aus der jüdischen Gemeinde aus. In der SPD stand sie auf dem linken Flügel, mit Rosa Luxemburg, Clara Zetkin sowie Franz Mehring war sie befreundet. Publizistische Tătigkeit, Mitarbeiterin an der von Clara Zetkin herausgegebenen Zeitschrift „Die Gleichheit", von 1909-1912 an dem von ihrem Bruder geleiteten radikalen SPD-Organ „Freie Volkszeitung " in Göppingen. Vor 1914 gehörte sie dem Landesvorstand der SPD Württemberg an; sie war Anhängerin der „Württemberger Linken “ um Friedrich Westmeyer, die sich vor allem auf die Stuttgarter Parteiorganisation stützen konnten. Seit Kriegsbeginn entstand dort unter Leitung von Westmeyer, Zetkin, Jacob Walcher*, Edwin Hoernle, Fritz Rück u.a. eine starke Opposition gegen die Burgfriedenspolitik. Stuttgart wurde neben Berlin zum Hauptstützpunkt der Spartakus-Gruppe. Zusammen mit Ernst Meyer nahm Berta Th. im September 1915 und im April 1916 als Vertreterin des Spartakus an den Konferenzen der Kriegsgegner in Zimmerwald und Kienthal in der Schweiz teil. Im Gegensatz zur Mehrheit der Teilnehmer trat sie zusammen mit Lenin für die Gründung einer III. Internationale ein; Mitglied des ständigen Ausschusses der "Zimmerwalder Bewegung". 1917 wurde sie wegen ihrer antimilitaristischen Tätigkeit verhaftet und 1918 wegen Hochverrat in Stuttgart zu zwei Jahren Zuchthaus verurteilt. Seit Oktober 1917 in der Strafanstalt Delitzsch, wurde sie vermutlich in der Novemberrevolution befreit. 1918/1919 gehörte sie zu den Mitbegründern der KPD. 1920 heiratete sie den gelernten Mechaniker Karl Wilhelm Schöttle, der sich später als Grossist für Tabakwaren selbständig machte, zwei Söhne. Meist in Stuttgart lebend, war Sch.-Th. in der Frauenarbeit der KPD tätig. 1925 war sie an der Gründung des „Roten Frauen- und Mädchenbundes“ der KPD beteiligt. Wie ihr Bruder wurde Sch.-Th. Anfang 1929 aus der KPD ausgeschlossen. Bis zum Verbot der Partei engagierte sie sich in der KPO.

Obwohl in Stuttgart recht bekannt, wurde Sch.-Th. nach der Machtergreifung der NSDAP nicht verhaftet. 1933 wurde sie geschieden. Ihren Lebensunterhalt verdiente sie, indem sie - 
vorwiegend unter Genossen - mit Kaffee handelte, daneben erhielt sie eine kleine Unterstiutzung von ihrem geschiedenen Mann. Seit der Emigration zahlreicher politischer Freunde stand sie in besonders engem Kontakt mit Lu Märten* in Berlin. Seit 1935 unterlag Sch.Th. als Jüdin den nationalsozialistischen Rassegesetzen und -bestimmungen. 194 I wurde sie in ein sog. Judenhaus eingewiesen und in einen Industriebetrieb, der für Wehrmachtsbedarf produzierte, dienstverpflichtet. 1943 in das KZ Theresienstadt deportier, dort wurde sie Anfang Mai 1945 von sowjetischen Truppen befreit.

Nach 1945 trat sie wieder in die jüdische Gemeinde ein. Sie kehrte nach Stuttgart zurück und wurde Mitglied der KPD. 1948 verließ sie die Partei und engagierte sich in der „Gruppe Arbeiterpolitik", für deren Zeitschrift "Arbeiterpolitik" sie jahrelang verantwortlich zeichnete. Sch.-Th. starb am 23.4. 1959.

Agnes Blänsdorf: Die Zweite Internationale und der Krieg. Die Diskussion über die internationale Zusammenarbeit der sozialistischen Parteien 1914-1917. Stuttgart 1979; Horst Lademacher (Hrsg.): Die Zimmerwalder Bewegung. Protokolle und Korrespondenz. The Hague 1967; Illustrierte Geschichte der deutschen Revolution. Berlin 1929, Reprint Frankfur a.M. 1968; K.P. Wittemann: Kommunistische Politik in Westdeutschland nach 1945 . Der Ansatz der Gruppe Arbeiterpolitik. Hannover 1977.

Schumacher, Erich, geboren am 22. S. 1910 in Stuttgart, ein Bruder. Der Vater, der der Neuapostolischen Gemeinde angehörte und von Beruf Schreiner war, fiel 1916 im Ersten Weltkrieg. Seitdem mußte die aus einer größeren Bauernfamilie stammende Mutter, eine Pazifistin mit „kommunistischen Tendenzen", die Familie durch Heimarbeit und durch Putzarbeiten in einer Fabrik ernähren. Sch. besuchte die Volksschule und eine sechsjährige Bürgerschule. Im Anschluß daran absolvierte er eine Mechaniker- und Werkzeugmacherlehre bei der Fa. Zeiss. Als Jugendlicher aktives Mitglied des "Arbeiter-Turn- und Sportbunds“, des "Arbeiter-Samariterbundes“ und der Jugend des „Touristenvereins Die Naturfreunde"; 1927 Jugendvertreter des DMV, seit 1929 im KJVO, der Jugendorganisation der KPO. Aus politischen Gründen - als gewerkschaftlicher Jugendvertreter protestierte er gegen die Verletzung des Tarifvertrags - verlor er im selben Jahr seine Arbeit; erst später stellte ihn die Fa. Bosch ein.

. Nach 1933 hielt Sch. Verbindungen zur KPO und zur KPD aufrecht, Einzelheiten über seine Tätigkeit im Stuttgarter Widerstand sind nicht bekannt. Im August 1942 wurde Schumachers Mutter verhaftet, weil sie Kontakte zu kommunistischen Kreisen unterhielt, u.a. war ihr Untermieter Kommunist; am I. I. I945 starb sie im Gefängnis. Sch. wurde im September 1942 zusammen mit 72 Sozialisten verschiedener politischer Richtungen, in erster Linie Kommunisten, festgenommen. Da die polizeilichen Ermittlungen nicht abgeschlossen werden konnten, erfolgte bis Kriegsende keine Verurteilung; Gefängnishaft, im April 1945 aus einem Gefangenentransport bei Ravensburg befreit.

1946 fand Sch. eine Anstellung als Garagenmeister bei der „Stuttgarter Zeitung“, diese Tätigkeit übte er bis 1973 aus. 1945 trat er der KPD bei, enttäuscht verließ er die Partei jedoch schon nach sechs Monaten; 1948 Mitglied der „Arbeiter-Partei“; gewerkschaftlich organisiert zunächst in der IG Metall, seit 1953 in der IG Druck und Papier; seit 1949 parteilos, gehörte er der Freireligiösen Gemeinde, dem „Touristenverein Die Naturfreunde“ sowie der "Internationale der Kriegsdienstgegner" an. Sch. starb im September 1980.

Seydewitz, Max, geboren am 19. I 2. 1892 in Forst/Lausitz; Buchdrucker; I 9 Io Mitglied der SPD, 1922 Vorsitzender des Bezirks Zwickau-Plauen, 1924-1932 MdR; Führer der SPDLinken, Mitherausgeber und Chefredakteur der Zeitschrift „Der Klassenkampf. Marxistische Blätter"; 1931 Mitbegründer und neben Kur Rosenfeld Vorsitzender der SAP; in der Emigration, die ihn in die CSR, nach Norwegen und Schweden führte, schloß sich Seydewitz zunächst den linkssozialdemokratischen „Revolutionären Sozialisten Deutschlands“ an, seit Mitte der dreißiger Jahre Annäherung und Übertritt zur KPD; 1946 SED, 1946 zunächst Chefredakteur der "Einheit“, dann Intendant des Berliner Rundfunks, Mitglied des 
Zentralkomitees der SED, 1947-1952 Sächsischer Ministerpräsident; I951 im Rahmen der SED-Kampagne „gegen die verräterische Rolle der SAP in der deutschen Arbeiterbewegung “ zu Selbstkritik gezwungen; von 1955 bis 1967 Generaldirektor der Staatlichen Kunstsammlungen Dresdens.

Biographisches Handbuch der deutschsprachigen Emigration nach 1933. Bd. 1. München 1980.

Siewert, Robert (1887-1973); Maurer; schloß sich 1906 der SPD an, 1919 KPD, 1929 KPO; 1933 Mitglied der illegalen KPO-Reichsleitung; Ende 1934 verhaftet und zu drei Jahren Zuchthaus verurteilt, von $193^{8}$ bis 1945 im KZ Buchenwald inhaftiert; 1945 Mitglied der KPD, 1946 der SED; seit 1946 Stellvertretender Ministerpräsident und Minister des Innern von Sachsen-Anhalt; im April 1950 wegen seiner früheren KPO-Zugehörigkeit abgesetzt, später rehabilitiert, Funktionen im DDR-Ministerium für Bauwesen.

Hermann Weber: Die Wandlung des deutschen Kommunismus. Bd. 2. Frankfur a. M. 1969.

Singer, Emst, geboren am 1 2.5. 1908 in Köln, kaufmännischer Angestellter, und seine Frau Lotte, geboren am 3.6. 1908, wurden am 16.6. 1936 in Köln festgenommen, weil in ihrer Wohnung SAP-Treffen stattgefunden hatten. Trotz Folter gab Emst S. den Namen von Hubert Pauli* nicht preis. Lotte S. wurde im Dezember 1936 aus der Untersuchungshaft entlassen, Emst S. wurde am 25.1. 1937 vom Oberlandesgericht Hamm zu zwei Jahren Zuchthaus verurteilt. Nach Verbüßung der Haft sollte er in ein $\mathrm{KZ}$ überführt werden. Da seine Frau jedoch eine Einreisegenehmigung nach Palästina vorweisen konnte, durften sie im Juli 1938 aus Deutschland ausreisen.

Singer, Hilde, geborene Tradelius (1911-?), Jüdin, Röntgenologin; von 1932 bis 1955 mit dem Publizisten Kurt Singer verheiratet; vermutlich SAP-Mitglied; nach Verhaftung im Jahr 1934 Emigration ins Saarland, dann nach Frankreich; 1940 mit ihrem Mann in die USA.

Specht, Minna (1879-1961), Pädagogin; seit 1915 Mitarbeiterin von Leonard Nelson, Mitbegründerin des IJB, gehörte zum engeren Führungskreis des 1925 gegründeten ISK, Mitarbeit an den Parteiorganen "isk" und „Der Funke“, Leiterin des ISK-Landerziehungsheims Walkemühle bei Kassel; 1933 nach Schließung der Schule durch die Nationalsozialisten Emigration nach Dänemark, die dort wiedererrichtete Schule, in der Sp. ihre Walkemühlen-Erziehungsarbeit fortführte, bildete ein wichtiges Kontaktzentrum zwischen der ISKEmigration und den Widerstandsgruppen im Reich; 1938 nach Großbritannien, Mitarbeit an den Programmkommissionen der „Union deutscher sozialistischer Organisationen in Großbritannien" für den Bereich Kultur, Schule und Erziehung, Mitherausgeberin des Deutschlandprogramms der „Landesgruppe deutscher Gewerkschafter in Großbritannien“, Mitglied der „Union deutscher Lehrer-Emigranten“; nach Kriegsende Rückkehr nach Deutschland, 1946-195I Leiterin des Reform-Landerziehungsheimes Odenwaldschule, später Mitarbeiterin am Pädagogischen Institut der UNESCO in Hamburg, bis 1959 Mitglied der deutschen UNESCO-Kommission, aktiv in der Bildungs- und Frauenarbeit der SPD.

Biographisches Handbuch der deutschsprachigen Emigration nach 1933. Bd. I. München 1980.

Spruch, Günter, geboren am 26.4. 1908 in Beuthen/Oberschlesien; Höhere Oberrealschule bis 1928, Studium der Fächer Jura und Volkswirtschaft an den Universitäten Breslau und Genf; SAJ, 1926 SPD, 1928-1933 aktives Mitglied der "Sozialistischen Studentenschaft" und der Jungsozialisten in Breslau, 193 I SAP; Ende 1932 Aufbau einer illegalen Organisation; im Oktober 1933 erste juristische Staatsprüfung, anschließend Gerichtsreferendar; am 
22. 4. 1935 verhaftet und, da man ihm nichts nachweisen konnte, in einem SAP-Prozess zu nur sechs Monaten Gefängnis verurteilt; 1940-1945 Soldat; 1945 SPD; im Mai 1946 Juristischer Dezernent der Berliner Reichsbahn, nach der Teilnahme am Eisenbahnerstreik gegen die kommunistische Leitung der Reichsbahn 1949 entlassen; danach Justitiar beim Senat von Berlin, 1953 Oberregierungsrat; 1959-1961 Vorsitzender des SPD-Unterbezirks Charlottenburg, Mitglied des Landesausschusses der SPD; 1964-197 I Bürgermeister von BerlinCharlottenburg; 1970-1975 Vorsitzender der "Arbeitsgemeinschaft Verfolgter Sozialdemokraten Berlin ; Sp. lebte $198 \mathrm{I}$ in Berlin.

Stepham, Adolf, geboren am 9.4. 1903 in Remscheid. Der aus Ostpreußen stammende Vater war Volksschullehrer, die Mutter Hausfrau. St. besuchte die Oberrealschule; er empfand jedoch Lehrer, Unterrricht und seine Mitschüler als derart reaktionär, daß er 1920 in der Untersekunda gegen den Willen seiner Eltern abging und eine kaufmännische Lehre begann. Nach Beendigung der Lehre arbeitete er 1923 einige Monate als Bankangestellter, bis er auf Grund der Wirtschaftskrise arbeitslos wurde. Seit 1925 Sozialarbeiter beim Wohlfahrtsamt Remscheid, Jugend-, Obdachlosen- und Arbeitslosenarbeit. In seinen politischen Anschauungen wurde St. Anfang der zwanziger Jahre durch Lehrer der Remscheider Volkshochschule beeinflußt. Er trat der KPD bei, verließ sie jedoch kurze Zeit später aus Unbehagen über die gegenseitige Bespitzelung unter den Parteimitgliedern. 1924/25 schloß er sich der SPD an, 1928 dem ZdA. Nach einem zweijährigen Studium am Sozialpolitischen Seminar der „Deutschen Hochschule für Politik“ in Berlin arbeitete er seit 1932 als Prüfer für Wohlfahrtsanträge im Bezirksamt Berlin-Kreuzberg. 1931 Mitglied der SAP.

Nach dem 30. I. 1933 illegale Kontakte im Rahmen der Berliner SAP, u. a. Verbergen von NS-Gegnern. 1936/37 wurde St. zwei Tage im Gestapo-Hauptquartier verhört. Um sich der drohenden Gefahr einer Verhaftung zu entziehen, siedelte er nach Köln zu seinen Eltern über. Dort fristete er eine karge Existenz als Versicherungsvertreter. Später, obwohl kein Mitglied der NSDAP, Angestellter der Wohlfahrtspflege in Nienburg/Weser; im Krieg wegen eines Augenleidens nicht als Soldat eingezogen; seit Juni 1944 bei der Kriegsbeschädigtenfürsorge in Hannover tätig.

Seit 1946 Mitglied der ÖTV, seit 1947 der SPD, zu der er aber als Linkssozialist immer ein distanziertes Verhältnis behielt. 1946 wurde St. von der englischen Militärregierung zum Landesjugendpfleger für Niedersachsen ernannt. Als solcher war er maßgeblich beteiligt am Aufbau des Jugendherbergswerks, des Landesjugendrings und an der Gründung von Jugendgruppenleiter-Schulen. Vergeblich trat er gegenüber der Militärregierung für ein Verbot nationalistischer Jugendverbände ein. Von 1958 bis zu seiner Pensionierung 1968 Leiter der Hauptfürsorgestelle für Kriegsbeschädigte und Kriegshinterbliebene. St. lebte 1980 in Hannover.

Stemberg, Charles (Karel), geboren nach 1900 in der CSR; in den dreißiger Jahren Mitglied einer linken Oppositionsgruppe in der KPĆ; Emigration nach Frankreich, 1940 in Montauban Betreuung antifaschistischer Flüchtlinge aus Deutschland, Österreich und anderen Ländern; nach I 945 als Beauftragter des IRRC in Deutschland, später langjähriger Leiter der Organisation in New York; St. lebte 1981 in New York.

Stemberg Fritz, geboren am I 1.6. I89s in Breslau als Sohn eines jüdischen Rechtsanwaltes; Studium der Nationalökonomie in Breslau und Berlin, 1917 Promotion zum Dr. rer. pol.; ab 1919 wiss. Assistent bei Franz Oppenheimer in Frankfurt, seit 1924 freier Publizist; seit dem Erscheinen seiner Untersuchung „Der Imperialismus“ (1926) einer der führenden zeitgenössischen marxistischen Wirtschaftstheoretiker in der Tradition Rosa Luxemburgs; Bildungsarbeit in der sozialistischen Arbeiterbewegung, Mitarbeiter verschiedener Zeitschriften, u.a. 1930-1933 der „Weltbühne“; 1931 SAP, als Vertreter des linken Flügels zusammen mit Klaus Zweiling maßgeblicher Einfluß auf die Parteiprogrammatik, 1933 Mitglied der 
illegalen SAP-Reichsleitung; im Mărz 1933 vor drohender Verhaftung Flucht ins Ausland, 1933-1936 in Basel, von dort aus Unterstützung illegal arbeitender SAP-Gruppen im Reich, insbesondere in Südwestdeutschland; 1936 Übersiedlung nach Paris, Mitglied der SAPAuslandsleitung; Frühjahr 1939 in die USA, dort uberwiegend journalistische und schriftstellerische Tätigkeiten; nach Kriegsende Vertreter eines demokratischen Sozialismus als „dritten Weg" für Europa; seit 1948 amerikanischer Staatsbürger, seit Anfang der fünfziger Jahre jedoch vor allem in der Bundesrepublik Deutschland und in Österreich politisch, pädagogisch und publizistisch tätig; zahlreiche Veröffentlichungen, die sich mit neuen Problemstellungen für die Arbeiterbewegung unter Einbeziehung bzw. Fortentwicklung Marxscher Theoreme auseinandersetzen; St. starb am 18. 10. 1963 in Munchen. Buch-Veroffentlichungen u. a.: Der Niedergang des deutschen Kapitalismus (1932), Der Faschismus an der Macht (1935), Kapitalismus und Sozialismus vor dem Weltgericht (I951), Marx und die Gegenwart (I955); vgl. neuerdings: Helga Grebing (Hrsg.): Fritz Stemberg. Für die Zukunft des Sozialismus. Köln 1981 .

Stetter, Georg, geboren am 10. 11.1892 in Wain bei Ulm. Der Vater war ein armer Schuhmacher; viele Geschwister. In seiner Kindheit arbeitete St. als Hütejunge, dann absolvierte er in Ulm eine Lehre als Lithograph; 1907 nahm er am I. Internationalen sozialistischen Jugendkongreß in Stuttgart teil, 1908 trat er der SPD und der Gewerkschaft bei. Später übersiedelte er nach Stuttgart. 1912-1919 Soldat, im Ersten Weltkrieg stellte er als Mitglied des Spartakusbundes Antikriegsflugblätter her. Zu seiner politischen Entwicklung in den zwanziger Jahren vgl, seinen Brief vom 3.4. 1947 S. 263.

Im Herbst 1924 beteiligte sich St. an Zusammenkünften der KPD-Rechten im Ruhrgebiet, die auf einen Richtungs- und Führungswechsel innerhalb der Partei hinarbeiteten. Nach einem Treffen mit dem Repräsentanten der sog. Mittelgruppe in der KPD, Ernst Meyer, wurde er am 18. 2. 1925 mit fünf anderen Mitgliedern aus der KPD ausgeschlossen. Im selben Jahr Ruckkehr nach Stuttgart, dort 1927 wieder in die KPD aufgenommen. 1929 wurde er nach erneutem Parteiausschluß Mitglied der KPO, die in Stuttgart bis 1933 einen beträchtlichen Einfluß in den Arbeiterkulturorganisationen und in verschiedenen Gewerkschaften, so im DMV, in der Schuhmachergewerkschaft und im Holzarbeiterverband, ausubte.

Nach 1933 Aufrechterhaltung seiner KPO-Verbindungen. 1945 trat St. wie die Mehrheit der ehemaligen Stuttgarter KPO-Mitglieder der KPD bei. Da er eine Reformierung der Partei zunehmend als aussichtslos erachtete, schloß er sich 1948 der sich formierenden ${ }_{n}$ Gruppe Arbeiterpolitik“ an, deren akrives Mitglied er während der fünfziger Jahre war. Nach 1945 Betriebsrat. Wie schon vor 1933 engagierte sich St. in der Bildungsarbeit der Gewerkschaftsjugend und des "Touristenvereins Die Naturfreunde". St. starb am 2. 10. 1962.

Stierle, Georg (1897-1980), von Beruf Kaufmann; 1916 SPD, später Mitglied des ISK und der SAP; nach illegaler Arbeit 1936 verhaftet und zu zehn Monaten Gefängnis verurteilt, bis April $1939 \mathrm{KZ}$ Lichtenburg und Buchenwald; Soldat; nach der Rückkehr aus der Gefangenschaft Anschluß an die SPD, 1947-1956 1. Vorsitzender des SPD-Unterbezirks FrankfurtMain sowie führende Funktionen in der SPD Hessen.

Stockhaus, Maria, geboren am 10. 5. 1903 in Frankfurt a. M. Der Vater, ein aktiver Sozialdemokrat, war Kassierer bei einer Brauerei, die Mutter Hausfrau; drei Schwestern; Volksschule. Politisch wurde sie stark von ihrem Vater beeinflußt und auch geschult. Mitglied der SAJ; 1917-1919 kaufmännische Lehre; Angestellte in einem Rechtsanwaltsbüro, dann beim Zentralverband der Angestellten in Frankfurt, dort zuständig für Jugendarbeit; Pressestenographin der auf dem linken Flügel der SPD stehenden Frankfurter „Volksstimme“; Verfasserin zahlreicher Artikel für die sozialdemokratische Presse in ganz Deutschland. $1927 \mathrm{Hei}-$ rat; ihr Mann, der aus einer sozialistischen Dortmunder Bergarbeiterfamilie stammte, war Angestellter beim Frankfurter Arbeitsamt. 1931 Mitglied der SAP; Angestellte beim SAPVorstand in Berlin unter Max Seydewitz*. 
Anfang 1933 kehrte Maria St. nach Frankfurt zurück. Am 1.4. 1933 verlor ihr Mann aus politischen Gründen seine Anstellung. Zwei Tage später bekam sie ihr erstes Kind, dabei erkrankte sie an einer schweren Schwangerschaftsinfektion und schwebte zeitweise in Lebensgefahr. Vermutlich war es dieser Umstand, der sie vor der Verhaftung bewahrte. Da ihrem Mann in den folgenden Jahren jegliche Arbeit verweigert wurde, verzogen sie 1938 nach Dortmund. Dort war Maria St. als Angestellte und Kontoristin tätig.

Kurz nach Kriegsende schloß sie sich der SPD an. 1946/47 war sie Stadtverordnete. Ehrenamtliche Wohlfahrtspflegerin; Mitglied in der SPD-Frauengruppe und im Freidenkerverband. Später trat sie aus der SPD aus wegen grundsätzlicher Meinungsverschiedenheiten über den politischen Kurs der Partei. St. lebte 1981 in Dortmund in einem Pflegeheim.

Thalbeimer, August, geboren am 18.3.1884 in Affaltrach/Württemberg als Sohn eines jüdischen Kaufmanns; 1904 SPD, I 907 nach Studien in München, Oxford und Straßburg Promotion zum Dr. phil; I909 Chefredakteur der radikalen sozialdemokratischen "Freie Volkszeitung " in Göppingen, enge Kontakte zur Württemberger Linken um Fritz Westmeyer und zu Rosa Luxemburg, Franz Mehring, Karl Liebknecht; 191 5-16 Chefredakteur des oppositionellen Braunschweiger „Volksfreunds“; Ende 1918 Mitglied der Zentrale des Spartakusbundes, dann bis 1924 der KPD, als deren theoretischer Kopf er galt; Redakteur des theoretischen Organs der KPD „Die Internationale“, zeirweise Chefredakteur der „Roten Fahne“; 1924 nach Moskau „gerufen “, wo er bis 1928 in „ehrenhafter “ Verbannung lebte, Arbeit am Marx-Engels-Institut, Professur an der Sun Yat-sen-Universität; im Mai 1928 Rückkehr nach Deutschland, im Januar 1929 Ausschluß aus der KPD und aus der KPdSU, Mitbegründer der KPO; zusammen mit Heinrich Brandler* war Th. ständig in der KPOReichsleitung vertreten; 1933 Emigration nach Frankreich, Mitglied des KPO-Auslandskomitees; 1939 interniert, I94I nach Kuba. Nach Kriegsende verweigerten ihm die Alliierten die Einreise in die Westzonen. Von Kuba aus stand er in politischem Kontakt mit der sich seit 1946/47 herausbildenden „Gruppe Arbeiterpolitik“, der Nachfolgeorganisation der KPO; Th. starb am 19.9. 1948 in Havanna.

Biographisches Handbuch der deutschsprachigen Emigration nach 1933. Bd. I. München 1980.

Theissen, Karl Franz, geboren am 1 2. 10. 1884 in Höfen/Nordeifel. Der Vater war Landwirt, die Eltern streng katholisch und „kaisertreu“. Volksschule, Gymnasium bis zum „Einjährigen", Landwirtschaftsschule mit Abschluß; Angestellter beim Landratsamt in Malmedy, seit 1910 bei der Stadtverwaltung in Essen; vor 1914 Mitglied der SPD. Zu Beginn des Ersten Weltkrieges desertierte Th., stellte sich dann jedoch und wurde zu einem Jahr Festungshaft verurteilt; nach sechs Monaten wegen guter Führung vorzeitig aus der Haft entlassen, anschließend vier Jahre Soldat bei der Marineküstenartillerie auf Wangerooge. 1917 schloß sich Th. der USPD an, Anfang November 1918 nahm er an dem Matrosenaufstand in Kiel teil. I 920 Übertritt zur KPD, im August 192 I Delegierter des VII. Parteitags der KPD; während der Ruhrbesetzung durch die Franzosen 1923 zwei Monate lang in "Schutzhaft". Seit 1924 hatte Th. führende Funktionen in der KPD in Essen inne. Im Mai 1924 wurde er Stadtverordneter, ab 1925 Leiter der KPD-Fraktion; Mitglied der erweiterten Leitung des KPDBezirks Ruhr. 1924-1928 verantwortlicher Redakteur beim "Ruhr-Echo“, der auflagenstärksten KPD-Zeitung nach der „Roten Fahne“, 1928 Chefredakteur des „Abend“ (ab Mai 1928: „Welt am Abend“"). 1928 stand Th. in Opposition zur RGO-Politik, aus Protest gegen den politischen Kurs der KPD legte er im März 1929 sein Stadtverordnetenmandat nieder; Mitglied der KPO; ein Jahr arbeitslos, dann Arbeit beim "Allgemeinen Bauverein“, einer Wohnungsgenossenschaft.

Wegen seiner politischen Einstellung und seiner Weigerung, mit „Heil Hitler“ zu grüßen, wurde Th. Ende 1933 entlassen. Spätere Angebote zur Mitarbeit in der NSDAP wies er zurück. Um weiteren Schwierigkeiten zu entgehen, verzog Th. 1934 nach Breitbrunn/Bayern. Zum selben Zeitpunkt trennte er sich von seiner Familie. Seit 1934 war er nicht mehr berufs- 
tätig; er lebte mit einer Frau zusammen, die über eigene Einkünfte verfügte. Th. arbeitete als Autodidakt auf naturwissenschaftlichem Gebiet über die Abstammungslehre des Menschen. Gegen Ende des Krieges von der Gestapo gesucht, tauchte er in München unter. Nach 1945 wurde er parteipolitisch nicht mehr aktiv. Th. starb am 3.5. 1972.

Beatrix Herlemann: Kommunalpolitik der KPD im Ruhrgebiet 1924-1933. Wuppertal 1977.

Thielcke, Herta, geb. Halbe, geboren im Juli 1914 in Hamburg; Tochter von Ena Lang und ihrem ersten, 1918 gestorbenen Mann Max Halbe; Schulbesuch bis zur Mittleren Reife, Mitglied des „Sozialistischen Schülerbundes“; 1929 Beitritu zum KJVO, 1932 zur SAP. Im selben Jahr verzog Th. nach Berlin, dort ließ sie sich zur Säuglings- und Krankenschwester ausbilden, anschließend Tätigkeit in diesem Beruf, ab 1938 wieder in Hamburg. Im September 1939 heiratete sie Werner Th.*; bis zur Geburt ihres ersten Kindes im Frühjahr 194I Krankenschwester in der psychiatrischen Universitätsklinik Hamburg, seitdem nur noch ehrenamtlich tätig. Nach Kriegsende war Herta Th. zusammen mit ihrem aus der amerikanischen Kriegsgefangenschaft zurückgekehrten Mann darum bemüht, frühere politische Freunde in verschiedenen Gegenden Deutschlands ausfindig zu machen und die Paketaktion zu koordinieren; seit 195 I Mitglied der SPD; Herta Th. lebte $198 \mathrm{I}$ in Hamburg.

Thielcke, Wemer, geboren im September 1910 in Hamburg; Abitur, Universitătsstudium, Mitglied im "Sozialistischen Schülerbund", im KJVD, nach Ausschluß 1929 Beitritt zur KPO; im November 1933, kurz vor Abschluß der Lehrerausbildung, wegen illegaler Tärigkeit verhaftet und im KZ Fuhlsbüttel inhaftiert; im Mai 1934 wegen Vorbereitung zum Hochverrat zu zwei Jahren und vier Monaten Zuchthaus verurteilt; nach der Entlassung aus dem Zuchthaus Bremen-Oslebshausen Tätigkeit als kaufmännischer Angestellter im Außenhandel und als technischer Zeichner; im November 1942 trotz Wehrunwürdigkeit zum Strafbataillon 999 eingezogen; im Mai 1943 von Nordafrika aus in amerikanische Kriegsgefangenschaft, im Frühjahr 1946 entlassen; ab September 1946 Volksschullehrer in Hamburg, als solcher Mitglied der GEW; Th. starb im September 1974.

Titteh Hans, geboren am 1.9. 1894 in Dresden als Sohn einer kinderreichen Arbeiterfamilie; Steindrucker; 1909 AJ, 1912 in Stuttgart Mitglied der SPD, 1914 Parteiausschluß wegen Opposition gegen die Bewilligung der Kriegskredite; aktiv in der Spartakus-Gruppe, Delegierter des Gründungsparteitags der KPD, Parteisekretär in Württemberg; 1920-1923 Mitglied der KPD-Zentrale, 1923 Politischer Leiter in Thüringen, 1924 abgesetzt, 1926 wiedergewählt, $1927 \mathrm{MdL}$ Thüringen. 1928/29 als führender Rechter aus der KPD ausgeschlossen; 1929-1933 Mitglied der KPO-Reichsleitung; nach illegaler Arbeit Emigration in die CSR, $193^{8}$ nach Frankreich; 1939 aus der KPO ausgeschieden. Von September 1939 bis I 941 in Vernet interniert, konnte T. in die USA entkommen, dort erneut als Steindrucker tätig; 1962 Rückkehr in die Bundesrepublik; T. lebte 1981 in Nürnberg.

Biographisches Handbuch der deutschsprachigen Emigration nach 1933. Bd. I. München 1980.

Treu, Fritz, geboren am 29.4. 1904 in Mamslau/Schlesien, jüdischer Konfession. Die Mutter, die Arbeitsanzüge in Heimarbeit anfertigte und als Putzfrau arbeitete, starb 191 3. Der bei seiner Geburt 59-jährige Vater war politisch sehr konservativ, bei dem Versuch, sich als Buchhändler selbständig zu machen, machte er bankrott. T. wuchs deshalb in großer Armut auf. Dank einer Freistelle konnte er bis 1918 die Mittelschule besuchen, nach deren Kündigung wurde er von der Schule verwiesen. Weil er zu ärmlich gekleidet war, mußte er eine Kaufmanns-Lehre nach neun Monaten abbrechen. Ein ihm persönlich bekannter Klempner nahm ihn schließlich als Lehrjungen und kaufte ihm einen Anzug, den er abarbeiten mußte. 1920 Beitritt zum DMV, um 1923 zur SPD; seit Mitte der zwanziger Jahre in Verbindung 
mit Otto Brenner* 193 I war T. einer der Mitbegründer der SAP in Hannover, für die in der Reichstagswahl vom 31.7. 1932340 Stimmen abgegeben wurden. Nach der Machtübernahme durch die Nationalsozialisten hielt $T$. so lange wie möglich seine SAP-Verbindungen aufrecht. 1934 heiratete er eine SAP-Genossin. Da er Jude war, fand er als Klempner keine Arbeit und wurde 1938 als Hausverwalter bei einem jüdischen Architekten tätig und seit 1939 bei der Israelitischen Gartenbauschule Hannover-Ahlem, der letzten jüdischen Schule in Deutschland. Nach der Auflösung der Schule wurde er auf Anforderung eines früheren Kollegen, der selbständig war und kriegswichtige Produkte herstellte, zur Arbeit als Klempner freigestellt - unter der Bedingung, allein und abgesondert in einem separaten Raum zu arbeiten. Im Dezember 194 I begannen in Hannover die Deportationen, bis Ende 1942 wurden 289 Juden nach Riga, Warschau und Auschwitz deportiert. Zusammen mit 62 anderen Juden, die wie er in einer sog. Mischehe lebten, war T. davon zunăchst ausgenommen.

Periodische Versuche der Gestapo und der NSDAP, seine Frau zur Scheidung zu bewegen, wurden von dieser zurückgewiesen. Am 25.2. 1945 wurde T. mit den letzten Hannoveraner Juden nach Theresienstadt deportiert. Dort wurde er im Mai von sowjetischen Truppen befreit. Im Juni 1945 kehrte er nach Hannover zurick. 1946 Gründung einer eigenen Klempnerei. Aus Enttäuschung über die politische Entwicklung folgte T. 1950 der Aufforderung von Freunden und wanderte in die USA aus. Dort arbeitete er zunächst als „Mädchen für alles $^{\alpha}$, später erneut als Hausverwalter. T. lebte 1980 in Monroe im Staate New York.

Triebel, Oskar, geboren am 1 3. 1. 1891 in Barmen. Der Vater war Weber in einer Wuppertaler Bandwirkerei; Volksschule, Schlosserlehre, Mitglied des DMV und der ${ }_{n}$ ArbeiterJugend"; 1914 Flucht nach Holland, um sich dem Kriegsdienst zu entziehen; 1918 Mitbegründer des Spartakusbundes in Barmen, Delegierter auf dem Gründungsparteitag der KPD, seit März 1919 Leiter der KPD-Ortsgruppe in Barmen; anläßlich des Kapp-Putsches zusammen mit dem Elberfelder Kommunisten Charpentier einer der Unterzeichner des „Bielefelder Abkommens “ zwischen Reichsregierung, Reichswehr und Vertretern der aufständischen Ruhrarbeiter; wegen seiner Unterschrift Androhung des Parteiausschlusses seitens der Bezirksleitung der KPD; im August 1921 Delegierter des VII. Parteitags der KPD. 1923 wurde $T$. nach einem Bombenanschlag von der belgischen Besatzungsmacht im Rheinland als sogenannte Fahrgeisel verhaftet: Vier Wochen lang mußte er mit der Eisenbahn zwischen Oberhausen und einem belgischen Brückenkopf pendeln, um potentielle Attentäter abzuschrecken. 1923-1929 Verlagsleiter und Redakteur der "Niederrheinischen Arbeiterzeitung “ in Duisburg; 1924 bis März 1929 Stadtverordneter und Vorsitzender der KPDFraktion, Mitglied des Provinzialrates; Leiter des KPD-Parteibüros, seit 1925 Gewerkschaftssekretär des KPD-Unterbezirks Duisburg. 1929 wurde T. wegen seiner Haltung in der Gewerkschaftsfrage zusammen mit einem anderen Stadtverordneten aus der KPD ausgeschlossen. Als Reaktion darauf legte die zwölfköpfige KPD-Stadtratsfraktion geschlossen ihre Mandate nieder. 1929 KPO, Leiter der Ortsgruppe Duisburg-Hamborn; Anfang der dreißiger Jahre von Beruf Gelderheber bei der Stadtverwaltung, im Juli 1933 entlassen. 1933 illegal tätig; im Rahmen des KPO-Widerstandes Kontakte zu Dagobert Lubinski in Düsseldorf und Bernhard Molz* in Schwelm; zugleich einer der aktivsten Mitarbeiter des Leiters der illegalen SAP im Ruhrgebiet, Eberhard Brünen*, dem T. seine Verbindungen im Rahmen einer Art linkssozialistischer Einheitsfront zur Verfügung gestellt zu haben scheint; unter anderem wurde monatlich über Bocholt aus Holland die SAP-Zeitung "Das Banner der revolutionären Einheit ${ }^{\star}$ eingeschleust. In Duisburg-Hamborn, wo etwa roo Mitglieder der illegalen SAP angehörten, leitete die Verteilung der Zeitungen Wilhelm Pennekamp*; Karl Völker" aus Hamborn leistete Kurierdienste. Ende 1934 wurde die SAP-Widerstandsorganisation im Ruhrgebiet von der Gestapo zerschlagen, 47 Mitglieder wurden verhaftet. $T$. war bereits am 26.3. 1934 in Essen festgenommen worden; wegen Verteilung von Flugschriften wurde er am I 2. 10. I 934 vom Oberlandesgericht Hamm zu einem Jahr und zehn Monaten Gefängnis verurteilt; im Januar 1935 Deportation in das Moorkommando Lager 
III Brual-Rhede; 1936 freigelassen, 1937 erneut verhaftet und mehrere Monate im KZ Oranienburg. Während des Krieges wurde T. zur Arbeit im Bergbau dienstverpflichtet; im Anschluß an den 20. Juli 1944 erneute kurze Inhaftierung.

Ab Mitte Mai r945 führendes Mitglied in der Duisburger „Antifaschistischen Einheitsfront ${ }^{\text {" }}$, einem losen Zusammenschluß von ehemaligen SPD-, SAP-, KPO- und KPD-Mitgliedern, darunter auch Wilhelm Pennekamp ${ }^{*}$ 1945/46 im Rat der Stadt; später Mitglied der SPD; Leiter des Duisburger Arbeitsamtes; 1954 wegen Erreichung der Altersgrenze aus dem Arbeitsamt ausgeschieden, jedoch emeut in den Rat der Stadt gewählt; im Oktober 1959 Rücktritt als SPD-Fraktionsvorsitzender wegen innerparteilicher kommunalpolitischer Zwistigkeiten; Mitbegrinder und 1. Vorsitzender des Theaterringes, Vorsitzender im Kulturausschuß; 1966 bei Bildung der Großen Koalition Austritt aus der SPD; T. starb am 24. 5.1968 nach langer Krankheit.

Hermann Weber (Hrsg.): Der Grundungsparteitag der KPD. Protokoll und Materialien. Frankfurt 2.M. 1969; Erhard Lucas: Marzrevolution 1920, Bd. 3 Die Niederlage. Frankfurt 2. M. 1978; Beatrix Herlemann: Kommunalpolitik der KPD im Ruhrgebiet 1924-1933. Wuppertal 1977; Kuno Bludau: Gestapo-Geheim! Widerstand und Verfolgung in Duisburg 1933-1945. Bonn-Bad Godesberg 1973; Hartmut Pietsch: Militărregierung, Barokratie und Sozialisierung. Zur Entwicklung des politischen Systems in den Stżdten des Ruhrgebietes 1945 bis 1948. Duisburg 1978.

Tüsfeld-Heine, Hertha, geboren am 4.6. 1906 in Dortmund. Der Vater war Chemiker, die Mutter Hausfrau; ein Bruder. Volksschule, danach Lyzeum bis zur mittleren Reife; 1924-1926 Säuglingspflegeschule, Staatsexamen als Săuglingspflegerin; aktives Mitglied in der katholischen Jugendbewegung .Jungborn ${ }^{\alpha}$; 1927 Mitglied der KPD; 1928-1930 Besuch der Wohlfahrtsschule für Hessen-Nassau in Frankfurt a.M., 1930 Examen als Fürsorgerin. Während ihrer Ausbildung war sie Mitglied der kommunistischen „Roten Studentengrup$\mathrm{pe}^{*}$, in der 1928/29 die KPO-nahen Studenten sehr stark vertreten waren. Anfang 1929 wurde sie wegen Fraktionsbildung aus der KPD ausgeschlossen, doch trat sie nach ihrer Rückkehr nach Dortmund erneut der Partei bei.

1931-1935 Amespraktikantin und Fürsorgerin bei der Stadt Dortmund. 1935 heiratete sie und mußte nach den damaligen gesetzlichen Bestimmungen ihren Beruf aufgeben; zwei Töchter, geboren 1939 und 1943 . Wie in anderen Städten des Ruhrgebiets mußte die KPD bei ihrem Versuch, einen Massenwiderstand zu organisieren, auch in Dortmund große Verluste hinnehmen. Bis zum Frühjahr 1935 wurden vom Oberlandesgericht Hamm 479 Dortmunder Kommunisten wegen Vorbereitung zum Hochverrat verurteilt. Auch ihr Mann war 1933 zweimal verhaftet worden, er wurde jedoch nicht verurteilt. Im Frühjahr 1943 führte die Gestapo eine Großaktion gegen die illegale KPD im Ruhrgebiet unter Wilhelm Knöchel und gegen die KPD-Inlandsleitung in Berlin durch. Nach der Verhaftung des KPD-Kuriers Willi Seng, zu dem T.'s Kontakt gehabt hatten, erfolgten Haussuchung und Verhör. Am i s. 4. 1943 wurde T.- H.'s Mann verhaftet, die Verdachtsmomente konnten jedoch nicht erhärtet werden. Nach seiner Entlassung verließ sie auch wegen der dauernden Bombardierungen mit ihren Töchtern die Stadt und zog in den Kreis Lübbecke-Minden.

Nach Kriegsende Rückkehr nach Dortmund; Beteiligung am Wiederaufbau der KPD; 1946 Einrichtung einer Küche für Schulspeisung, Aufbau eines Kindergartens; Bezirksvorsteherin der Wohlfahrtspflege in Dortmund-Hombruch, Mitglied des Hauptwohlfahrts- und Hauptwohnungsausschusses der Stadt; 1947 Mitbegründerin des Ausschusses der Dortmunder Frauenverbände; von 1947-1959 Bezirksfürsorgerin der „Gemeinschaftshilfe e.V.“, Bezirk Westfalen; 1950 Mitglied des „Schwelmer Kreises“, einer Vereinigung von Reformpädagogen, die für die Wiedervereinigung Deutschlands eintraten; 195 I Gründungsmitglied der „Westdeutschen Frauenfriedensbewegung ${ }^{\prime}$, im Rahmen dieser Organisation Beteiligung an Aktionen gegen Wiederbewaffnung und atomare Aufrüstung; später im DGB-

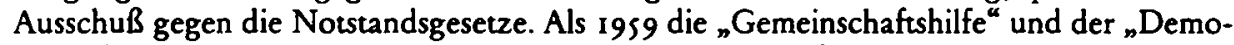
kratische Kulturbund “ als kommunistisch verboten wurden, fanden bei Hertha T.-H. Haus- 
suchung, Beschlagnahmungen und Verhöre statt. In der Folgezeit wurden ihr alle ehrenamtlichen Tätigkeiten innerhalb der Wohlfahrtspflege aberkannt, ein Ermittlungsverfahren wegen Staatsgefährdung wurde 1961 eingestellt, ein weiteres 1962. 1963-1968 Beteiligung an der Ostermarschbewegung, ab 1968 Leiterin des Arbeitskreises der Westdeutschen Frauenfriedensbewegung in Dortmund; seit 1968 Mitglied der DKP. Hertha T.-H. lebte 1980 in Dortmund.

Tulatz, Herbert A., geboren am 21.6. 1914 in Breslau. Der Vater war Metallarbeiter, die Mutter Näherin. T. besuchte die städtische Oberrealschule. 1928 organisierte er sich in der SAJ, 1931 in der SPD. Mit der großen Mehrheit der jüngeren Breslauer Sozialdemokraten gründete er im Oktober 1931 den SJV und die SAP.

Seit dem Frühjahr 1933 war T. in der illegalen SAP aktiv, als Auslandskurier unterhielt er Verbindungen zur SAP-Gruppe in der CSR und war an der Verbreitung illegaler Schriften beteiligt. Um zum Abitur zugelassen zu werden, trat er wie alle seine Klassenkameraden im September 1933 der Hitler-Jugend (HJ) bei. Da er versuchte, in der HJ sozialistische Überzeugungen lebendig zu halten, wurde er im Sommer 1935 ausgeschlossen. 1936 legte er im Anschluß an eine zweieinhalbjährige Banklehre die Kaufmannsgehilfenprüfung $a b$. Nach der Verhafungswelle gegen die Breslauer und die schlesische SAP im Frühjahr 1936 versuchte T. zusammen mit anderen, die illegale Arbeit fortzusetzen. Bereits am 7.9. 1936 wurde er jedoch verhaftet und am 24. 3. 1937 vor dem Oberlandesgericht Breslau in einem SAPProzeß zu drei Jahren und sechs Monaten Zuchthaus und zu fünf Jahren Ehrverlust verurteilt. Bis zum März 1940 war er in den Zuchthäusern Brandenburg-Görden, Coswig und in den Elberegulierungslagern Dessau-Rosslau und Griebo inhaftiert. Nach der Entlassung aus der Haft Geschäftsführer des Schlesia-Verlags. Im Oktober 1942 wurde T. zum Strafbataillon 999 eingezogen, im April 1943 geriet er in Tunesien in Gefangenschaft; seit Mai 1943 in einem Kriegsgefangenenlager in Oklahoma. Nachdem es dort zu tätlichen Auseinandersetzungen $z$ wischen NS-Anhängern und Antifaschisten gekommen war, verlegte man ihn zusammen mit hundert weiteren Kriegsgefangenen nach Fort Devens, Mass.; in diesem Antifaschisten-Lager wurde er zum Lagersprecher gewählt.

Nach seiner Rückkehr nach Deutschland im Januar 1946 bekam T. ein Angebot aus der französischen Zone, sich an einer Jugendzeitschrift zu beteiligen. Er wurde Mit-Lizenzträger von „Die Zukunft. Unabhängige Zeitschrift junger Menschen“ in Reutlingen. Seit Januar 1948 gab er die politische Zeitschrift Weltpresse. Stimme des Auslands. Die deutsche Meinung " in Metzingen heraus, die jedoch schon im Mai ihr Erscheinen einstellen mußte. 1949 heiratete T.; zwei Kinder. Im selben Jahr wurde er Stellvertreter des Leiters der DGBBundesjugendschule in Oberursel i.T., Willi Birkelbach*, I952-196I dessen Nachfolger als Leiter der Bundesjugendschule. Neben dieser Arbeit entfaltete T. eine rege politische Tätigkeit. Er war Vorsitzender der SPD Oberursel, acht Jahre lang Stadtverordneter, Mitglied des Bezirksvorstandes der SPD Hessen-Süd, Leiter der SPD-Betriebsgruppenorganisation Hessen-Süd und Mitglied des Landesvorstands Hessen der SPD. Im März 196 I wurde T. als Nachfolger von Hans Gottfurcht zum Stellvertretenden Generalsekretär des „Internationalen Bundes Freier Gewerkschaften" (IBFG) in Brüssel gewählt. Im Rahmen dieses Amtes galt sein besonderes Interesse und Engagement dem Aufbau der Gewerkschaftsbewegung in den Entwicklungsländern, vor allem in Afrika, sowie der Jugend- und Bildungsarbeit. T. starb am 28.6. 1968.

Völker, Karh, geboren am 5.4. I880; von Beruf Maurer, gewerkschaftlich organisiert erst im christlichen, dann im sozialdemokratischen Bergarbeiterverband, um 1917/18 Mitglied der syndikalistischen Freien Vereinigung in Hamborn; 1917 USPD, Vorsitzender von GroßHamborn; Anfang 1919 Überritt zur KPD; Mitglied des Arbeiter- und Soldatenrats Essen und der Sozialisierungskommission; nach der Besetzung des westlichen Ruhrgebiets durch deutsche Truppen verhaftet, Anklage vor einem Kriegsgericht, einen bewaffneten Umsturz 
geplant zu haben; Verurteilung zu sechs Jahren Zuchthaus, im September 1920 Entlassung im Rahmen einer Amnestie; 1928 KPO, 1932 SAP, Vorsitzender des SAP-Bezirks Niederrhein; 1933 illegale Arbeit; im August 1933 "Schutzhaft ${ }^{*}$, im Juni 1936 wegen Vorbereitung zum Hochverrat zu zwei Jahren Zuchthaus verurteilt; nach der Haftentlassung erneut illegal tätig. Am 21 . 4. 1937 entging V. knapp der Verhaftung und floh nach Holland; seit der Besetzung des Landes im Untergrund, Unterstützung Untergetauchter, Zusammenarbeit mit der holländischen Widerstandsbewegung; nach Kriegsende Organisator von Paketsendungen für deutsche Antifaschisten; V. starb am 20. 2. 1949.

Vogh Hermann geboren 1912, Steinmetz; 1926 KJVD, Mitglied der Bezirksleitung, im Herbst 1931 wegen „Luxemburgismus ${ }^{*}$ ausgeschlossen; Beitritt zur SAP, nach 1933 bis zur Einberufung zur Wehrmacht im April 1940 illegal tätig; 1945-1948 in sowjetischer Kriegsgefangenschaft; 1951 UAP, 1952 SPD, Mitglied des Unterbezirks-Vorstandes, aus Protest gegen die Bildung der Großen Koalition 1966 Parteiaustritt; V. lebte 1980 in Köln.

Walcher, Jacob, geboren am 7.5. 1887 in Bethleheim bei Wain/Württemberg; Dreher, 1906 DMV und SPD, Redakteur der Stuttgarter Parteizeitung „Schwäbische Tagwacht"; führendes Mitglied der Spartakusgruppe, Delegierter und 2. Vorsitzender des Gründungsparteitags der KPD; 1919-1923 Mitglied der KPD-Zentrale, als Anhänger Heinrich Brandlers* verantwortlich für Gewerkschafisarbeit; nach dem innerparteilichen Sieg der Linken einer der Führer der Rechtsopposition; 1924-1926 in der Sowjetunion; 1927-28 erneut Mitglied der Gewerkschaftsabteilung beim ZK der KPD, am I4. 12 . 1928 aus der KPD ausgeschlossen; Gründungsmitglied der KPO, Mitglied der KPO-Reichsleitung, 1931 und 1932 zusammen mit Paul Frölich* einer der Repräsentanten der zur Zusammenarbeit mit der SAP bereiten KPO-Minderheitsgruppe; 1932 SAP, hauptamtliches Mitglied des Parteivorstandes, 1933-1939 Sekretär der Pariser SAP-Auslandsleitung. Bei Kriegsausbruch interniert, konnte er 1941 in die USA entkommen; in New York Mitarbeit in dem von linken Sozialdemokraten und Kommunisten gegründeten "Council for a Democratic Germany ; 1946 Rückkehr nach Deutschland, in der SBZ Mitglied der KPD/SED, 1946 Chefredakteur der Gewerkschaftszeitung "Tribüne“ in Ostberlin, 1949 gemaßregelt und aus der SED ausgeschlossen; 1956 rehabilitiert und erneut Parteimitglied; W. starb am 27.3. 1970.

Biographisches Handbuch der deutschsprachigen Emigration nach 1933. Bd. I. München 1980.

Walter, Paul (1897-1955), I919 SPD, 1931 Übertritt zur SAP, nach der nationalsozialistischen Machtübernahme illegale Arbeit, Dezember 1933 Festnahme, bis 1935 in Haft, nach Entlassung Flucht in die CSR, 1938 Emigration nach Großbritannien, dort Leiter der SAPLandesgruppe, seit 194I Vertreter der SAP in der „Landesgruppe deutscher Gewerkschafter in Großbritannien " und in der "Union deutscher sozialistischer Organisationen in Großbritannien“, Mitarbeit an deren Programmen; im Mai 1945 Rückkehr nach Deutschland, Funktionär der DAG. -

Seit 1940 verheiratet mit Frida Schotz (geb. 1902).

Biographisches Handbuch der deutschsprachigen Emigration nach 1933. Bd. I. München 1980.

Winguth, Fritz, geboren am 8. 1. 1892 in Berlin; von Beruf Mechaniker; 1908-1913 2. Vorsitzender der Berliner SPD-Jugendorganisation. Im Ersten Weltkrieg war W. im Rahmen der Spartakus-Gruppe aktiv. Zusammen mit etwa dreißig Jugendlichen nahm er im April I 916 an der Reichskonferenz der oppositionellen Jugend in Jena teil, die unter Leitung von Karl Liebknecht den Befürwortern der Kriegskredite das Recht absprach, im Namen der Jugend aufzutreten und zum Boykott der „Arbeiter-Jugend ${ }^{\star}$, der Jugendorganisation der SPD aufrief. Im April 1917 Mitglied der USPD, Vorsitzender der USPD in Neukölln; im Herbst 1918 Mitbegründer der Spartakus-Jugend; Ende Dezember 1918 Delegierter auf 
dem Gründungsparteitag der KPD; seit Juli 1919 Angestellter des DMV. Im Februar und April 1920 wurde W. vom III. und IV.KPD-Parteitag als Vertreter Berlins in den Zentralausschuß der Partei gewählt. 1920 Kassenrevisor der KPD; Kandidat bei den Reichstagswahlen; Anfang Dezember 1920 Delegierter auf dem Vereinigungsparteitag mit dem linken Flügel der USPD. 1921 wurde W. als Anhänger des ehemaligen Parteifuhrers Paul Levi, der das putschistische Vorgehen der KPD während der sog. März-Aktion in Mitteldeutschland offentlich scharf kritisiert hatte, aus der KPD ausgeschlossen. Er trat erneut der USPD bei und ging mit dieser im September 1922 zur SPD zurück. Bis 1933 war er Sekretär des DMV. Nach 1933 gehörte W. einer sozialdemokratischen Widerstandsgruppe in Berlin an, die von dem ehemaligen Abgeordneten des thüringischen Landtags, Hermann Brill, und dem früheren Reichstagsabgeordneten Otto Brass, der ebenfalls 1921 aus Solidarität mit Paul Levi die KPD verlassen hatte, geleitet wurde. Bis zum Zeitpunkt der Verhaftung ihrer beiden Leiter im September 1938 trat diese Gruppe für den Zusammenschluß aller liberalen, demokratischen, sozialistischen und kommunistischen Kräfte in Deutschland zu einer Volksfront ein.

1945 wurde W. Leiter des Arbeitsamtes in Potsdam. Der im April 1946 gegründeten SED trat er nicht bei. W. starb am 3. 2. 1948.

Ziegler, Hans (1887-1957), Dreher, SPD, später USPD, 1918 Mitglied des 1. Rätekongresses, Vorsitzender des SPD-Orts- und Kreisvereins, des Gewerkschaftskartells und Bildungsausschusses in Heilbronn, 1920-1924 MdL Württemberg; 1930-Juli 1932 Abgeordneter im Deutschen Reichstag für den Wahlkreis Breslau, im Oktober 1931 Übertritt zur SAP; im März 1933 in „Schutzhaft“; 1945-1948 Oberbürgermeister von Nürnberg.

Zweiling, Klaus (1900-1968), Studium der Physik, Mathematik, Philosophie und Volkswirtschaft in Berlin, Anhänger des ISK, später SPD, 1924-1931 Chefredakteur verschiedener sozialdemokratischer Zeitungen; 1931 Mitbegründer der SAP, zusammen mit Fritz Sternberg* Exponent der SAP-Linken, maßgeblicher Einfluß auf die SAP-Programmatik; 1934 wegen Vorbereitung zum Hochverrat zu drei Jahren Gefängnis verurteilt; im Krieg Soldat in einem Strafbataillon; 1946 SED, 1946-1950 Chefredakteur der „Einheit“, des theoretischen Organs der SED, I950 abgesetzt, danach ohne politischen Einfluß; bis I95s Leiter des Verlags "Die Technik“; in den sechziger Jahren Professor für dialektischen Materialismus und Direktor des Instituts für Philosophie an der Universität Leipzig. 